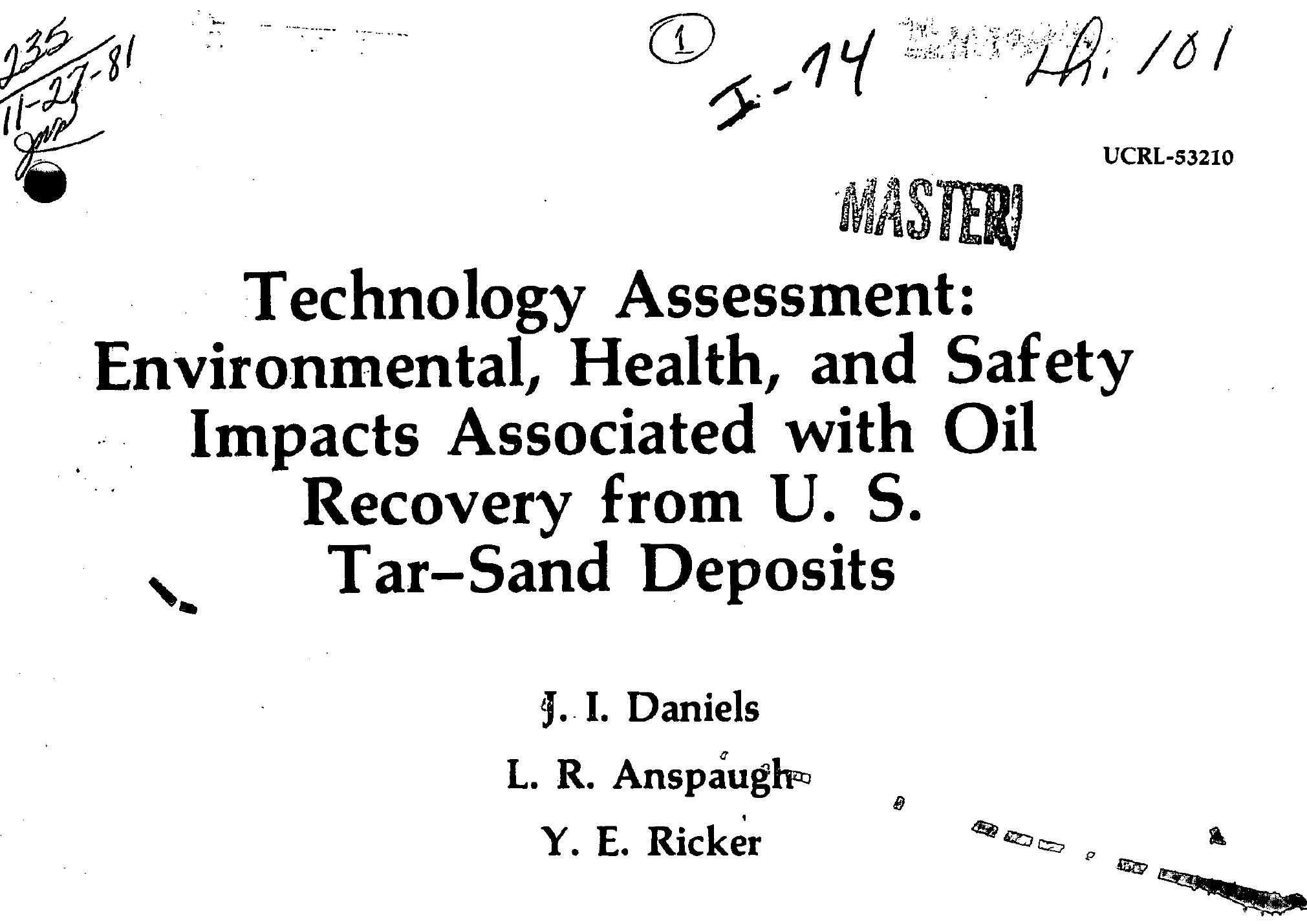

October 13, 1981

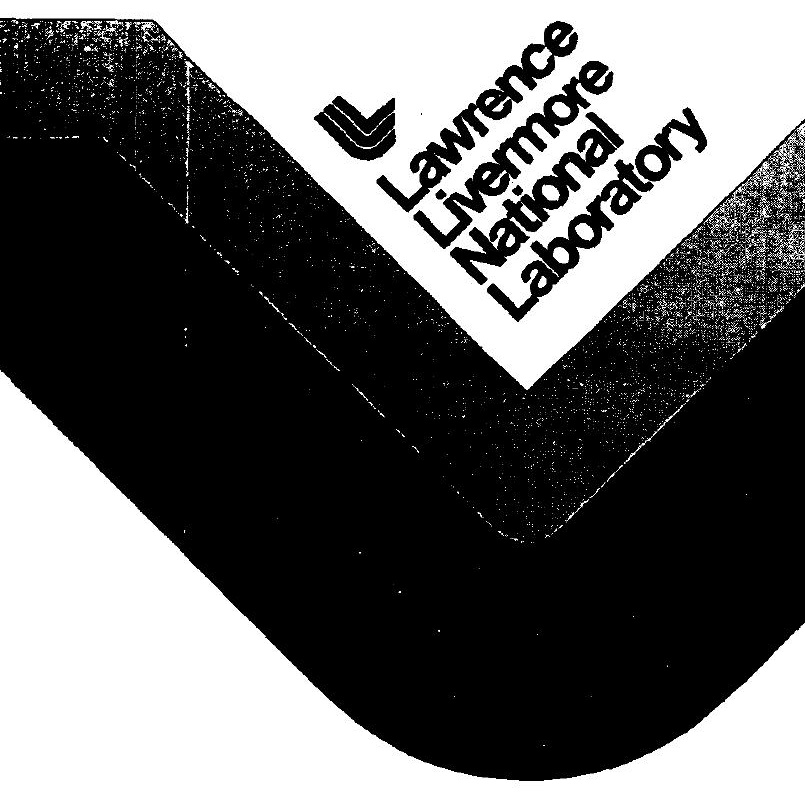




\section{DISCLAIMER}

This report was prepared as an account of work sponsored by an agency of the United States Government. Neither the United States Government nor any agency Thereof, nor any of their employees, makes any warranty, express or implied, or assumes any legal liability or responsibility for the accuracy, completeness, or usefulness of any information, apparatus, product, or process disclosed, or represents that its use would not infringe privately owned rights. Reference herein to any specific commercial product, process, or service by trade name, trademark, manufacturer, or otherwise does not necessarily constitute or imply its endorsement, recommendation, or favoring by the United States Government or any agency thereof. The views and opinions of authors expressed herein do not necessarily state or reflect those of the United States Government or any agency thereof. 


\section{DISCLAIMER}

Portions of this document may be illegible in electronic image products. Images are produced from the best available original document. 


\section{DISCLAIMER}

This document was prepared as an account of work sponsored by an agency of the United States Government. Neither the United States Government nor the University of California nor any of their employees, makes any warranty, express or implied, or assumes any legal liability or responsibility for the accuracy, completeness, or usefulness of any information, apparatus, product, or process disclosed, or represents that its use would not infringe privately owned rights. Reference herein to any specific commercial products, process, or service by trade name, trademark, manufacturer, or otherwise, does not necessarily constitute or imply its endorsement, recommendation, or favoring by the United States Government or the University of California. The views and opinions of authors expressed herein do not necessarily state or reflect those of the United States Government thereof, and shall not be used for advertising or product endorsement purposes.

Work performed under the auspices of the U.S. Department of Energy by Lawrence Livermore National Laboratory under Contract W-7405-Eng-48. 


\title{
Technology Assessment: Environmental, Health, and Safety Impacts Associated with Oil Recovery from U. S. Tar-Sand Deposits
}

\author{
J. I. Daniels
}

L. R. Anspaugh

Y. E. Ricker

\section{Manuscript date: October 13, 1981}

This document is

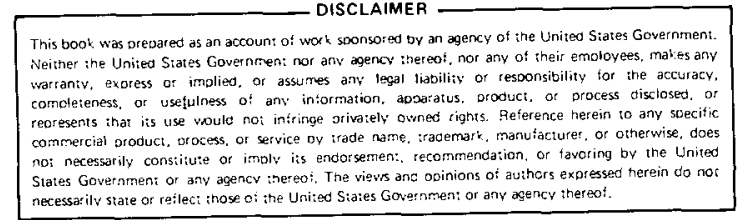
PUBLICLY RELEASABTE Authorizing Official Date: $\quad 3 / 22 / 06$

\section{LAWRENCE LIVERMORE LABORATORY \\ University of California $\bullet$ Livermore, California 94550}


$\theta$

$\theta$ 
FOREWORD

The U.S. Department of Energy, Office of Environmental Assessments, Office of Environmental Protection, Safety and Emergency Preparedness, has been conducting technology assessments of the evolving energy technologies. The purpose of these is to evaluate the potential environmental, health, and socioeconomic impacts of each technology as it moves towards commercialization, in as quantitative a manner as possible. The assessments identify where further information is needed; provide an analys is of potential environmental, health, and socioeconomic consequences of each developing technology; and define research and development (R\&D) needed to ensure environmentally acceptable commercialization. 


\section{ACKNOWLEDGMENTS}

The authors extend their gratitude to the following people and organizations for their cooperation and assistance: Dr. George J. Rotariu, in the Technology Assessments Division, Office of Environmental Protection, Safety and Emergency Preparedness of the U.S. Department of Energy, Washington, D.C.; Dr. Arnold J. Goldberg, Manager, Fossil Fuels Programs, Technology Assessments Division, Office of Environmental Protection, Safety and Emergency Preparedness of the U.S. Department of Energy, Washington, D.C.; the Division of $0 i 1$ and Gas, particularly Mr. H.R. (Bob) Anderson, Office of Fossil Energy of the U.S. Department of Energy, Washington, D.C.; the Environmental Control Technology Branch, especially Dr. Henry F. Walter, Office of Environmental Protection, Safety and Emergency Preparedness of the U.S. Department of Energy, Washington, D.C.; Mr. Leland C. Marchant and his colleagues on the Tar-Sand Project at the U.S. Department of Energy Laramie Energy Technology Center, Laramie, Wyoming; members of the Downhole SteamGenerator Project of the Geoenergy Technology Department, particularly Dr. Burl Donaldson and Dr. Carolyn M. Hart, of Sandia Laboratories, Albuquerque, New Mexico; Dr. Alex Oblad, Dr. James Bunger and their associates at the University of Utah, Salt Lake City, Utah; Ms. Carolyn Mangeng, Los Alamos National Laboratory, Los Alamos, New Mexico; Or. George Neeson, Syncrude Canada, Inc., Ft. McMurray, Alberta, Canada; Dr. Wes Patrick of the Earth Sciences Division, Lawrence Livermore National Laboratory, Livermore, California; and finally, members of the Environmental Sciences Division, Analysis and Assessment Section, Lawrence Livermore National Laboratory, Livermore, California, principally Ms. Barbara Fox. 
Foreword ...............................

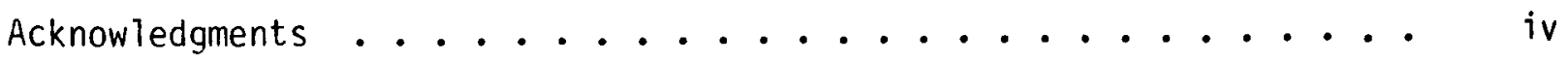

List of figures .................. ix

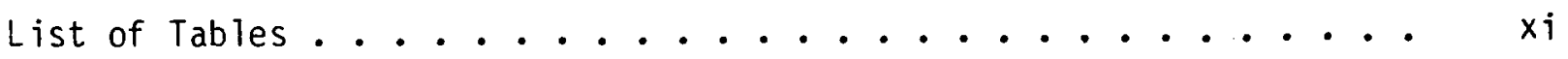

Glossary................................ $x v$

Abstract ......................... . .

Summary ............................. xxi

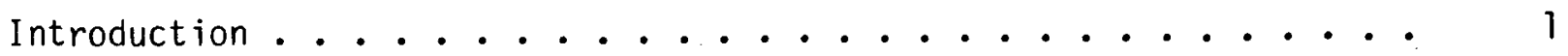

Resource Characteristics and Properties ........... 2

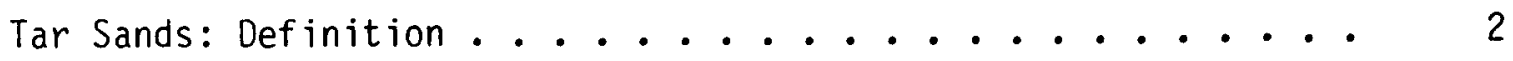

Bitumen Properties and Distinguishing Characteristics..... 3

Evolution of Tar-Sand Deposits ........... 4

U.S. Tar-Sand Resources .............. . 4

Bitumen Recovery Methods ................ . . . 7

Parameters Influencing Selection of a Recovery Process . . . 8

Federal Regulatory Framework . . . . . . . . . . . 9

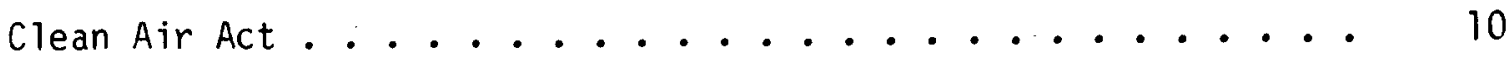

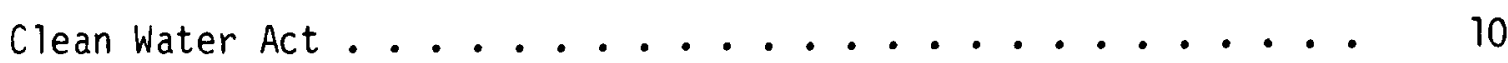

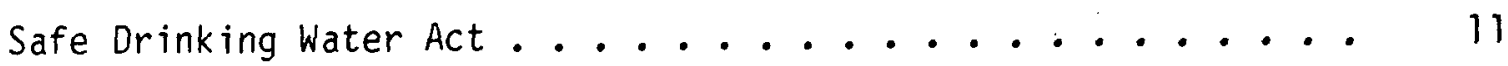

Resource Conservation and Recovery Act .......... 11

Toxic Substances Control Act ............... 11

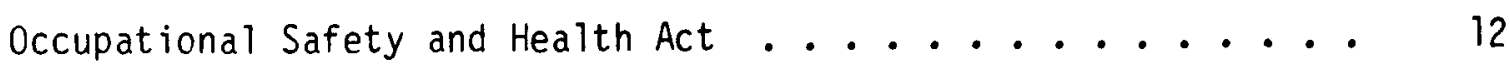

National Historic Preservation Act ............ 12

Geological Survey Regulations.............. 12

Surface Mining Control and Reclamation Act ........ 13

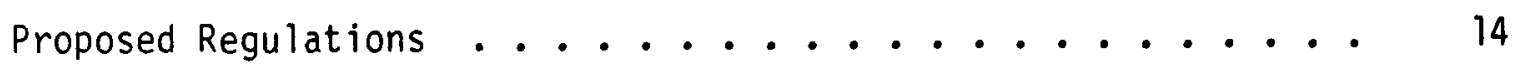

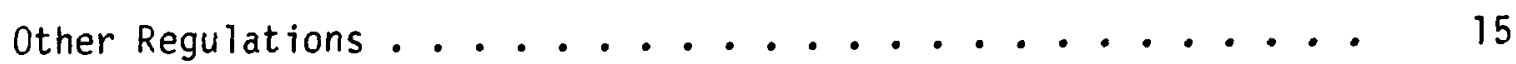

Process Descriptions .............................. 15

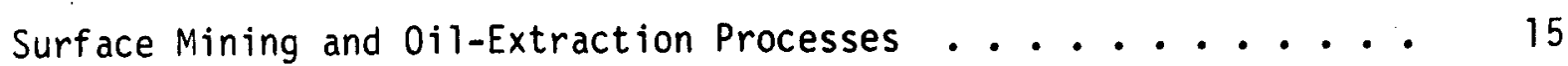

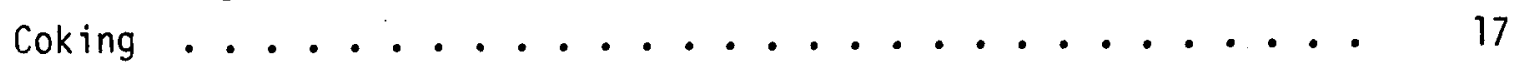

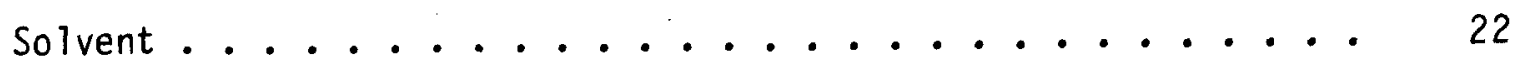

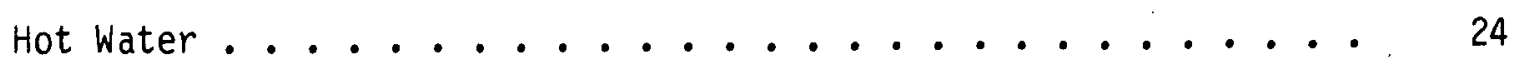

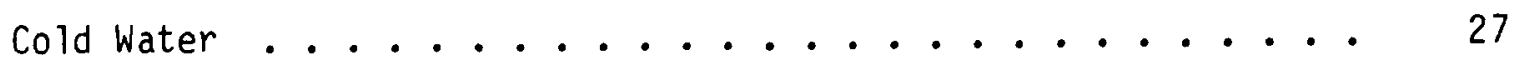




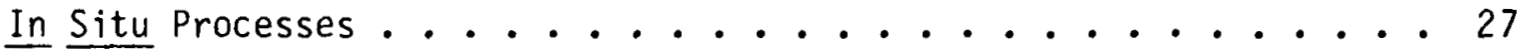

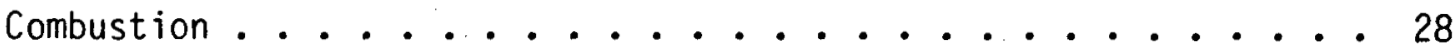

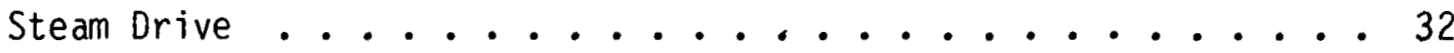

Upgrading Processes......................... 34

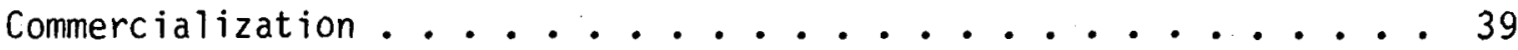

Environmental Analysis and Assessment ............ 40

Environmental, Health, Safety, and Socioeconomic Impacts. . . . 40

Surface-Mining Activities. ............ 41

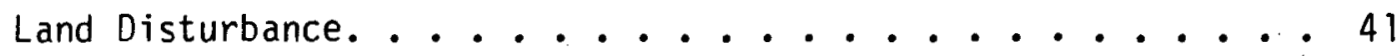

Atmospheric Emissions ................ 42

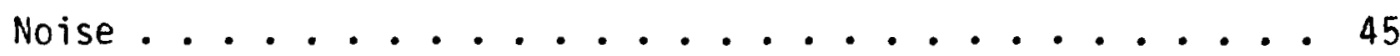

Light ................... . . 45

Worker Health and Safety. ............ 46

water..................... 46

Waste Generation and Disposal .......... 47

Community Infrastructure............. 48

Surface Retort or Solvent Processes. . . . . . . . 48 48

Land Disturbance. . . . . . . . . . . . 48

Atmospheric Emissions ................. 49

Noise .......................... 57

Worker Health and Safety............. 57

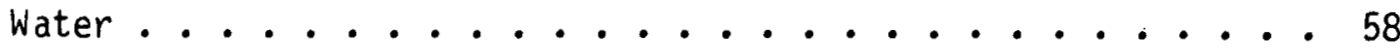

Waste Generation and Disposal ........... 59

Community Infrastructure............ 59

In Situ Combustion or Steam-Injection Processes....... 61

Land Disturbance........................ 61

Atmospheric Emissions .............. 63

Noise ............................ 70

Worker Health and Safety................. 70

water ...................... 72

Waste Generation and Disposal .......... 78

Community Infrastructure............ 78

Elaboration of Socioeconomic Considerations ........ 80 


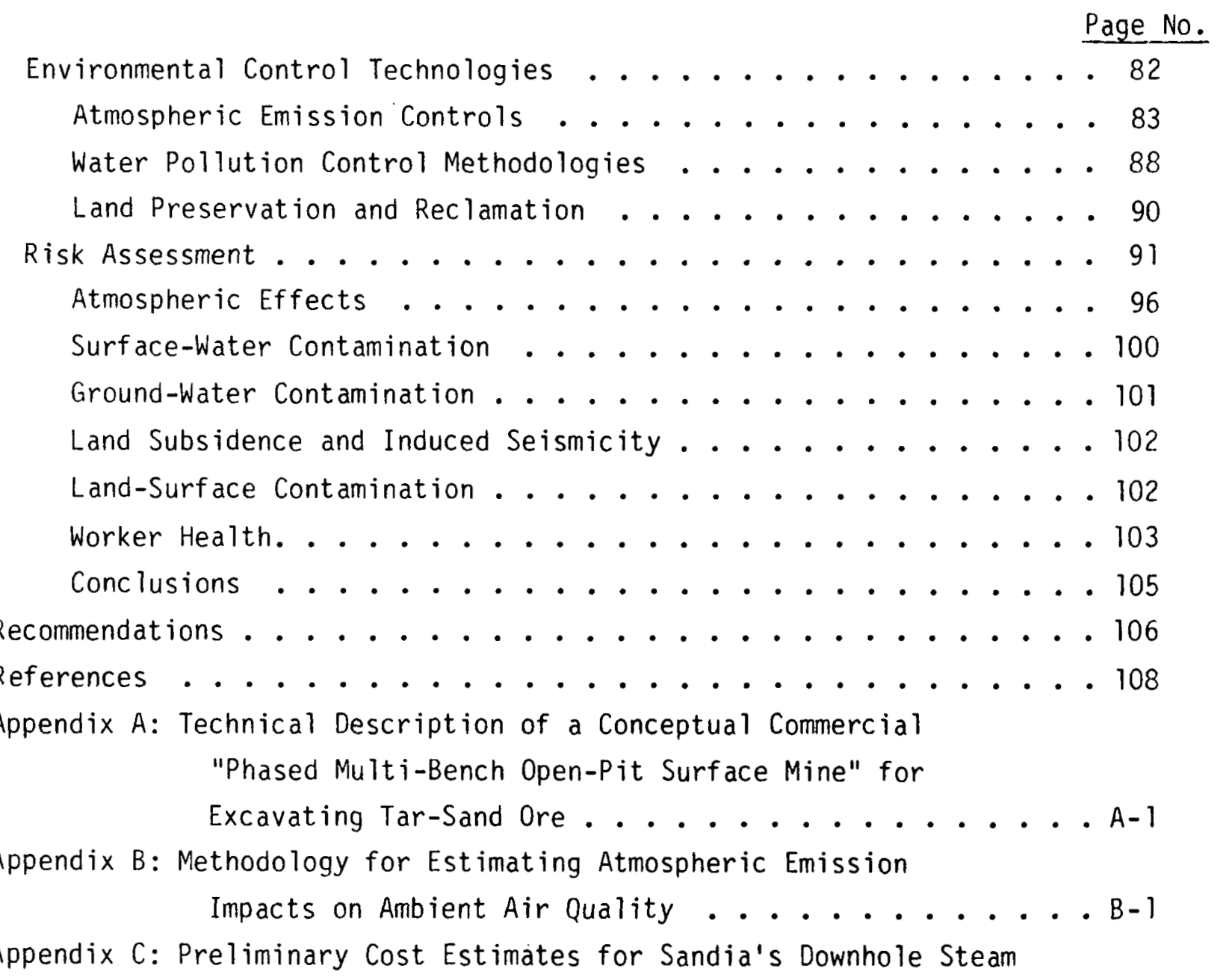

Generator .................. C-1 
$\theta$

$\theta$ 
Figure No.

Page No.

1 Location of the six largest tar-sand deposits

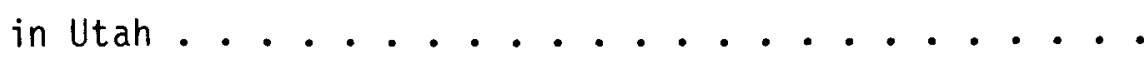

Schematic diagram of a representative 20,000-bb1/d commercial surface-retort system for extracting petroleum from surface-mineable domestic tar-sand

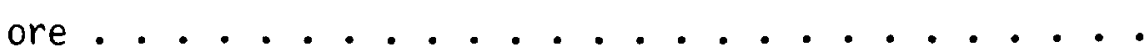

3 Schematic diagram of a representative 20,000-bbl/d commercial surface-solvent system for extracting petroleum from surface-mineable domestic tar-sand

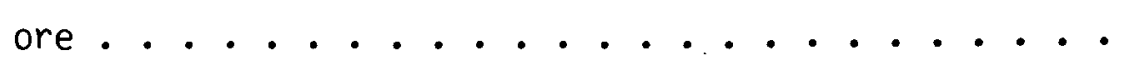

4

Schematic diagram of an experimental hot-water process for the potential commercial extraction of bitumen from surface-mineable tar-sand ore in $U t a h \ldots \ldots \ldots . . . \ldots$

5 Schematic diagram of a representative 20,000-bb1/d commercial in situ forward-combustion procedure for extracting petroleum directly from underground tar-sand deposits in the U.S. ..........

Schematic diagram of a representative 20,000-bb1/d commercial in situ reverse-combustion procedure for extracting petroleum directly from underground tar-sand deposits in the U.S. ........... 
Figure No.

7 Schematic diagram of a representative 20,000-bbl/d commercial in situ steam-injection procedure for extracting bitumen directly from underground tarsand deposits in the U.S. ...........

A-1 Diagram of a conceptual phased multi-bench open-pit surface mine for excavating tar-sand ore ..... A-2

B-1 Maximum $x u / Q$ as a function of plume height .... B-3 
Table No.

Page No.

1 Comparison of liquid-condensate characteristics of different bitumens.............. 36

2 Comparison of results from the simulated distillation of bitumen-liquid products ............. 36

3 Mole percent of $C_{1}$ to $C_{5}$ gases detected after coking bitumen from various sources . . . . . . . . . . .

4 Comparison of coke characteristics from different bitumens.........................

5 Estimated controlled criteria-pollutant atmospheric emission rates and control technologies for the typical "phased multi-bench open-pit surface mine" planned for use at the proposed 20,000-bbl/d commercial diatomaceousearth tar-sand oil-recovery facility near Mckittrick, California ..................

6 Estimated controlled criteria-pollutant atmospheric emission rates and control-technologies for a proposed 20,000-bbl/d commercial tar-sand surface-retort process . . 50

7 Estimated controlled criteria-pollutant atmospheric emission rates and control-technologies for a proposed 20,000-bbl/d commercial tar-sand surface-solvent process. . . . . . . . . . . . . . . . . 
Table No.

8 Estimated ambient-air-quality impact for controlled stack-gas emissions of criteria pollutants from a proposed 20,000-bbl/d commercial tar-sand surfaceretort system. . . . . . . . . . . . .

9 Estimated ambient-air-quality impact for controlled stack-gas emissions of criteria pollutants from a proposed 20,000-bbl/d commercial tar-sand surfacesolvent system .................

10 Average composition of the product gas from the TS-2C in situ combustion experiment. ...........

11 Estimated emission rates and ambient-air-quality impacts from the uncontrolled release of product gases from a conceptual 20,000-bbl/d commercial in situ tar-sand combustion process ...............

12 Estimated emission rates and ambient-air-quality impacts from the uncontrolled release of product gases from steam generators associated with a conceptual 20,000-bbl/d commercial in situ steam-injection tar-sand project ....

13 Emission-rate estimates of uncontrolled $\mathrm{SO}_{2}, \mathrm{NO}_{x}$, and TSP pollutants from steam-injection systems in Kern County, California, and Vernal, Utah, with fuelconsumption rates normalized to $6700 \mathrm{bbl} / \mathrm{d}$........

14 Concentrations of selected effluents in water from in situ tar-sand experiments: Comparison of experimental data with standards ............... 
15 Air-pollution-control systems potentially suitable for reducing emissions of criteria pollutants (i.e., TSP, $\mathrm{SO}_{2}$, $\mathrm{NO}_{x}, \mathrm{HC}$, and $\mathrm{CO}$ ) and $\mathrm{H}_{2} \mathrm{~S}$ from commercial tar-sand projects . . . . . . . . . . . . . . .

16 Estimated uncontrolied emissions from a prototype 5-MBtu/h downhole steam-generator ............

17 Water-pollution control technologies potentially suitable for removing contaminants from wastewater streams produced by commercial tar-sand oil-recovery processes . . . . . . . . . . . . . . . .

18 Likelihood-of-occurrence of effects from the operation of commercial tar-sand oil-recovery procedures .......

C-1 Representative input parameters for the downhole-steamdelivery-system cost case-study performed by Sandia National Laboratories . . . . . . . . . . . .

C-2 Tabulation of capital and operating costs required for a 10-MBtu/h non-vented downhole-steam-delivery system ... 
$\theta$

$\theta$ 
ACRONYM

af Acre-feet

API American Petroleum Institute

bbl Barrel

B0D Biochemical 0xygen Demand

Btu British thermal unit

CAA Clean Air Act

$\mathrm{CaO} \quad$ Calcium oxide (1 ime)

$\mathrm{CaSO}_{3} \quad$ Calcium sulfite

CFR Code of Federal Regulations

$\mathrm{CO}_{2} \quad$ Carbon dioxide

$\mathrm{CO} \quad$ Carbon monoxide

COD Chemical Oxygen Demand

CP Centipoise

$\mathrm{CR} \quad$ Threshold concentration of $\mathrm{SO}_{2}$ for growth reduction (ppmv)

CWA Clean Water Act

$d B A \quad$ Sound pressure level expressed in decibels with frequencies weighted according to the "A" scale. The A-weighted scale is a frequency response curve that simulates the response of the human ear.

DOE Department of Energy

EDTA Ethylenediaminetetra-acetic acid

EPA Environmental Protection Agency

GR Growth response

$\mathrm{H}_{2} \mathrm{~S} \quad$ Hydrogen sulfide

KGRA Known Geothermal Resource Area

$L_{d n} \quad$ Average day/night sound level. It is the A-weighted equivalent sound level for a 24-hour period, with an additional 10-decibel weighting imposed on the equivalent sound levels occurring during night-time hours of $10 \mathrm{p} . \mathrm{mi}_{\text {. }}$ to $7 \mathrm{a} . \mathrm{m}$.

LETC Laramie Energy Technology Center

L-R Lurgi-Ruhrgas Company 


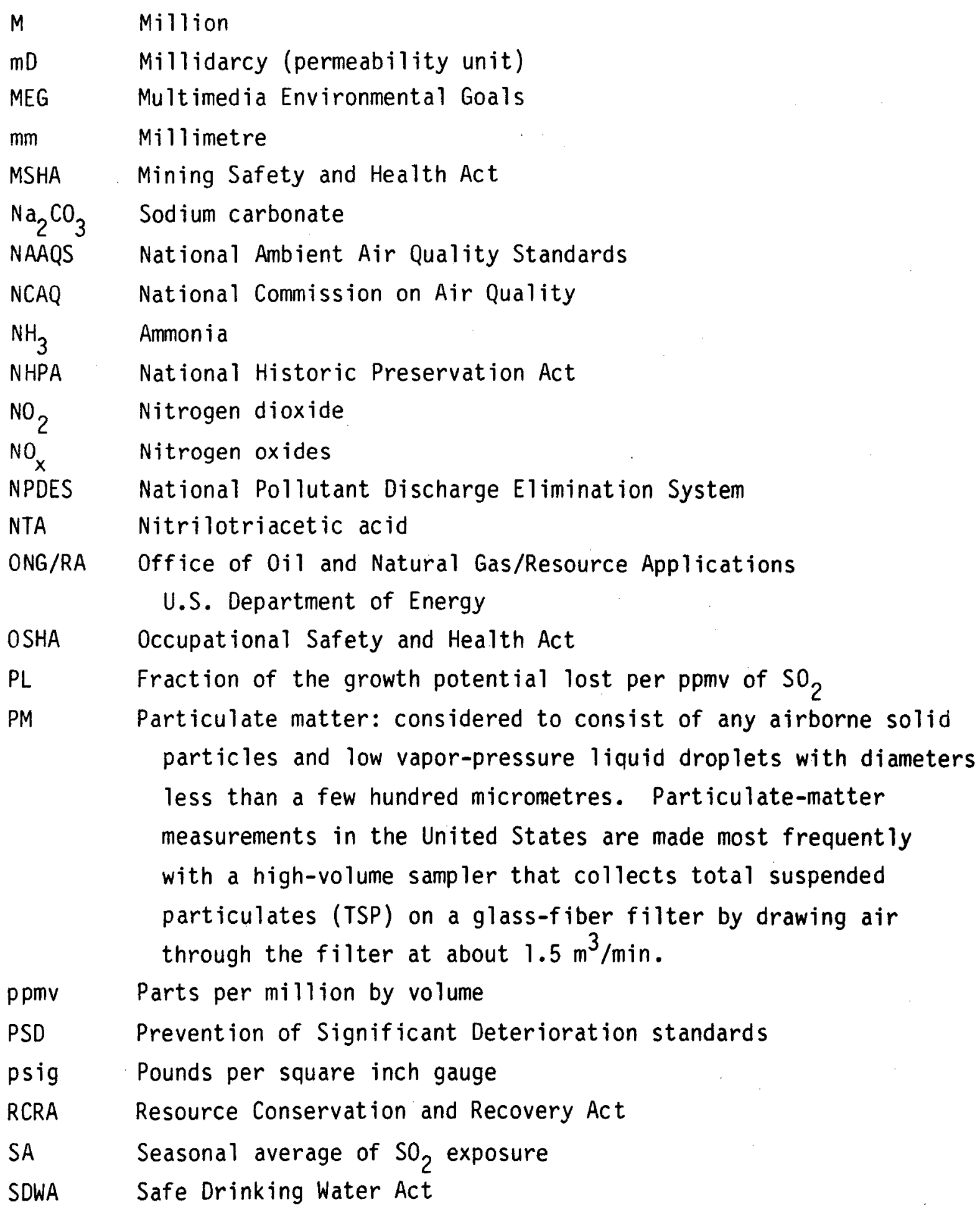




\section{GLOSSARY (continued)}

ACRONYM

SMCRA Surface Mining Control and Reclamation Act

$\mathrm{SO}_{2} \quad$ Sulfur dioxide

SOHIO Standard 0 il of Ohio

THC Total hydrocarbons

TS-IC Tar-sands reverse in situ combustion field test number 1

TS-iS Tar-sands steam-injection field test number 1

TS-2C Tar-sands echoing in situ combustion field test number 2

TSCA Toxic Substances Control Act

TSP Total suspended particulates: considered to be a measurement of the particulate matter (PM) suspended in ambient air when the high-volume sampling method is used.

UIC Underground Injection Control program

USGS United States Geological Survey 
0

$\theta$ 


\section{ABSTRACT}

The tar-sand resources of the United States have the potential to yield as much as 36 billion barrels (bbls) of oil. The tar-sand petroleum-extraction technologies now being considered for commercialization in the United States include both surface (above ground) systems and in situ (underground) procedures. The surface systems currently receiving the most attention include (1) thermal decomposition processes (retorting), (2) suspension methods (solvent extraction), and (3) washing techniques (water separation). Underground bitumen extraction techniques now being field tested are (1) in situ combustion and (2) in situ steam-injection procedures.

At this time, any commercial tar-sand facility in the U.S. will have to comply with at least 7 major federal regulations in addition to state regulations; building, electrical, and fire codes; and petroleum-industry construction standards. Pollution-control methods needed by tar-sand technologies to comply with regulatory standards and to protect air, land, and water quality will probably be similar to those already proposed for commercial oil-shale systems. The costs of these systems could range from about $\$ 1.20$ to $\$ 2.45$ per barrel of $0 i 1$ produced.

Estimates of potential pollution-emission levels affecting land, air, and water were calculated from available data related to current surface and in situ tar-sand field experiments in the U.S. These data were then extrapolated to determine pollutant levels expected from conceptual commercial surface and in situ facilities producing $20,000 \mathrm{bbl} / \mathrm{d}$. The likelihood-of-occurrence of these impacts was then assessed. Experience from other industries, including information concerning health and ecosystem damage from air pollutants, measurements of ground-water transport of organic pollutants, and the effectiveness of environmental-control technologies was used to make this assessment.

Conclusions reached from this assessment are that certain effects are more likely to occur than others. In this final report these effects are discussed and ordered according to their likelihood-of-occurrence for surface and in situ tar-sand oil-extraction technologies. 


\section{SUMMARY}

According to recent estimates, the tar-sand resources of the United States have the potential to yield as much as 36 billion barrels (bbls) * of oil. However, at the present time the technologies that could be used to recover this oil are still in an emerging state of development, and therefore have not achieved commercial status.

The tar-sand petroleum-extraction technologies being seriously considered for commercialization in the United States include both surface (above-ground) systems and in situ (underground) procedures. The surface systems currently receiving the most attention include (1) thermal decomposition processes (retorting), (2) suspension methods (solvent extraction), and (3) washing techniques (water separation). All three methods are being investigated for their effectiveness in extracting the organic constituent of tar sand (bitumen) from surface mineable tar-sand ore. Underground bitumen extraction techniques now being field tested are (1) in situ combustion and (2) in situ steam-injection procedures. Both in situ techniques are designed to heat the bitumen underground and then drive the resulting fluids to collection wells for transport to the surface. All five of the aforementioned procedures may be needed to establish a tar-sand industry in the U.S. This is because the geochemical and physical properties of U.S. tar-sand deposits can differ considerably and therefore no single extraction procedure is expected to be suitable for extracting bitumen from all tar-sand deposits.

Tar-sand reservoirs have been referred to by several other names. These include oil sands, bituminous sands, oil-impregnated rocks, bitumen-bearing rocks, asphaltic rocks, and heavy-oil-producing rocks. A formal definition currently proposed by the U.S. Department of Energy states that "Tar sand is any consolidated or unconsolidated rock (other than coal, oil shale, or gilsonite) that (1) contains a hydrocarbonaceous material with a gas-free viscosity, at original reservoir temperature, greater than 10,000 centipoise $(\mathrm{CP})$, or (2) contains a hydrocarbonaceous material that is extracted from the mined or quarried rock." Tar sand has also been defined as having an API gravity generally $\leq 12^{\circ}$ and a viscosity of $10^{5}$ to $10^{6} \mathrm{cP}$. Tar-sand bitumen

\footnotetext{
${ }^{*}$ l bbl of $0 i 1=42$ U.S. gallons (159 litres)
} 
also exhibits a decreasing viscosity with increasing temperature, and general solubility in strong solvent members of the petroleum family (e.g., benzene and toluene). This behavior is characteristic of petroleum family members and can be exploited by tar-sand oil-extraction processes.

Commercially operating tar-sand technologies in the U.S. will have to comply with at least 7 major federal regulations in addition to state regulations; building, electrical, and fire codes; and petroleum-industry construction standards. There are also proposed regulations that may be applicable to tar-sand technologies should they be passed into law. Pollution-control methods needed by tar-sand technologies to comply with regulatory standards and to protect air, land, and water quality will probably be similar to those already proposed for commercial oil-shale systems. The costs of these systems could range from $\$ 0.92$ to $\$ 1.16$ per barrel of 0 il produced for atmospheric-emission-controls of criteria pollutants (i.e., $\mathrm{SO}_{2}, \mathrm{NO}_{x}, \mathrm{HC}, \mathrm{CO}$, and TSP); $\$ 0.25$ to $\$ 1.25$ per barrel of syncrude produced for water-pollution-abatement systems; and about $\$ 0.01$ to $\$ 0.04$ per barrel of petroleum produced for land reclamation and restoration. These costs are considered accurate to within a factor of 2, and are of minor economic importance now that oil prices range from $\$ 23 / \mathrm{bb} 1$ to $\$ 40 / \mathrm{bb}$ for domestic and imported petroleum, respectively.

Estimates of potential pollution-emission levels affecting land, air, and water were calculated from available data related to current U.S. tar-sand field experiments involving (1) surface processes (including retort and solvent extraction methods) and (2) in situ techniques (including combustion and steam-injection methods). These data were then extrapolated to determine pollutant levels expected from conceptual commercial surface and in situ facilities producing $20,000 \mathrm{bbl} / \mathrm{d}$. The likelihood-of-occurrence of these impacts was then assessed. Experience from other industries, including information concerning health and ecosystem damage from air pollutants, measurements of ground-water transport of organic pollutants, and the effectiveness of environmental-control technologies was used to make this assessment. These estimates were used to examine the nature and magnitude of potential environmental, health, and safety risks.

Conclusions reached from this assessment are that certain effects are more likely to occur than others. These effects can be ordered for surface and in situ technologies according to their likelihood-of-occurrence as follows 
Surface Extraction Technologies

- Occupational health problems, including those related to worker exposure to carcinogenic and other hazardous substances, are likely to occur.

- Public health and/or ecosystem effects from airborne effluents, ground-water contamination, and land-surface contamination may occur but will be localized and/or controllable.

- Public health and/or ecosystem effects from surface-water contamination are possible, but unlikely to occur.

- Land subsidence and induced seismic effects are not applicable to surface extraction techniques.

- In Situ Processes

- Occupational health problems, including those related to worker exposure to carcinogenic and other hazardous substances, may occur but will be localized and/or controllable.

- Public health effects from airborne effluents (particularly $\mathrm{SO}_{2}$ and $\left.\mathrm{H}_{2} \mathrm{~S}\right)$ and ground-water contamination may occur but will be localized and/or controllable.

- Ecosystem effects from airborne effluents and land subsidence may occur but will be localized and/or controllable.

- Public health and/or ecosystem effects from surface-water contamination and land-surface contamination are possible, but unlikely to occur.

- Induced seismic effects are possible, but unlikely to occur.

Research projects currently under way do not adequately address all environmental concerns. This is primarily due to the fact that investigators in the U.S. have concentrated primarily on producing technically successful processes; and, during initial development, concomitant environmental analyses have been limited in scope. Now that the tar-sand technologies are nearer to commercialization, however; this situation must change, and efforts must be made to improve not only the effectiveness of the technologies but also their environmental acceptability. Studies that need to be performed during current field testing include the following: (1) complete chemical characterization of emissions, (2) analyses of process operating characteristics and products so 
that worker health and safety can be properly protected, (3) evaluation of the risks to exposed public populations from potential emissions from tar-sand technologies, and (4) determination of the specific control technologies that will be effective in protecting air, land, and water quality from pollutants emitted by commercial tar-sand facilities. 
0il-price increases and supply interruptions by oil producing and exporting countries have focused attention on the need for the United States to reduce its dependence on foreign oil. This situation has created economic and political incentives for industry and government to examine seriously methods for recovering petroleum from significant domestic tar-sand resources. One recent synfuels cost survey even suggests that tar sands may be a relatively inexpensive synfuel to produce.

Current activities in the United States to recover petroleum from tar sands involve experiments and small-scale field projects sponsored by either industry or the U.S. Department of Energy (DOE). These research efforts have concentrated on two strategies. One strategy entails mining tar sands and then utilizing surface (above-ground) facilities to separate the petroleum from the sand grains. The separation methods currently receiving the most attention include (1) thermal decomposition (retorting), (2) suspension (solvent extraction), and (3) washing (hot-water separation). The other strategy for obtaining oil from tar sands involves inducing in situ (underground) flow of the hydrocarbon components through the tar-sand formation. The in situ procedures being field tested in the U.S. are combustion methods and steam-injection techniques, both of which are designed to heat the petroleum and drive it to collection wells where the fluids can be brought to the surface.

The successful production of oil from tar sands by U.S. research projects and the existence of commercial tar-sand surface-recovery operations in Alberta, Canada, are encouraging indications that U.S. tar-sand resources can be used to augment domestic-oil production. However, because the Canadian surface-recovery methods are not directly applicable to U.S. tar sands and techniques for recovering oil from domestic tar-sand deposits are in an embryonic stage of development; investigators in the U.S. have concentrated primarily on producing technically successful processes. Environmental analyses have therefore been limited in scope.

The purpose of this technology assessment is to (1) define the tar-sand resources in the United States, (2) describe research involving representative surface and in situ tar-sand oil-recovery techniques potentially suitable for 
commercial use, (3) determine the nature and magnitude of the environmental, heaith, safety, and socioeconomic consequences from commercialization of these technologies, and (4) identify future research needs. This information will provide timely guidance to industry and government for furthering environmentally acceptable commercialization.

\section{RESOURCE CHARACTERISTICS AND PROPERTIES}

TAR SANDS: DEFINITION

Tar sands are deposits of consolidated or unconsolidated clastic sediments (e.g., sandstone, limestone, diatomite) that have pore spaces partially or completely saturated with a heavy, viscous petroleum known as bitumen. Easily accessible tar sands, usually from surface outcrops, have been used effectively as roofing tar and asphalt pavement. In underground reservoirs the high viscosity and high specific gravity of tar-sand bitumen produce behavior superficially comparable to that of the heavier crude oils. For example, neither bitumen nor heavy-crude oils flow very well under natural reservoir conditions. Tar-sand deposits, however, may be distinguished from heavy-oil reservoirs because tar sands are generally coarse or fine sedimentary deposits that contain a semi-solid petroleum (bitumen) that cannot be pumped through its confining mineral matrix and collected at a well bore under natural reservoir conditions. Heavy $0 i 1$, on the other hand, is a very viscous liquid petroleum that, in most circumstances, can be pumped and collected (albeit extremely slowly) under natural reservoir conditions. Thus, the pertinent similarities between heavy $0 i l$ and tar-sand bitumen are that both are members of the petroleum family of organic substances and both are currently attractive sources of liquid-hydrocarbon fuels, but neither can be economically recovered by the relatively simple techniques used for obtaining typical light-crude oils.

Tar-sand reservoirs are also called oil sands, bituminous sands, oil-impregnated rocks, bitumen-bearing rocks, asphaltic rocks, and heavy-oil-producing rocks. 
The bitumen in tar-sand deposits generally has a high molecular weight, specific gravity, viscosity, and carbon-to-hydrogen ratio $(\mathrm{C}: \mathrm{H})$, and may also contain elevated concentrations of sulfur, nitrogen, oxygen and heavy metals. ${ }^{2}$ A wide variability in these properties of bitumen may, however, exist within and among different tar-sand reservoirs. For example, the concentration of sulfur in some bitumen deposits in Utah is much lower than that found in Canadian tar sands and in many heavy - and even some light-crude oils; and, even though the heavy-metal content in bitumen may be high in some reservoirs, some heavy-crude oils also contain elevated quantities of heavy metals. 3

Tar-sand bitumen exhibits the following behavior that is characteristic of petroleum-family members, and is useful for tar-sand oil-extraction processes $^{2}$ :

- Decreasing viscosity with increasing temperature, and

- General solubility in strong solvent members of the petroleum family (e.g., benzene and toluene).

The sand-grain mineral composition of tar sand is usually conducive to fluid flow through the mineral matrix; therefore, in many cases the need for mechanical fracturing for in situ recovery is el iminated.

The specific characteristics used most frequently to classify and identify tar-sand bitumen are a $^{4-7}$

- An API Gravity* generally $\leq 12^{\circ}$ where, Degrees API Gravity $=\frac{141.5}{\text { specific gravity }}-131.5$, and

- A viscosity of $10^{5}$ to $10^{6}$ centipoise (CP).

Another more formal definition of tar sand has been proposed by the Office of $0 i 1$ and Natural Gas formerly under the Assistant Secretary for Resource Applications (ONG/RA), and now under the Assistant Secretary for Fossil Energy, in the U.S. Department of Energy. This definition was derived

\footnotetext{
*API Gravity: A scale devised by the American Petroleum Institute to measure the density of petroleum.
} 
for purposes of leasing, taxation, and financial assistance for a tar-sand industry, and was developed during a tar-sand workshop sponsored by ONG/RA. According to the proposed definition ${ }^{8}$ :

"Tar. sand is any consolidated or unconsolidated rock (other than coal, oil shale, or gilsonite) that

(1) contains a hydrocarbonaceous material with a gas-free viscosity, at original reservoir temperature, greater than 10,000 centipoise, or (2) contains a hydrocarbonaceous material that is extracted from the mined or quarried rock."

In comparison to tar-sand petroleum, most crude oils have gravities above $12^{\circ} \mathrm{API}$, and crude oils with gravities above $18^{\circ} \mathrm{API}$ and viscosities less than $10^{5} \mathrm{cP}$ are common. Almost all current U.S. production involves crude oils with viscosities less than $10^{4} \mathrm{cP} .9$

\section{EVOLUTION OF TAR-SAND DEPOSITS}

There are currently three plausible explanations for the origin of tar-sand deposits. 2,5 According to one explanation, which is based on a considerable amount of geochemical evidence, tar sands are the highermolecular-weight hydrocarbons remaining after near-surface water washing and biodegradation of the lighter hydrocarbons of conventional crude oil. These natural processes occurred after the oil was trapped in a porous formation following migration from its "source rocks." The other theories, which are not as well substantiated, consider tar sands to be either (1) the result of evaporation and diffusion of the lower-molecular-weight hydrocarbons along lengthy diffusion paths, or (2) precursors of conventional crude oil that have been arrested before maturity by thermal, chemical, and physical alteration.

\section{U.S. TAR-SAND RESOURCES}

Tar-sand resources located in the United States, Venezuela, and Canada are substantial. According to recent estimates, the U.S. tar-sand resource may contain as much as $3.6 \times 10^{10}$ barrels (ibls) of oil. 10 This is considered to be approximately equal to the amount of $0 i 1$ now available from the remaining easily obtainable petroleum reserves located in the U.S. 11 Tar-sand deposits in Venezuela are estimated to contain between $7.0 \times 10^{11}$ 
and $1.0 \times 10^{12}$ barrels of $0 i 1^{2,12}$ (however, Venezuelan heavy oil reservoirs may also be included in these estimates), and the Canadian tar-sand resource is presumed to be the largest in the world with an estimated $1.3 \times 10^{12}$ barrels of oil. 2,5 Other major tar-sand deposits may be found in Malagasy, Albania, Trinidad, Rumania, and the Soviet Union. 13

Although the tar-sand deposits in the United States are less extensive than those in Canada and Venezuela, commercial development can still make an important contribution to domestic petroleum production. Utah is believed to have over $80 \%$ of the domestic tar-sand resource (approximately $2.9 \times 10^{10}$ bbls of 0 il) $)^{10}$; the remaining $20 \%$ is located in several other states. The other states containing tar-sand deposits with over 1 million barrels of oil are California, Kentucky, New Mexico, and Texas. 10 Less well-defined deposits are located in Alabama, Kansas, Missouri, and Ohio. 4

In Utah, more than $96 \%$ of the resource is present in the sandstone host rocks of six giant deposits (Figure 1), and the remainder is in approximately 44 smaller deposits. 14 The six giant deposits are located in two principal groups: a northeast group, called the Uinta Basin group; and a central southeast group. 2,14 The Uinta Basin group includes the Asphalt Ridge, Northwest Asphalt Ridge, P.R. Spring, Hill Creek, and Sunnyside deposits. The central southeast group consists of the Tar Sand Triangle and Circle Cliffs deposits.

The other noteworthy tar-sand deposits in the U.S. that are now being considered for commercial development are in California, New Mexico, and Texas. 10,11 These deposits, like those in Utah, are considered to be sufficient in size to support commercial tar-sand activities for 20 to 30 years or more. This is important because it is not economically attractive for industry to exhaust a resource too quickly due to the advantages of amortizing the capital investment over the long term.

The only commercial tar-sand oil-recovery activities now being carried out are those in the Athabasca formation near Edmonton in Alberta, Canada. 5 No commercial-scale facility has been constructed in the United States for two main reasons: (1) the simple oil-recovery techniques used for the Canadian deposits cannot be readily adapted to most domestic tar-sand resources, and (2) research on techniques for recovering 0 il from U.S. tar sands has been sporadic due primarily to adverse economic conditions. However, economic constraints have recently been eased because of increasing oil prices, and U.S. experiments and field tests are now under way. 


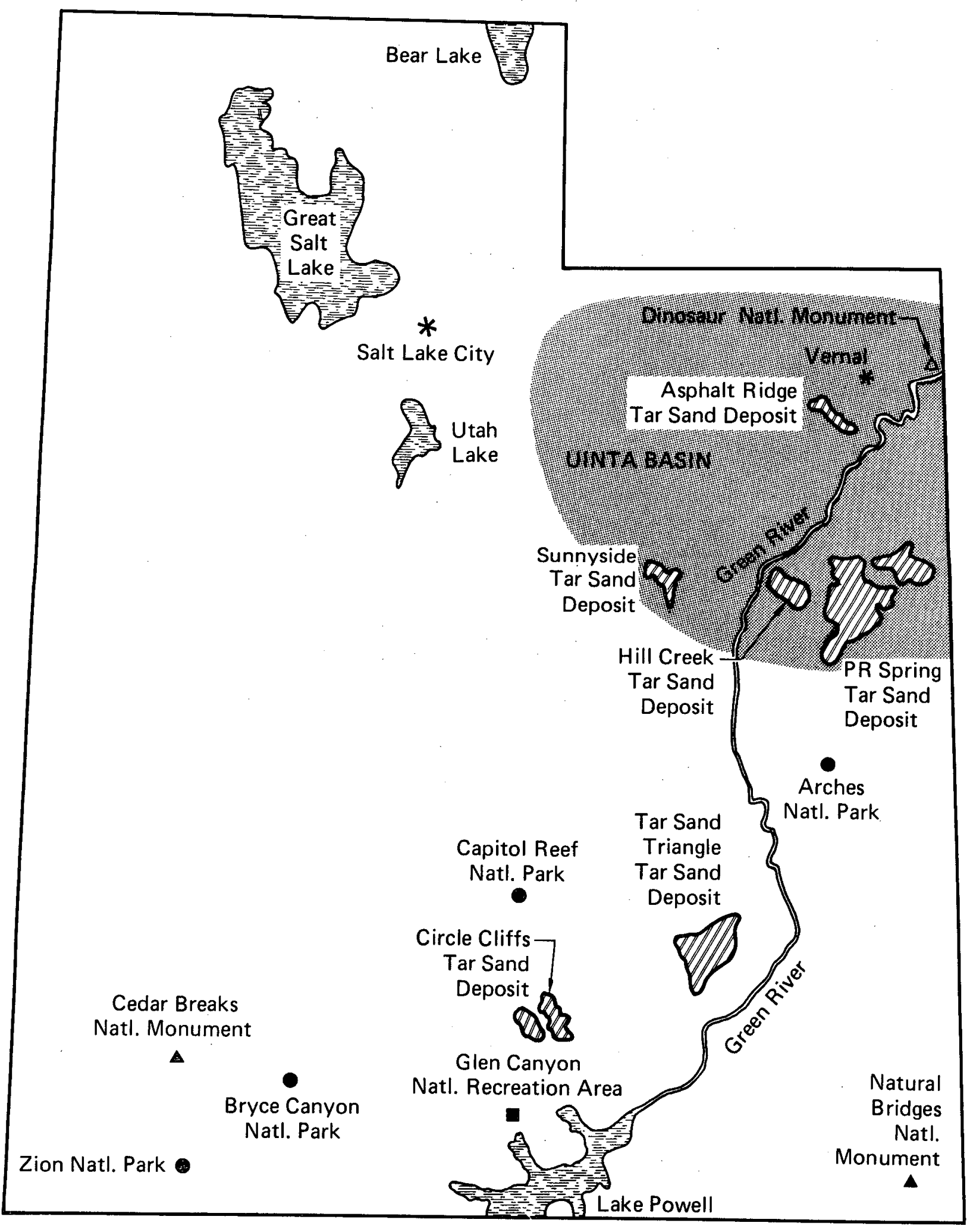

Figure 1. Location of the six largest tar-sand deposits in Utah (redrawn from Ref. 15, p. 1312). 
Although some tar-sand technologies that may be suitable for commercial application in the U.S. are now being field tested, they are still in a nascent stage of development. There are also additional tar-sand oil-recovery techniques that are still being researched and in many instances remain proprietary. Moreover, there are many in situ and surface tar-sand oilrecovery methods that have been patented, ${ }^{3}$ but never applied commercially. In some cases the process experimentation and development are taking place on tar-sand deposits that are easily accessible and conveniently located for economic reasons, but are not representative of deposits in more remote locations where the tar-sand reservoirs are larger and therefore even more suitable for commercial development.

Analysis of the available quantitative data from tar-sand oil-recovery experiments and pilot projects will indicate the potential environmental, health, safety, and socioeconomic consequences that may be encountered from their commercial application. This information can then be used to ensure that these impacts $c$ an be properly mitigated so that development proceeds in the most environmentally acceptable manner.

\section{BITUMEN RECOVERY METHODS}

There are essentially only two procedures for producing oil from the bitumen in tar-sand deposits. One method is to mine the tar sands as ore and then extract the bitumen from the ore by separation procedures performed in above-ground (surface) facilities. The other method is to induce in situ flow of the bitumen through the underground tar-sand formation and bring the product fluids to the surface by means of collection wells, in a manner similar to that used for heavy-oil recovery.

Generally, these two process strategies employ variations of the following methods:

- Suspending the bitumen in solvents or water,

- Heating the bitumen to cause it to flow or vaporize, or

- Combinations of the above processes.

Surface extraction procedures can be $90 \%$ or more efficient, although mining and handling losses can lower this value considerably. In situ methods are estimated to attain a total recovery efficiency of between 50 and $60 \% .4,5$ 
The chemical and physical properties of tar sands differ considerably among the various deposits throughout the world. As a result, no single recovery process is likely to be applicable to all tar-sand deposits. $4,5,11$ Parameters that will influence the selection of a particular tar-sand oil-recovery process include ${ }^{2}$

- Shallow vs deep deposits,

- Hard vs soft confining matrix material,

- Water-vs oil-wet sand grains,

- High-vs low-sulfur content of bitumen,

- Small vs large sand-grain size, and

- Bitumen concentration of the deposit.

Shallow tar-sand deposits are recoverable using appropriate surface mining practices. However, an estimated $80 \%$ of tar-sand deposits in the United States, and 90\% of the tar-sand deposits in Canada, are too deep for surface mining to be profitable. ${ }^{2,5}$ These deep deposits are best suited for recovery by either underground mining or in situ extraction methods. Underground mining will not be acceptable if the tar-sand formation is composed of a soft, friable material that lacks the structural integrity to support the overburden safely. Alternatively, if the tar-sand deposit is deep within hard, consolidated sandstone, and explosives can be safely used to break the deposit apart, then underground mining may be considered although a more attractive alternative might be in situ extraction. In situ recovery methods might be more suitable because they are potentially less costly and less dangerous than subterranean mining, and they may be more adaptable for use on any deep tar-sand deposits.

Another variable that can dictate selection of the recovery process is the presence or absence of water encapsulating the sand grains. At the Athabasca Deposit in Alberta, Canada, surface mining and a simple hot-water extraction technique are being used. This procedure is feasible because approximately $10 \%$ of the Canadian deposit is estimated to be economically recoverable using open-pit mining, and the bitumen in the deposit is not in intimate contact with the sand grains due to a water film between them. This 
water-film condition, however, is not an intrinsic property of most U.S. tarsand deposits, particularly those located in Utah, and therefore simple hotwater displacement techniques need to be modified before they can be used on these tar sands. Tar sands that do not possess the water film separating the bitumen from the sand grains have been labeled "oil wet," and tar sands like those in Canada that do have this water film are known as "water wet."

other distinguishing characteristics of tar sands that can constrain development or affect the acceptability of a particular procedure include sulfur content, grain size, and bitumen yield. For instance, tar-sand oil-recovery processes that lead to the emission of sulfur compounds to the atmosphere are likely to be constrained by U.S. air-pollution regulations. Sand grains smaller than $0.1 \mathrm{~mm}$ tend to form emulsions with bitumen in water, and this may preclude the use of some water extraction processes. ${ }^{2}$ The concentration of bitumen in a reservoir is an indicator of whether recovery is economically feasible; and also, in combination with knowledge of the ratio of overburden thickness to oil-sands thickness, can provide a criterion for selecting surface mining over in situ methods.

\section{FEDERAL REGULATORY FRAMEWORK}

Any commercial tar-sand facility will have to operate in compliance with regulations set forth in the following federal Acts:

- Clean Air Act (CAA),

- Clean Water Act (CWA),

- Safe Drinking Water Act (SDWA),

- Resource Conservation and Recovery Act (RCRA),

- Toxic Substances Control Act (TSCA),

- Occupational Safety and Health Act (OSHA), and

- National Historic Preservation Act (NHPA).

U.S. Geological Survey regulations contained in chapters $221^{16}$ and $231^{17}$ of Title 30 of the Code of Federal Regulations (CFR) may also apply. 
The Clean Air Act and its amendments contain regulations and standards intended to protect ambient-air-quality from significant degradation, and where necessary to improve and restore it to acceptable levels. National Ambient-Air-Quality Standards (NAAQS) have been promulgated for specif ic air pollutants on the basis of the air-quality criteria determined for them. These pollutants are therefore called "Criteria Pollutants." They include nitrogen dioxide $\left(\mathrm{NO}_{2}\right)$, sulfur dioxide $\left(\mathrm{SO}_{2}\right)$, carbon monoxide $(\mathrm{CO})$, hydrocarbons, and particulate matter $(P M)^{*}, 18$ all of which will be of concern to operators of commercial tar-sand facilities.

Another portion of the Clean Air Act that may influence tar-sand development is the section dealing with Prevention of Significant Deterioration (PSD) of air quality. The PSD standards set maximum allowable increments of increase-over-baseline concentrations for total suspended particulates (TSP) ${ }^{\dagger}$ and sulfur dioxide in areas that NAAQS are not exceeded. The most restrictive increments are applicable to areas which include the National Parks, and there are a number of these near the major tar-sand deposits located in Utah (see Figure 1). A discussion of estimated emissions of criteria pollutants associated with various tar-sand oil-recovery processes is included in the Environmental Analysis and Assessment Section.

\section{CLEAN WATER ACT}

The Clean Water Act and its amendments establish a permitting process to protect surface waters from contamination. This process is administered under the National Pollutant Discharge Elimination System (NPDES). The Act prohibits discharge of pollutants to U.S. waters without a permit. Two major functions of the NPDES permitting process are 19

\footnotetext{
*Particulate matter: solid particles and low vapor-pressure liquid droplets with diameters less than a few hundred micrometres that are measured most frequently in the U.S. with a high-volume sampler that collects total suspended particulates (TSP) on a glass-fiber filter by drawing air through the filter at about $1.5 \mathrm{~m}^{3} / \mathrm{min}$.

TTotal suspended particulates: a measurement of the particulate matter (PM) suspended in ambient air when the high-volume sampling method is used.
} 
- To establish specific levels of performance that must be maintained by a discharger, and

- To require the discharger to report failure to achieve the specified level of performance.

SAFE DRINKING WATER ACT

Applicable Safe Drinking Water Act regulations include an Underground Injection Control Program (UIC), and Public Drinking Water Standards. 18 Public Drinking Water Standards are designed to ensure that potable waters are safe for public consumption. (Selected drinking-water standards are presented in Table 14 in the Environmental Analysis and Assessment Section.) The UIC is designed to prevent pollution of underground drinking water supplies from the generation or disposal of hazardous or toxic waste.

Potential water-quality impacts from tar-sand oil-recovery processes could result from run-off or leaching from stockpiles of ore and waste. In situ processes could also cause water contamination either from the migration of produced gases in the case of combustion processes, or from the migration of injection waters in the case of steam injection. Other water-contamination sources are discussed in the Environmental Analysis and Assessment Section.

RESOURCE CONSERVATION AND RECOVERY ACT

The portion of the Resource Conservation and Recovery Act of concern to developers of commercial tar-sand technologies is contained in Subtitle C., "Hazardous Waste Management," of Title II - Solid Waste Disposal. Regardless of the particular process used, oil recovery from tar sands will generate waste that may be classified as hazardous, and RCRA regulations will apply to both generation and disposal of these wastes.

TOXIC SUBSTANCES CONTROL ACT

The Toxic Substances Control Act (TSCA) is concerned with the unreasonable risk of health damage or environmental deterioration from the manufacture,' processing, distribution in commerce, use, or disposal of a 
chemical substance or mixture. This Act requires testing and, when necessary, use-restrictions on certain chemical substances. These regulations may apply to the production of synfuels and the use of recycled process waters and waste material. 20 All of these factors are characteristic of tar-sand technologies.

OCCUPATIONAL SAFETY AND HEALTH ACT (OSHA)

Regulations contained in OSHA establish levels of pollutants permissible in a work-place. For instance, among the toxic agents of potential hazard to workers at tar-sand in situ steam-injection facilities would be oil/water and water/oil de-emulsifiers as well as water-treatment chemicals, oxygen scavengers, organic sequestering agents, and corrosion-control substances. Hydrogen sulfide emissions could also be a hazard to workers at tar-sand facilities, particularly where in situ combustion processes are used. Above-ground solvent processes could expose workers to the solvent vapors. Adverse health impacts could also result from worker exposure to substances used or produced by above-ground retort systems. OSHA regulations also apply to noise, equipment and vehicle safety, and other aspects of worker safety and health.

NATIONAL HISTORIC PRESERVATION ACT

The National Historic Preservation Act (NHPA), 21 and Executive Order $11593^{22}$ mandate protection for sites, buildings, structures, and objects of significance in American history, architecture, archaeology, or culture.

GEOLOGICAL SURVEY REGULATIONS

Title 30, "Mineral Resources," of the Code of Federal Regulations (CFR), contains material applicable to commercial development of tar sands. The regulations of interest are contained in Chapters 221, "0i1 and Gas Operating Regulations," and 231, "Operating Regulations for Exploration, Development, and Production." Under these regulations, the U.S. Department of Interior's Geological Survey (USGS) has responsibility for approving operating plans for tar-sand development on both federal and Indian land. The USGS is also responsible for approving tar-sand operations on private land when the land is 
developed simultaneously with federal land by the same company. Mineral activities on other private- and state-owned lands are under the jurisdiction of individual state regulatory agencies.

Regulations in Chapter 221 cover tar-sand in situ recovery technologies that use conventional wells. 16 The USGS "Area 0 il and Gas Supervisor" is authorized to require compliance with these regulations, and

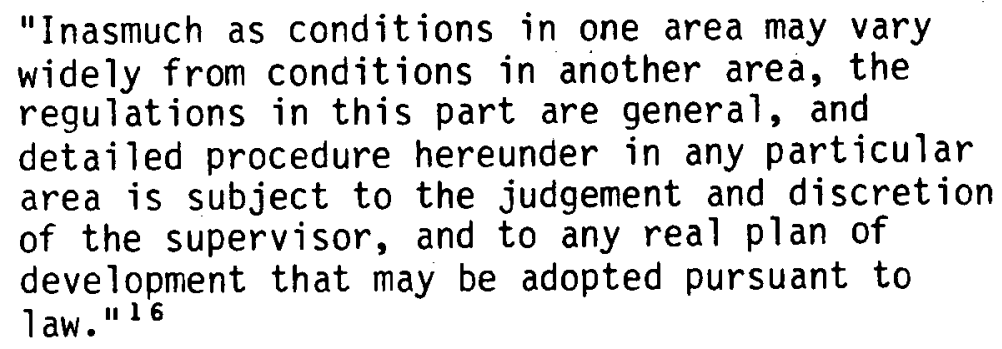

Tar-sand surface or subsurface mining activities must comply with regulations in Chapter 231 of CFR Title 30.17 The stated purpose of these regulations is to

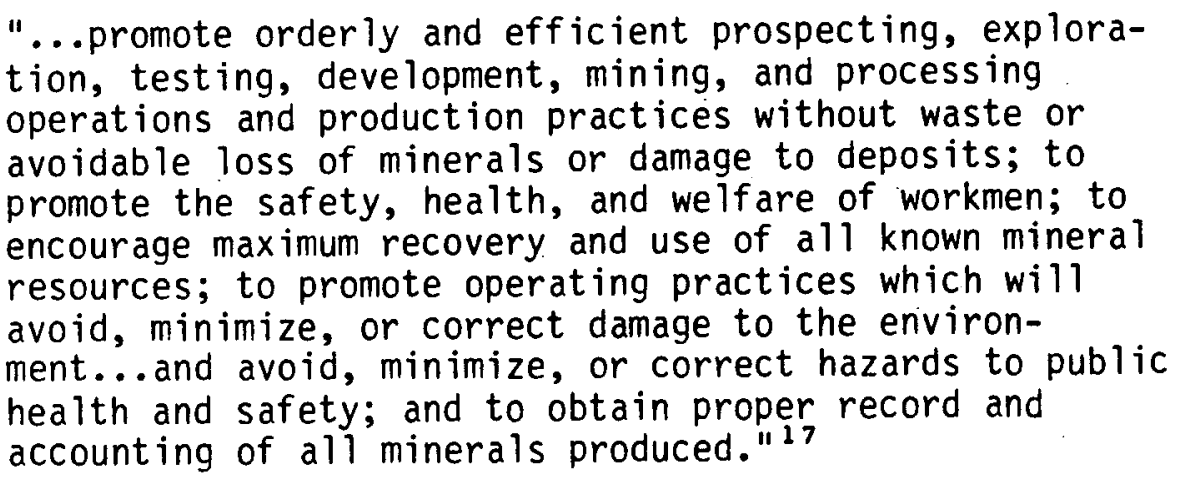

Some of the environmental, safety, and health impacts addressed include fire dangers, hazards associated with surface openings, and problems related to the volume, physical properties and composition of the generated wastes.

SURFACE MINING CONTROL AND RECLAMATION ACT

At the present time, the Surface Mining Control and Reclamation. Act (SMCRA) regulations do not apply to tar-sand oil recovery. A statement of findings and policy in SMCRA states that while there is a need to regulate surface mining operations for minerals other than coal, more data and analyses 
are needed to serve as a basis for effective and reasonable regulations of such operations. Nevertheless, the detailed standards presented in SMCRA can serve as a useful guide to the type of regulation that may evolve for the developing tar-sand industry.

\section{PROPOSED REGULATIONS}

The Environmental Protection Agency (EPA) is reviewing criteria used to establish National Ambient-Air-Quality Standards (NAAQS) for carbon monoxide $(\mathrm{CO})$, nitrogen dioxide $\left(\mathrm{NO}_{2}\right)$, sulfur dioxide $\left(\mathrm{SO}_{2}\right)$, and particulate matter (PM). ${ }^{23}$ These standards will be revised where appropriate to protect public health and welfare. A second draft of a revised combined-criteria document for $\mathrm{PM} / \mathrm{SO}_{\mathrm{x}}$ consisting of five volumes, has been prepared by the EPA and is undergoing review. ${ }^{24}$ The Environmental Protection Agency is also proposing a regulation, called "Prevention of Significant Deterioration from Set II Pollutants," to protect air quality from significant degradation from "Set II" pollutants in those areas that already meet NAAQS. ${ }^{23}$ Set II pollutants include $\mathrm{CO}, \mathrm{NO}_{x}$, hydrocarbons, and ozone. PSD increments have already been established for $\mathrm{SO}_{2}$ and PM.

The National Commission on Air Quality (NCAQ) is reviewing the Clean Air Act and has just completed a report recommending many changes. ${ }^{25}$ of interest to the tar-sand oil-recovery industry are the following recommendations for the Environmental Protection Agency:

- Continue to set NAAQS based solely on health effects, without regard to cost,

- Move faster to regulate pollutants such as complex organic compounds or heavy metals,

- Rule within a year whether a fine-particulate standard is needed to supplement the existing standard for PM (which does not discriminate according to particle size), or to replace it,

- Eliminate the increment system in the PSD program and rely on "best available control technology" (BACT) to control the amount of pollution a source can add to the air, and

- Eliminate national deadlines to meet NAAQS. 
In addition to proposed and current federal regulations, individual states may have other, possibly more stringent regulations that require compliance before a tar-sand facility may operate. It is also presumed that commercial tar-sand projects will comply with appropriate building codes and regulations, and that applicable electrical and fire codes will be obeyed. Industry standards for construction and operation of pipelines, storage tanks, and drainage diversions and ditches must also be met.

The requirements of federal and state regulations may prove to have a constraining influence on commercial tar-sand development because of the expense required to purchase and install the necessary pollution-control equipment. The degree of economic constraint imposed by this dynamic regulatory framework is, of course, dependent on other economic factors, such as the rising price of oil.

\section{PROCESS DESCRIPTIONS}

The tar-sand recovery processes now under examination for implementation in the United States are surface mining and extraction, and in situ recovery. Underground mining and modified in situ processes have been virtually excluded from U.S. tar-sand research due primarily to economic constraints associated with the amount of material that these procedures would leave in place. For example, underground mining of the soft and friable material characteristic of some U.S. tar sands would require extensive use of room and pillar construction, which necessitates that a large portion of the deposit be left in place to support the overburden. 2

Information about many of the surface and in situ tar-sand oil-extraction processes now being investigated by industry still remains proprietary. Therefore this section describes only representative surface and in situ methods for which information is available.

SURFACE MINING AND OIL-EXTRACTION PROCESSES

Surface mining is accomplished by excavating a tar-sand deposit using either open-pit or strip-mining techniques. The mining method that is chosen 
is commonly determined by the topographic configuration, distribution, and richness of the tar-sand deposit. Surface mining involves various materials-handling operations; these may include 4

- Surface clearing and removal of overburden,

- Mining of tar sands,

- Removal of barren rock or ore that is too low-grade,

- Construction of haul roads,

- Transportation of ore to processing facility,

- Construction of impoundments and drainage diversion channels,

- Transportation of tailings,

- Surface grading and contouring for reclamation, and

- Rehandling of temporarily stored waste for ultimate disposal.

The economic acceptability of surface mining operations is directly related to the ratio of the depth of the overburden to the thickness and richness of the tar-sand pay zone. An overburden-to-pay-zone ratio greater than 1.0 will generally be economically unfavorable. 2,5

Preliminary calculations for a proposed commercial tar-sand project to be located in Kern County, California, indicate that production of approximately 20,000 barrels per day (bbl/d) of $0 i 1$ can be achieved by using a surface-mining procedure known as phased multi-bench open-pit mining (see Appendix A). This proposed mining project will have the following configuration and operating parameters ${ }^{26}$ :

- A maximum open-pit size at any one time of 350 acres $\left(0.55 \mathrm{mi}^{2}\right)$ and a maximum depth of 1200 feet $(360 \mathrm{~m})$,

- A total mined area encompassing 1026 acres $\left(1.6 \mathrm{mi}^{2}\right)$ over a 48-year active lifetime for the mining activities,

- Removal of 1.1 billion tons of material consisting of 590 million tons of process-grade diatomite ore, 340 million tons of overburden, 64 million tons of underburden (waste material mined with the ore), and 117 million tons of low-grade ore (18 gallons of 0 illton),

- A total work force of 307 workers to provide the necessary complement of 90 workers on site during any one 8-hr shift, 3 times a day, every day of the year, 
- A water requirement of $4,000 \mathrm{~m}^{3} / \mathrm{d}(3.2 \mathrm{af} / \mathrm{d})$ for mining and related activities,

- Mining equipment consisting of shovels, trucks, drills, auxiliary and miscellaneous machinery, and vehicles that will require an estimated 500 gallons per hour of diesel fuel and 10 gallons per hour of gasoline (collectively equal to a fuel-consumption rate of $300 \mathrm{bbl} / \mathrm{d}$ ) and,

- Reclamation activities, consisting of backfilling the mined-out area with overburden, spent ore, and low-grade ore; followed by replacement of top soil and subsequent recontouring and revegetation.

After removal from the deposit, the tar-sand ore will be subjected to a surface oil-extraction process that converts the bitumen to liquid petroleum. The oil-extraction process selected could be one of the following:

- Thermal decomposition by coking in a retort system,

- Suspension in a petroleum solvent, or

- Washing using either hot or cold water.

The extraction procedure may need to be followed by an appropriate upgrading technique in order to make the liquid petroleum acceptable as a refinery feedstock. These four surface extraction processes are discussed in detail below.

Coking

Coking is a proven technology that can be used to extract oil from tar sands by means of thermal decomposition. Temperatures between 900 and $1200^{\circ} \mathrm{F}$ (about 480 to $650^{\circ} \mathrm{C}$ ) are employed in a retort apparatus to produce both gases and a solid coke from the bitumen. Condensation of the volatile portion results in the formation of a hydrocarbon liquid with a lower averagemolecular-weight, suifur content, and carbon-to-hydrogen ratio ( $C: H$ ) than the bitumen. The coke residual is composed mostly of carbon and contains sulfur that has been removed from the liquid product. With the use of higher temperatures $\left(1400^{\circ} \mathrm{F}\right)$ and additional oxygen, the coke can be burned off to 
produce a hot clean sand that $c$ an be used to provide heat for recirculation in the process. Thus, coking may conceptually be considered a technique for reducing the $\mathrm{C}: \mathrm{H}$ ratio by removing carbon. ${ }^{2}$

One representative coking procedure that will soon be pilot-tested in California (scheduled for the fall of 1981) on oil-impregnated diatomaceousearth (i.e., tar-sand ore composed of the fossilized remains of marine diatoms that are saturated with bitumen) is the Lurgi-Ruhrgas (L-R) retort technique developed by Mineroltechnik of West Germany. 6,11 A commercial L-R retort system, which could be adopted as a result of this study, would be expected to produce 20,000 barrels per day of 011 and naphtha by processing an estimated 32,000 tons per day of diatomite tar-sand ore. 26

A commercial L-R retort system (Figure 2) includes the following essential components:

- The L-R retort,

- A sulfur recovery system,

- A hydrogenation unit, and

- A hydrogen production plant.

The integrated operation of these units, along with any additional upgrading system that may be necessary, is designed to yield a liquid-petroleum feedstock that $c$ an be transported through available crude-oil pipeline networks to refineries for further processing using standard techniques.

Principal functions to be performed by the $L-R$ retort system include 26

(1) Crushing the incoming ore and then heating it with steam in a rotary drier to extract most of the water and some of the volatile hydrocarbons,

(2) Heating the predried ore to a temperature of 950 to $1000^{\circ} \mathrm{F}$ (510 to $540^{\circ} \mathrm{C}$ ) in the $L-R$ retort mixer to vaporize and "crack" (a process using heat to break up heavy hydrocarbons into lighter products) any remaining volatile hydrocarbons,

(3) Reheating the residual solids in a retort lift-pipe combustion system to burn off the carbonaceous material and produce hot solids with temperatures between 1150 and $1200^{\circ} \mathrm{F}\left(620\right.$ to $\left.650^{\circ} \mathrm{C}\right)$, 


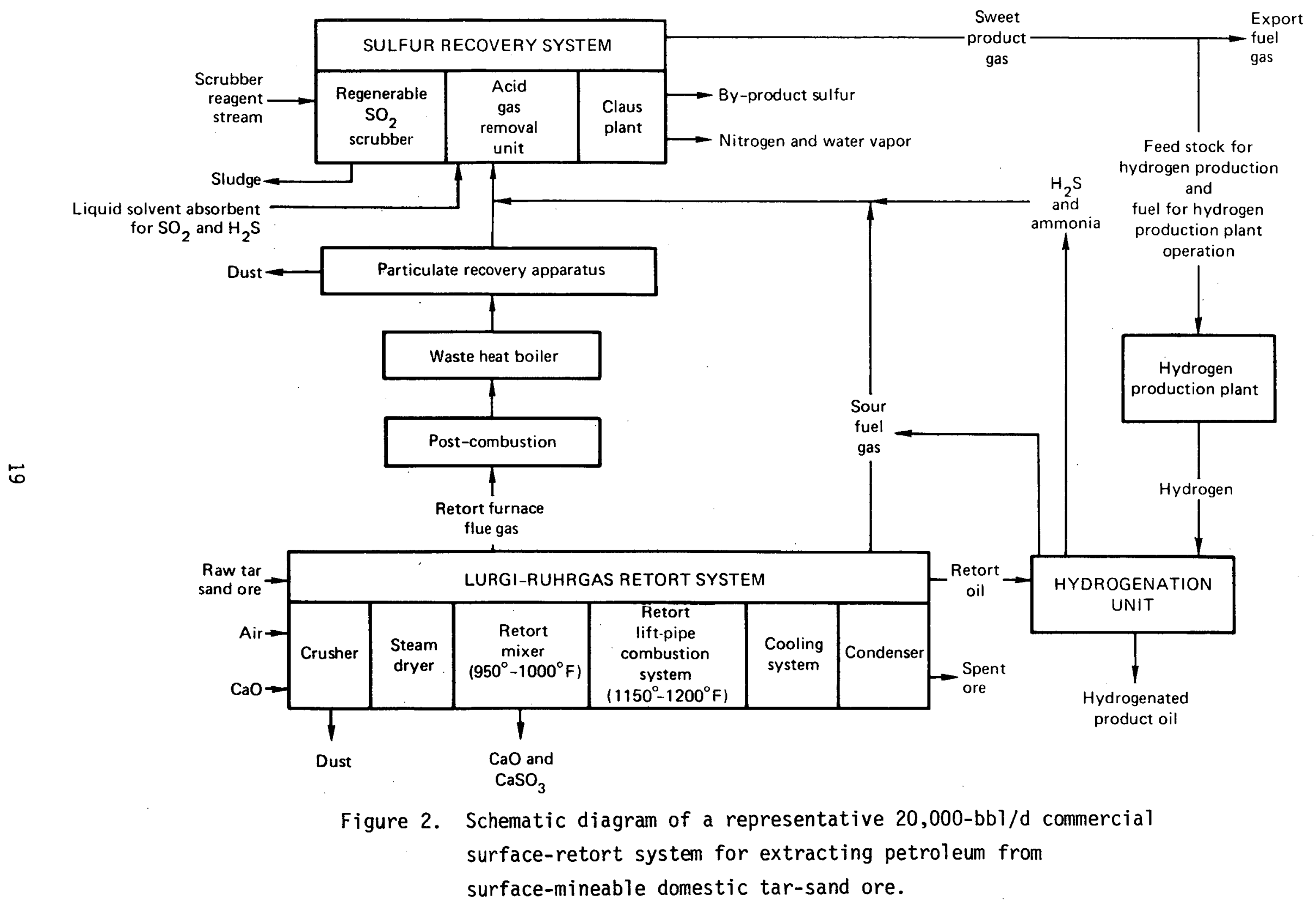


(4) Recirculating the hot solids to the retort mixer to supply heat for vaporization and thermal cracking of the volatile hydrocarbon components of the predried ore,

(5) Cooling, condensing, and separating the product gases to produce naphtha, middle oil, heavy oil, and a sour, phenolic gas liquor (i.e., an aqueous liquor containing hydrogen sulfide, ammonia, and phenols),

(6) Cleaning up product streams to remove and recover potential pollutants (e.g., $\mathrm{H}_{2} \mathrm{~S}, \mathrm{NH}_{3}$, particulates, $\mathrm{SO}_{2}$, and possibly phenols) and produce refinery quality $0 i 1$, and

(7) Recycling of product streams for alternative uses and disposal.

The exact inputs to the retort itself will be the diatomite ore, air, and 1 ime $(\mathrm{CaO})$, and the outputs will be the condensed product gases from the rotary drier and retort mixer, dried dust, flue gas, excess $\mathrm{CaO}, \mathrm{CaSO}_{3}$, and moistened solid residue.

A sulfur-recovery system is necessary to remove significant quantities of gaseous sulfur-compounds contained in (1) the raw product gas, (2) the L-R retort flue gases, (3) sour fuel gas produced by the hydrogenation unit used for treating the product oil to make it acceptable for transport and refining, and (4) off-gas from the sour-water stripper used to remove the ammonia and hydrogen sulfide from the sour-gas liquor. A sulfur-recovery-system design that could achieve $98 \%$ emission control may involve 26

- Injecting lime into the retort lift-pipe combustion system to remove about $80 \%$ of the $\mathrm{SO}_{2}$ generated in the lift pipe,

- Using a regenerable $\mathrm{SO}_{2}$ scrubber to remove $90 \%$ of the remaining $\mathrm{SO}_{2}$ after the gases have been passed through a post-combustion, waste-heat boiler and particulate-recovery apparatus,

- Installing an acid-gas removal unit to absorb $\mathrm{SO}_{2}$ and $\mathrm{H}_{2} \mathrm{~S}$ in a liquid solvent to produce sweet product-gas from the retort sour product-gas and the hydrogenation-process sour fuel-gas, and

- Utilizing a Claus plant to convert $95 \%$ of the sulfur into by-product solid sulfur from the acid gases absorbed in the solvent, the sourwater stripper off-gas and the $\mathrm{SO}_{2}$ removed from the flue gases. 
A hydrogenation unit and a hydrogen-production plant are used to make the resulting oil acceptable for transport with virgin crude oil in existing pipelines and also to make it suitable for refining with standard refinery practices. A hydrogen-production unit will use some of the produced gas from the retort operation, after hydrogen sulfide and acid gases (including carbon dioxide) are removed, as feedstock to manufacture hydrogen in a catalytic steam-gas reforming process. The hydrogen would then be used in the hydrogenation process, where the unsaturated hydrocarbons (olefins and diolefins) will be saturated. 26

The hydrogenation process would involve passing the $0 i l$ and hydrogen through a fixed bed of catalyst at high temperature and pressure; hydrogen sulfide and ammonia would also be formed. Unreacted hydrogen, the saturated oil, and hydrogen sulfide and ammonia would then be separated from each other. The desulfurized, denitrogenated, hydrogenated oil is the finished product ready for transport and refining or any additional upgrading that may be necessary prior to transport. Unreacted hydrogen would be returned to the hydrogenation unit and the sulfur-recovery system would receive the hydrogen sulfide and ammonia. The sulfur-recovery process would convert hydrogen sulfide to elemental sulfur which would then be sold. It would also convert the ammonia to elemental nitrogen and water for release to the atmosphere.

In addition to the aforementioned processes, it is also possible that a representative coking process like the 20,000-bbl/day retort system may have to remove and recover as much as 18 tons/day of phenols from the stripped gas 1 iquor. 26 Fresh water may be required to satisfy the total water complement of $1800 \mathrm{~m}^{3} / \mathrm{d}(1.5 \mathrm{af} / \mathrm{d})$ that is anticipated for retorting methods like the $L-R$ process.

The manpower requirements have been projected and are estimated to be $\mathrm{e}^{26}$

- 1000 construction workers, with an average daily work force of 500 for the anticipated two-year installation period, and

- 146 employees per 24-hour day to operate the system.

It is likely that other organizations are investigating similar retorting mechanisms for obtaining oil from mineable tar-sand ore. However, information from these studies is not available due to its proprietary nature. 
Anhydrous solvent extraction of bitumen from tar sands has been described and reviewed in the literature. $2,6,11$ The process basically uses a petroleum solvent to wash the bitumen from the sand grains. The solvent could presumably be either a light hydrocarbon such as benzene or toluene, or a group of light hydrocarbons such as heptane, cyclohexane, and ethanol. Washing allows bitumen to come into contact with the solvent and be dissolved. The solvent with the dissolved bitumen is then separated from the sand, and treated (e.g., by distillation) to remove the bitumen and recover the solvent for recycling through the process.

A number of investigations are underway to perfect a commercially suitable solvent-extraction method. A solvent method that is now being studied during pilot-plant testing on diatomite tar sands in California is the Dravo solvent-extraction method. 11,26

Commercial application of the Dravo process would be expected to produce about 20,000 barrels of crude $0 i l$ per day from an estimated 37,000 tons per day of diatomite ore (i.e., 5,000 more tons per day of this ore is required than for the L-R retort process). This process will consist of a multistage solvent-extraction system, steam-stripping apparatus, vapor-recovery system, decanter, and multi-effect evaporation process. The Dravo process is presented in Figure 3 and includes the following procedures $^{26}$ :

(1) Slurrying a heptane, cyclohexane, and ethanol solvent with crushed diatomite ore to create a "miscella" (oil-solvent-water mixture);

(2) Clarifying the miscella to remove the fine diatomite particles; and steam-stripping and filtering the spent residue to extract residual solvent and generate a final spent-ore filter-cake;

(3) Using a multi-effect evaporation system to produce a solvent/water mixture that is separated in a decanter so that solvent and water can be recovered for reuse,

- a solvent/oil mixture (predominantly solvent) that is separated by a solvent-recovery system so that solvent can be recovered for reuse and additional product-oil can be obtained,

- an oil/solvent mixture (predominantly oil) that is separated by oil-stripping so that product-oil can be obtained and solvent $c$ an be recovered for reuse, and

- a clean solvent (oil and water free) that can be reused; 


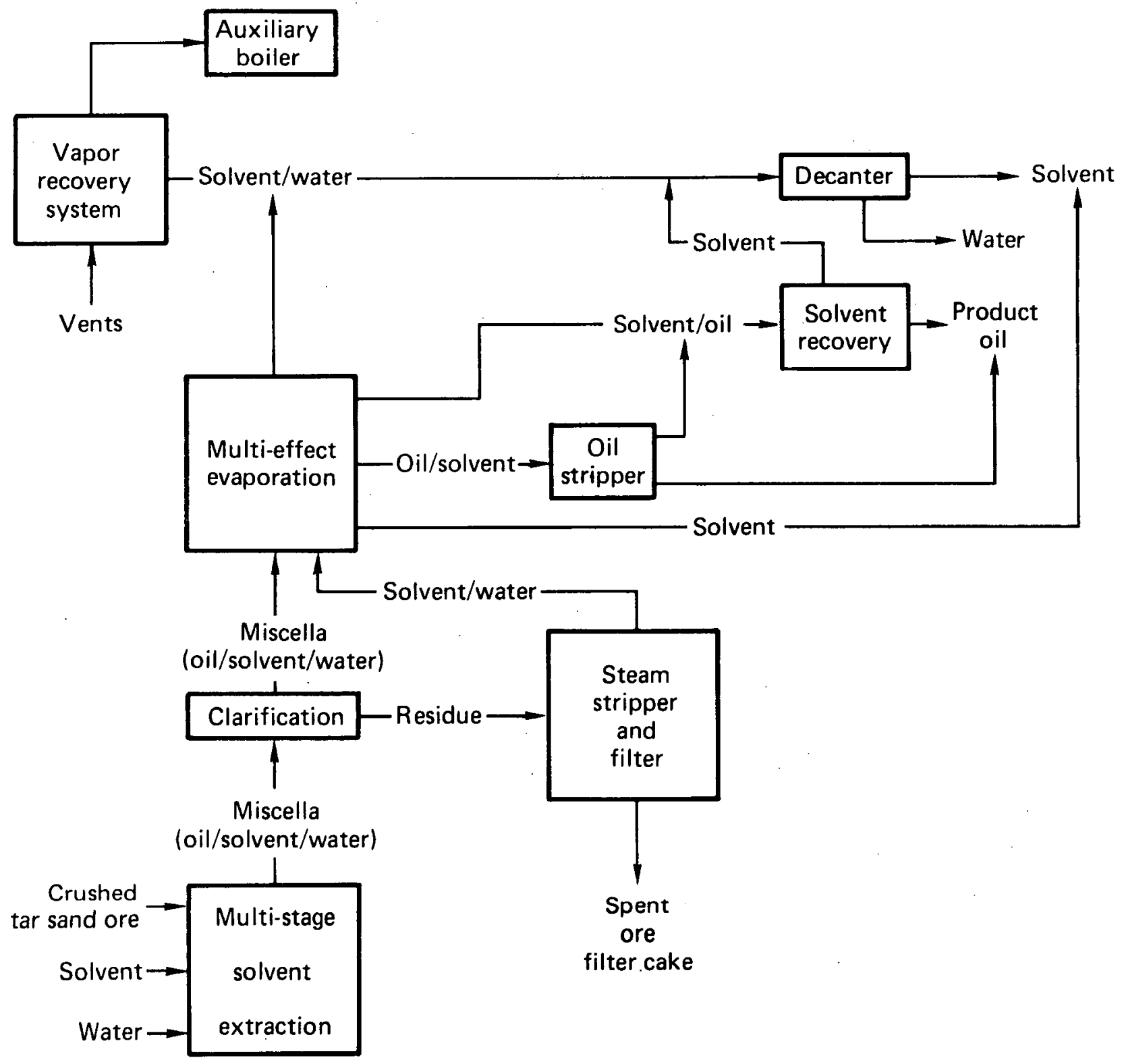

Figure 3. Schematic diagram of a representative 20,000-bbl/d commercial surface-solvent system for extracting petroleum from surface-mineable domestic tar-sand ore. 
(4) Using a vapor-recovery system to prevent the escape of the volatile solvent mixture and to recover solvent and water for reuse, and

(5) Heating the multi-effect evaporation system with recycled solvent and water vapors removed during the stripping of the spent ore. Inputs are expected to consist of the diatomite ore, steam from makeup water, and solvent. Outputs would be product-oil, spent-ore filter cake, and residual vapors (95\% air, $5 \%$ water and solvent) that are conveyed to auxiliary boilers for combustion. 26

A solvent recovery system like this one may not require additional sulfur recovery devices because it is not a direct-coking combustion process as is the $L-R$ retort system. Furthermore, hydrogen reactors like those described for the $L-R$ retort are not necessary for the solvent process.

The water requirement for this solvent system to produce 20,000 barrels of oil per day is estimated to be more than $16,000 \mathrm{~m}^{3} / \mathrm{d}$ (approximately $13 \mathrm{af} / \mathrm{d}$ ); however, unlike the direct-coking L-R process, this solvent method will not require its total water complement to be fresh water. Instead, over $99 \%$ of the water can be treated wastewater. 26

Employment requirements for the commercial solvent process are projected to $\mathrm{be}^{26}$

- 450 laborers at peak times over the two-year construction period, and an average daily work force of 200 , and

- 128 total employees to operate the plant for each 24-hour period.

In addition to the solvent system to be examined in California, other more proprietary research activities are underway to perfect solvent recovery processes for use on tar sands located in Utah. 2 For example, Standard $0 i_{1}$ of Ohio (SOHIO) is planning to build a $24 \mathrm{bbl} / \mathrm{d}$ countercurrent solvent extraction process to investigate the commercial feasibility of such a system. The SOHIO pilot plant will be constructed on SOHIO's Asphalt Ridge property near Vernal, Utah, and is expected to begin operation in 1982. 27

\section{Hot Water}

Another above-ground procedure for extracting petroleum from mined tar-sand ore involves the application of hot water. One hot-water extraction process was developed by K.A. Clark in the 1920 s. 5,6 It is well documented 
in the literature, and even the thermodynamics of the process have been determined. $2,5,6$ The process is being used in Canada on a commercial level, and involves agitating $t a r$ sands in hot water (about $200^{\circ} \mathrm{F}$ ) that contains enough sodium hydroxide to raise the $\mathrm{pH}$ slightly above neutrality. The hot water causes the water film around the sand grains to swell and permit the bitumen to float away. The sodium hydroxide causes the carboxylic acids in the bitumen to form detergents and this improves separation. ${ }^{2}$ The bitumen is then partitioned from the sand grains by clarification. The clarification process allows sand to settle downward and bitumen to float upward, where it forms a froth that is removed from the surface.

Unfortunately, because most tar sands in the U.S. (especially those in Utah) are not "water wet," direct application of the Clark hot-water procedure is not feasible. In addition, any washing method using a water-separation process requires excessively large volumes of water. This large quantity of water is readily available in Canada but is not available for use at many U.S. tar-sand sites. Although these facts appear to indicate limitations to the application of water extraction methods in the U.S., work has been performed on development of a hot-water process for use on U.S. tar sands. 15

Results from laboratory studies, performed by researchers at the University of Utah, indicate that about $96 \%$ of the bitumen contained in high-grade tar-sand ore ( $>10 \%$ by weight bitumen) from Asphalt Ridge and P.R. Spring, Utah (see Figure 1) can be extracted by means of hot-water digestion in a high shear, opposing-pitch blade, stirred-tank reactor (Figure 4). The optimum conditions for this process were found to be the following ${ }^{15}$ :

- A temperature of $203^{\circ} \mathrm{F}\left(95^{\circ} \mathrm{C}\right)$,

- A 70- to 80\%-solids concentration, i.e., "amount of tar sand with respect to the total mass of material in the system," and

- A sufficient concentration of caustic wetting agent.

Results of laboratory tests of this hot-water system with low-grade tar-sand ore (<10\% by weight bitumen) from the Sunnyside Deposit in Utah (see Figure 1) revealed that the hot-water process strategy used for high-grade ore was not directly applicable to the lesser-grade material. 15 Addition of an organic diluent (e.g., toluene) in the digestion step may 
improve the quality of separation of petroleum from the mineral components of lower-grade tar-sand ore. The intrinsic properties of the low-grade ore from the Sunnyside Deposit were found to include 15

- A bitumen viscosity that is an order of magnitude higher than for the high-grade tar-sand ore from the Asphalt Ridge, and

- Strong interparticle bonding that is responsible for producing aggregates in the bitumen feed that can maintain their integrity during digestion and flotation.

Although the aforementioned hot-water procedures are now being examined only in the laboratory, proposals are being formulated to field test such systems at tar-sand deposits in Utah.

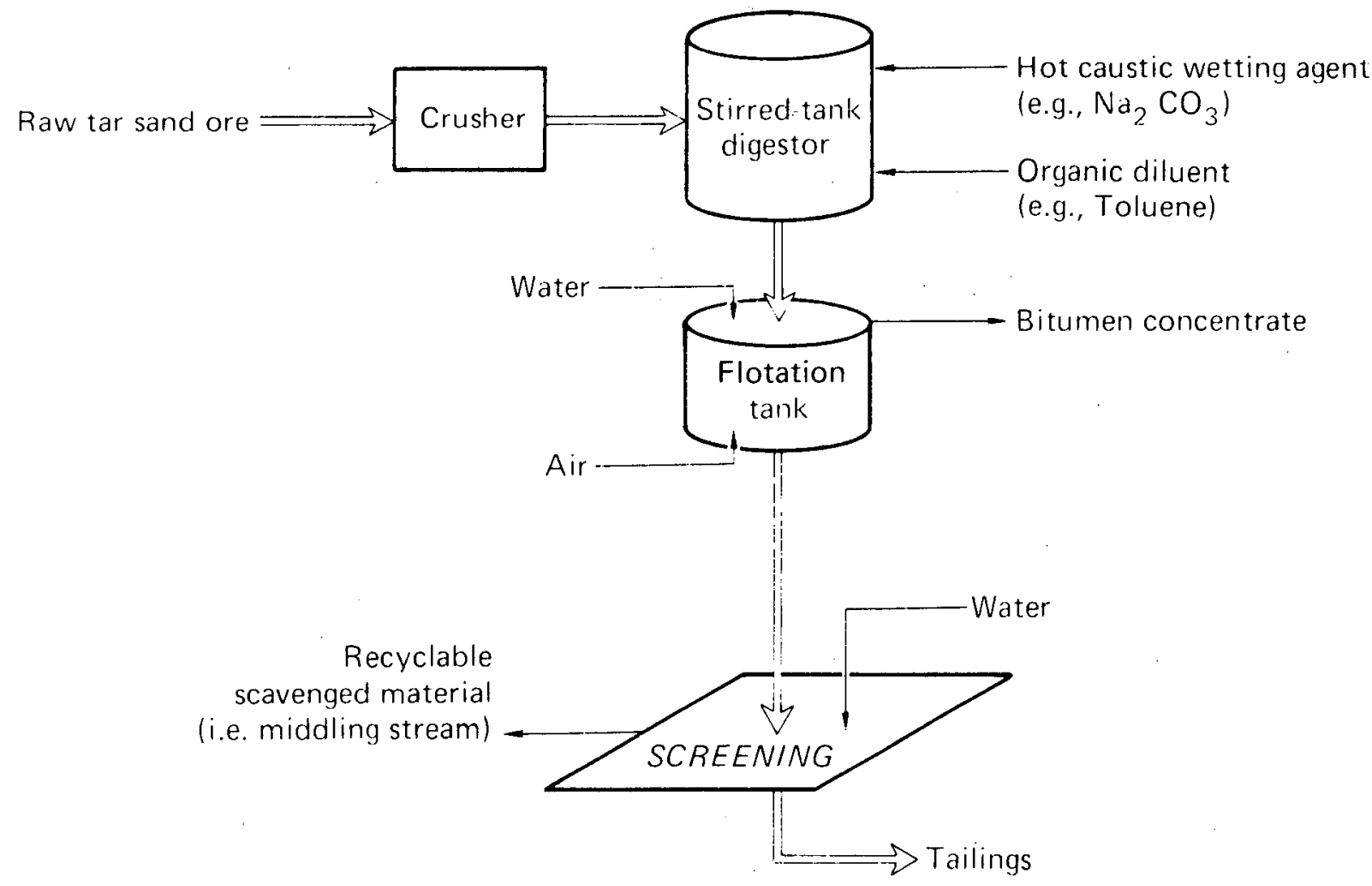

Figure 4. Schematic diagram of an experimental hot-water process for the potential commercial extraction of bitumen from surface-mineable tar-sand ore in Utah (redrawn from Ref. 15, p. 1313). 
A cold-water extraction technology has been investigated principally in Canada and basically involves mechanical and chemical separation of the bitumen from the tar sands. Some specific approaches described in the literature ${ }^{6}$ are briefly explained here. One process investigated in Canada in 1949 through 1950 combines cold water, solvent (e.g., kerosene) and reagents such as soda ash with physical agitation, clarification, and thickening to separate bitumen from the tar-sand ore. A similar process called "sand reduction" was developed by Imperial 0il Enterprises, Ltd. The sand-reduction method is designed to reduce the mineral-matter concentration of the oil by mixing tar sands with $70^{\circ} \mathrm{F}$ water and solvent at a proper $\mathrm{pH}$, then separating the bitumen by agglomeration and settling. Another cold-water method is spherical agglomeration, which was investigated by the National Research Council of Ottawa and is similar to sand reduction.

Cold-water-recovery processes are most effective with "water-wet" tar sands; therefore, experiments have been performed primarily in Canada. No cold-water method, however, has been used commercially.

\section{IN SITU PROCESSES}

It is estimated that only $10 \%$ of the'tar-sand deposits of Alberta, Canada, 5 and $15 \%$ of the tar sands located in Utah ${ }^{28}$ have a ratio of overburden-to-pay-zone thickness sufficient for recovery by contemporary surface-mining practices. Therefore, to recover oil from the deeper deposits, some form of in situ processing is likely to be selected.

The alternative in situ recovery processes that could conceivably be employed include 2,6

- Non-thermal methods that employ a low-viscosity fluid, chemical solvent, or diluent to dissolve the bitumen and stimulate its flow, and

- Thermal techniques that use steam, combustion, or electricity to exploit the rapid decrease in bitumen viscosity with increasing temperature, and provide a driving force for the produced fluids and vapors. 
In situ processes for tar sands are therefore similar to those used for enhanced oil recovery. In both instances the objective is to remove a "trapped" petroleum by reducing its viscosity and causing the resulting fluid to be readily driven through the formation for collection.

Thermal methods, particularly combustion techniques and steam-injection strategies, are presently being studied. These approaches are receiving the most attention for two reasons. First, the high cost of solvent and the anticipated problems associated with its effective underground recovery make non-thermal in situ methods economically questionable at this time. Secondly, electrical systems for thermal stimulation of tar sands are unproven. Furthermore, forward- and reverse-combustion and steam-injection methods are considered the most feasible in situ techniques based on evidence from field studies conducted in the U.S. and Canada over the past three decades. $4,5,29$

\section{Combustion}

In situ combustion techniques are designed first to reduce the viscosity of the bitumen and then to mobilize the resulting fluids for collection at a production well. To accomplish these objectives a combustion process is initiated in the tar-sand formation to produce temperatures between 600 and $900^{\circ} \mathrm{F}$ (about 320 to $480^{\circ} \mathrm{C}$ ). These temperatures will volatilize the water and light hydrocarbons contained in the bitumen. Combustion is sustained by injecting air and burning the residual bitumen and coke. The injected air also serves as the driving force for the produced fluids.

The most effective procedures for accomplishing in situ combustion have been identified $\mathrm{as}^{4,28}$

- Forward combustion,

- Reverse combustion, and

- A combination of forward combustion and water flooding.

A forward-combustion procedure essentially entails igniting a fire in the $t$ ar-sand target zone and injecting compressed air into the formation at the same well. The mobilized bitumen components move ahead of the flame (burn front) and are brought to the surface in a production well. A forwardcombustion system is diagramed in Figure 5 . 
A reverse-combustion process (Figure 6) involves igniting the burn front at the production well, and injecting the compressed air into the formation at the injection well. This method is designed to permit the flame to volatilize bitumen components as it moves "backward" from the production well while the compressed air conducts the volatilized hydrocarbons "forward" through the hot burned-out zone and towards the production well. The reverse-combustion procedure requires a substantial volume of air, and a well-controlled advancing flame in order to be successful. When performed properly, reverse combustion can eliminate the plugging problems from the cooling and congealing of hot substances that can develop in forward combustion because fluids are driven through a relatively cool area ahead of the burn front. In addition, reverse combustion can conceivably improve product-oil quality by increasing thermal cracking.

A combination forward-combustion and water-flood procedure involves heating the tar-sand reservoir to a temperature of $1500^{\circ} \mathrm{F}$ (about $820^{\circ} \mathrm{C}$ ) using forward combustion. Air and water are then injected at the same well at which the flame was initiated. The resultant steam lowers the combustion temperature and is expected to facilitate a more rapid transfer of heat into the formation and thereby improve the rate of oil recovery. This procedure is therefore a variation of the forward-combustion method presented in Figure 5 .

During the middle 1970's a major effort was initiated by the Laramie Energy Technology Center (LETC) of the U.S. Department of Energy to study the application of in situ combustion. The LETC group prepared a demonstration project on approximately 10 acres of Standard $0 i 1$ of Ohio (SOHIO) property under the terms of a cooperative agreement. The site is located in NE Utah on the Northwest Asphalt Ridge tar-sand deposit near the community of Vernal, Utah (see Figure 1).

The first field test (TS-1C) took place during November and December, 1975, and lasted 23 days. 30 This test involved reverse combustion. The researchers initiated the field test by using a nine-well pattern of 3 rows of 3 wells each on a small portion of the 10-acre site. The reverse-combustion process was conducted in an 11-foot-thick tar-sand section at a depth of 295 feet near the top of the Rimrock Sandstone member of the Mesaverde formation. 30 


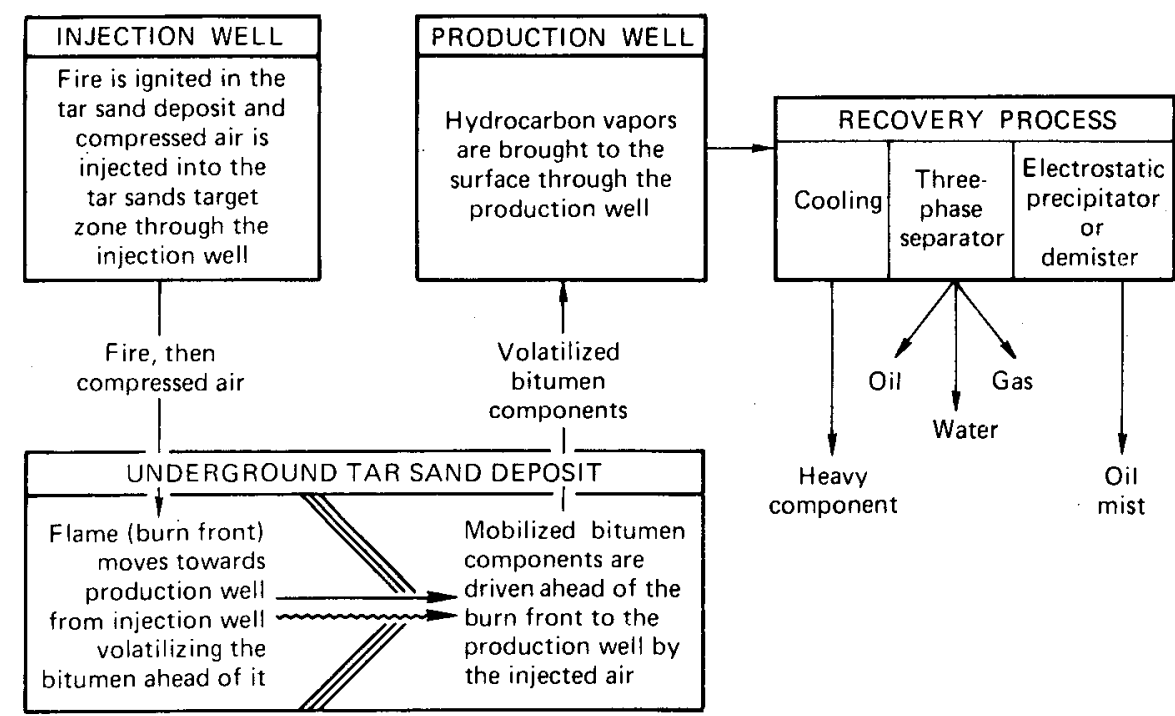

Figure 5. Schematic diagram of a representative 20,000-bbl/d commercial in situ forward-combustion procedure for extracting petroleum directly from underground tar-sand deposits in the U.S.

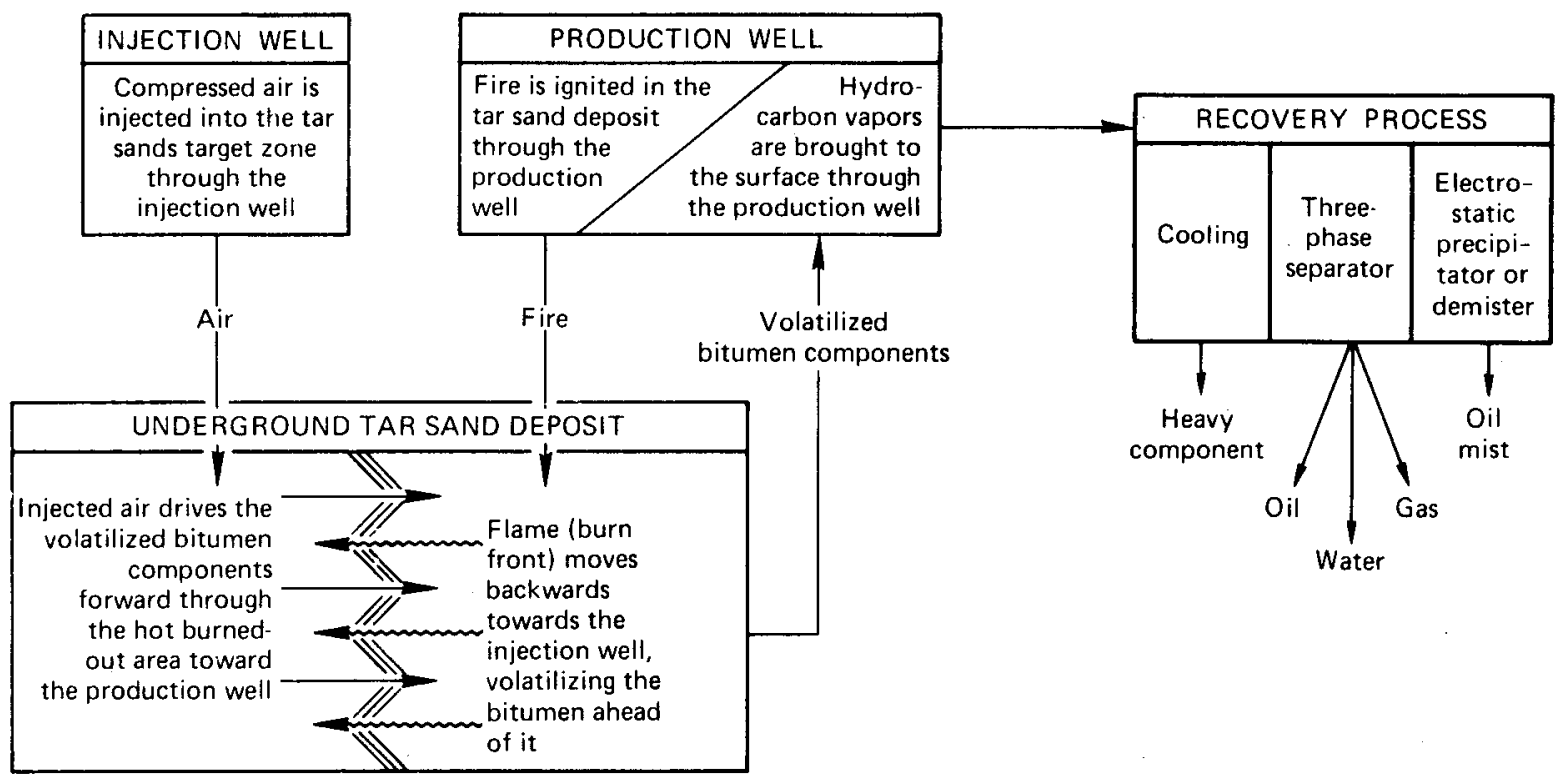

Figure 6. Schematic diagram of a representative 20,000-bb1/d commercial in situ reverse-combustion procedure for extracting petroleum directly from underground tar-sand deposits in the U.S. 
During the 23 days that the experiment was in progress, it produced approximately 70 barrels of $0 i 1$ and $264 \mathrm{~m}^{3}(0.2$ af) of water. 30,31 Electric air-compressors were employed to generate the air required for combustion and fluid drive. 30,32

For an in situ reverse-combustion process to be successful, a tar-sand formation should have an effective air permeability with the bitumen and water in place. This property is important because it permits a relatively high air flux to be injected, which is essential for sustaining the procedure and displacing the fluids. ${ }^{30}$ Adequate compressive strength is also essential in order to prevent surface subsidence after the bitumen has been extracted.

The average permeability of the Northwest Asphalt Ridge reversecombustion tar-sand test-zone is 182 millidarcies (mD). This value approaches the 250-mD average effective-air-permeability recorded for a 60-foot-deep, 6- to 12-foot-thick tar-sand zone near Bellamy, Missouri, where Phillips Petroleum Company achieved sustained reverse combustion during experiments in 1955 through 1958. 30 Permeabilities for the six giant tar-sand deposits in Utah have been reported in the literature 14,30 and are known to vary over a wide range (less than 1 to greater than $5000 \mathrm{mD}$ ).

The Northwest Asphalt Ridge tar sands have a fairly high average compressive strength of 1632 pounds per square inch (psi) following bitumen extraction, relative to an average value of $2491 \mathrm{psi}$ prior to recovery of the bitumen. 30 This compressive strength after bitumen extraction is indicative of good supporting quality that can resist subsidence.

Other important properties of the Northwest Asphalt Ridge tar sands include an oil saturation that ranges from 45 to $54 \%$ by weight, a water content that ranges from 16 to $20 \%$ by weight, and a remarkably low sulfur concentration that ranges from less than 0.5 to about $0.6 \%$ by weight. 30,33

Another combustion experiment $(T S-2 C)$ was conducted by LETC on its Northwest Asphalt Ridge site from August, 1977, through February, 1978. This one lasted 183 days. 34 The purpose of this experiment was to determine the effect of utilizing reverse combustion as a preparatory phase for forward combustion. This technique approximates reverse combustion and is designed to reduce the tendency for plugging of the tar-sand zone that can result during forward combustion. 
The tar-sand target-zone for this experiment was again in the Rimrock Sandstone of the Mesaverde formation but this time was 13-feet thick and at a depth of 350 feet. 34

The combined reverse- and forward-combustion field experiment also incorporated techniques to prevent some of the equipment failures evident in the first experiment that were caused by cooling and congealing of the heavy viscous crude $0 i 1 .^{34}$ These techniques included steam tracing the production lines, (running pipes containing steam next to those containing product oil to transfer heat and prevent congealing of oil while in transport), and the injection of steam and water at the well bores to maintain the pour point of the fluids and thereby prevent any blockage. The experiment produced 580 barrels of oil, which was more than $25 \%$ of the $0 i 1$ in place, and about $110 \mathrm{~m}^{3}$ (0.09 acre feet) of water. 34

In both in situ combustion experiments conducted by LETC, vapor recovery was accomplished in the following way. First the vapors were conducted through a two-phase separator where air cooling would permit condensation of a portion of the heavy component. Next, the remaining vapors were cooled to $100^{\circ} \mathrm{F}\left(38^{\circ} \mathrm{C}\right)$ after passing through a water-cooled heat exchanger. Separation of gas, oil, and water then took place in a three-phase separator. The vapors from this separator were then conducted through an electrostatic precipitator or demister for oil-mist removal, and the remainder was passed through a stack vented to the atmosphere. 30

\section{Steam Drive}

Steam-drive technology has been used successfully for recovery of highviscosity heavy oils. When the process was field-tested on Canadian tar sands during the early 1960's, it was discovered that four barrels of steam would be required to produce each barrel of oil. 4 Steam-drive procedures involve the continuous injection of high-temperature steam to mobilize the tar-sand bitumen for collection in a set of wells surrounding the steam-injection we11. Success of the process depends on good communication between injection and production wells and the use of steam with sufficient temperature and pressure to mobilize the bitumen and drive it to the collection wells. $4,6,11$ Figure 7 is a schematic representation of a commercial steam-drive process. 
In addition to performing field studies using combustion methods, the Laramie Energy Technology Center has recently completed steam-drive field tests at their Northwest Asphalt Ridge facility. The steam-drive strategy being examined by LETC consists of continuously injecting high-temperature steam (500 to 550 psi) into a 50-foot-thick tar-sand pay zone that is located in the Rimrock Sandstone of the Mesaverde formation at a depth of 532 to 582 feet. 35 A single injection we 11 is used and the product fluid is collected initially in the four closest production wells of the eight wells that surround the injection well. The eight production wells are in a configuration of two concentric circles of four wells each.

The product fluid, an emulsion of petroleum and water, is pumped to the surface by standard oil-field pumping procedures. At the surface the oil and water emulsion can then be separated. Separation techniques can include

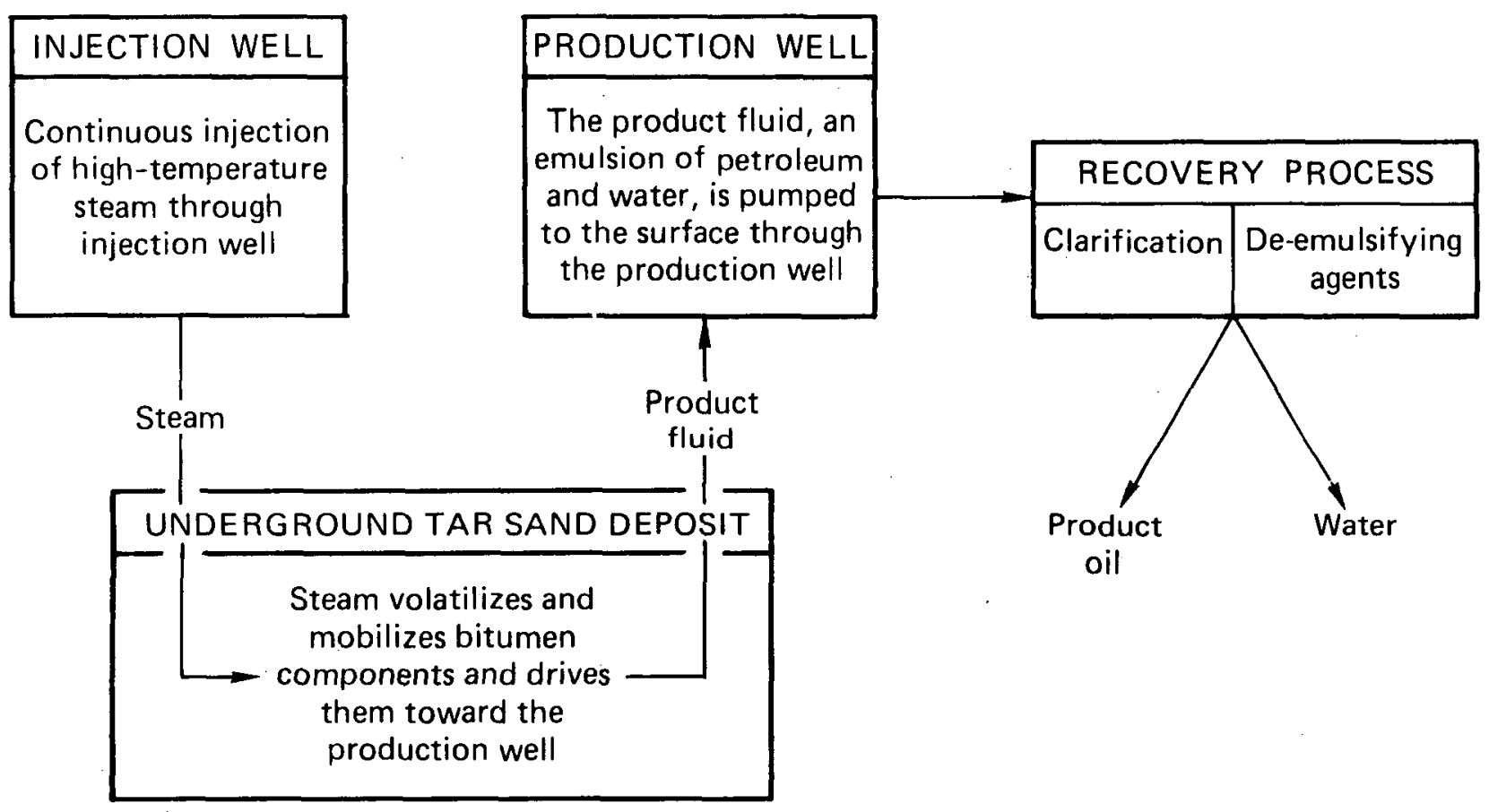

Figure 7. Schematic diagram of a representative 20,000-bbl/d commercial in situ steam-injection procedure for extracting bitumen directly from underground tar-sand deposits in the U.S. 
gravity settling and the application of a de-emulsifying agent. Breaking of . the emulsion yields a product $0 i 1$, and regenerates water for reuse in the process.

The LETC steam-drive field demonstration (TS-1S) began in the spring of 1980, and after the first 64 days of operation produced about 110 barrels of 0 il along with approximately $16 \mathrm{~m}^{3}$ (0.01 acre-feet) of water. ${ }^{36}$ These are preliminary values, however, and with completion of the test will come a more accurate evaluation of the effectiveness of the process.

UPGRADING PROCESSES

Upgrading of tar-sand oil may be necessary to prepare the product oil for utilization by an oil refinery. Upgrading involves 4

- Removing residual mineral matter from the oil,

- Further reducing the density, viscosity, molecular weight and $\mathrm{C}: \mathrm{H}$ ratio, and

- Lowering sulfur content to a level acceptable for refining.

Additional coking is the method used in Canada for upgrading tar-sand bitumen after it has been extracted. Some of the more applicable coking process designs are 2,6 (1) the delayed coking process used by the Suncor facility in Canada, (2) the fluidized-bed coking procedure employed by the Syncrude organization in Canada, and (3) a flexicoking approach, which is a variation of the fluidized-bed method that is being proposed for use on extracted Canadian tar-sand bitumen.

Laboratory studies have been performed at the University of Utah to determine the products that can be derived from upgrading extracted bitumen using a coking procedure. 37 The laboratory research was conducted using a batch-type coking apparatus with extracted bitumen from the Tar Sand Triangle, Asphalt Ridge, and P.R. Spring Deposits located in Utah (see Figure 1), a representative petroleum residue (from Wilmington, California), and bitumen extracted from the Athabasca Deposit in Alberta, Canada. Upgrading of extracted bitumen using a coking process yieids gases, liquid condensate, and coke residue (a solid carbonaceous fuel). Complete bitumen conversion to these products was observed in all of the laboratory tests when the reaction 
temperature was above $1100^{\circ} \mathrm{F}\left(>600^{\circ} \mathrm{C}\right)$. The batch-type testing protocol also employed a reproducible set of reaction conditions. This laboratory study revealed that

- Generally, the bulk properties of the liquid condensate were similar for all samples tested (Table 1).

- A noticeable difference exists in the yields of distillable products obtained from the liquids produced by the samples (Table 2).

- A significant variation of gas composition from the coking of the various bitumens was observed (Table 3 ).

- The coke residue produced from each sample possessed the characteristics of a high-density material (i.e. shiny appearance, with infrequent pores), and heating values were about the same for each sample; but sulfur concentrations were elevated in the Tar Sand Triangle and Athabasca samples and were extremely low in the samples from Asphalt Ridge and P.R. Spring Deposits (Table 4)

- Gas production and compositions for the Athabasca sample were found to be analogous to those produced by the commerical delayed-coking process in Canada; however, the liquid yields were greater and the coke production was lower in the experimental system.

Several conclusions were reached and include the following ${ }^{37}$ :

- The characteristics of the liquid condensate are nearly uniform for all five of the samples tested.

- The products derived from tar-sand bitumen are comparable to those produced by the coking of a representative petroleum residue.

- Tar-sand bitumen extracted from the Uinta Basin (i.e., Asphalt Ridge and P.R. Spring samples) yields a coke product containing a very low concentration of sulfur.

- Upgrading surface-extracted bitumen from the Asphalt Ridge and P.R. Spring Deposits can yield products that are greater in quantity, as well as lower in sulfur and higher in hydrogen content, than those derived from surface-extracted bitumen from the Athabasca Deposit.

The two most important variables that can exert an influence on the outcome of upgrading extracted bitumen by coking are temperature and pressure. 
Table 1. Comparison of liquid-condensate characteristics of different bitumens.

$\frac{\text { Utah }}{T_{S T^{\mathrm{a}}}} \frac{\text { Canada }}{A R^{b}} \quad \frac{\text { California }}{\mathrm{PRS}^{\mathrm{C}}}$

\begin{tabular}{lccccc}
\hline Carbon (wt. pct.) & 85 & 87 & 86 & 85 & 86 \\
Hydrogen (wt. pct.) & 12 & 12 & 12 & 11 & 12 \\
Nitrogen (wt. pct.) & 0.16 & 0.58 & 0.57 & 0.19 & 0.43 \\
Sulfur (wt. pct.) & 2.7 & 0.32 & 0.29 & 3.8 & 1.4 \\
Oxygen (wt. pct.) & trace & trace & trace & trace & trace \\
C:H atomic ratio & 0.62 & 0.62 & 0.60 & 0.63 & 0.62 \\
API gravity & 24 & 26 & 26 & 22 & 22 \\
\hline
\end{tabular}

Heating values were approximately 19,000 Btu/lb for all samples. From Ref. 37, p. 64.

Table 2. Comparison of results from the simulated distillation of bitumenliquid products (weight percent).

\begin{tabular}{|c|c|c|c|c|c|}
\hline & \multicolumn{3}{|c|}{ Utah } & \multirow{2}{*}{$\frac{\text { Canada }}{A T H^{d}}$} & \multirow{2}{*}{$\frac{\text { California }}{\text { WIL }^{\mathrm{e}}}$} \\
\hline & $\mathrm{TST}^{\mathrm{a}}$ & $A R^{b}$ & $\mathrm{PRS}^{\mathrm{C}}$ & & \\
\hline Gasoline $\mathrm{C}_{5}^{+}\left(200^{\circ} \mathrm{C}\right)$ & 7 & 12 & 10 & 8 & 9 \\
\hline Kerosene $\left(200-275^{\circ} \mathrm{C}\right)$ & 12 & 20 & 15 & 13 & 12 \\
\hline Gas oil $\left(275-325^{\circ} \mathrm{C}\right)$ & 13 & 17 & 13 & 14 & 9 \\
\hline Heavy gas oil $\left(325-450^{\circ} \mathrm{C}\right)$ & 51 & 34 & 47 & 48 & 40 \\
\hline Vacuum gas oil $\left(450-538^{\circ} \mathrm{C}\right)$ & 17 & 17 & 16 & 18 & 30 \\
\hline
\end{tabular}

From Ref. 37, p. 67.
a TST: Tar Sand Triangle tar sand
b AR: Asphalt Ridge tar sand
C PRS: P.R. Spring tar sand
d ATH: Athabasca tar sand
e WIL: Wilmington, California, petroleum residue 
Table 3. Mole percent of $C_{1}$ to $C_{5}$ gases detected after coking bitumen from various sources.

\begin{tabular}{lccccc}
\hline & \multicolumn{3}{c}{ Utah } & Canada & California \\
\cline { 2 - 5 } & TST $^{\mathrm{a}}$ & AR $^{\mathrm{b}}$ & PRS $^{\mathrm{C}}$ & ATH $^{\mathrm{d}}$ & WIL $^{\mathrm{e}}$ \\
\hline Methane & 62 & 65 & 58 & 88 & 74 \\
Ethane & 3.4 & 11 & 4.5 & 3.6 & 9.1 \\
Ethylene & 12 & 5.6 & 12 & 0.8 & 1.8 \\
Propane & 6.8 & 7.4 & 7.9 & 2.8 & 6.0 \\
Propylene & 4.6 & 7.4 & 4.3 & 1.9 & 3.8 \\
n-butane & 1.8 & 0.5 & 3.6 & 0.8 & 1.5 \\
i-butane & 2.9 & 0.8 & 2.6 & 0.3 & 0.8 \\
j-butylene & 1.0 & 0.4 & 1.1 & 0.5 & 0.0 \\
1-butene & 1.1 & 0.5 & 0.1 & 0.4 & 0.0 \\
T, 3-butadiene & 1.1 & 0.1 & 1.2 & 0.1 & 0.0 \\
n-pentane & 0.4 & 0.1 & 0.3 & 0.2 & 1.0 \\
1-pentane & 0.4 & 0.1 & 0.1 & 0.1 & 0.1 \\
Unidentified & 3.1 & 1.3 & 3.6 & 1.0 & 2.2 \\
\hline
\end{tabular}

From Ref. 37, p. 60 .

Table 4. Comparison of coke characteristics from different bitumens (weight percent).

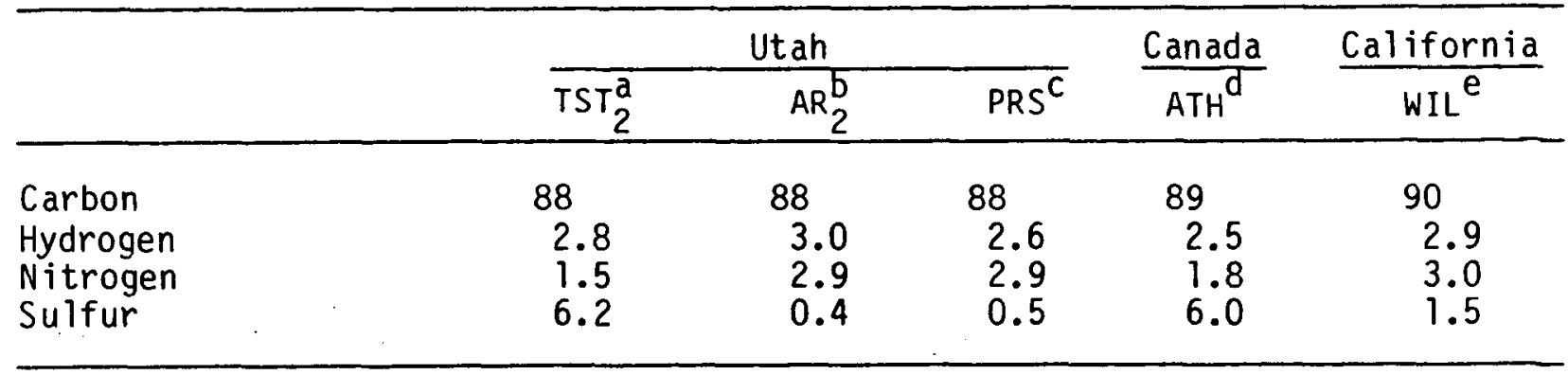

Heating values were approximately 15,000 Btu/lb in all cases. From Ref. 37, p. 69.

a TST: Tar Sand Triangle tar sand (subscript 2 designates second of two samples)

b AR: Asphalt Ridge tar sand (subscript 2 designates second of two samples)

C PRS: P.R. Spring tar sand

d ATH: Athabasca tar sand

e WIL: Wilmington, California, petroleum residue 
Temperature dictates product yield and production rate, and the properties of the coke formed. Pressure determines the amount of hydrocarbons produced, and the distribution of carbon compounds in the liquid condensate as well as their density and average-molecular-weight. A coking operation is likely to be most effective when operated near atmospheric pressure because, although product quality improves slightly with increasing pressure, major losses in yield result. Current research indicates that improved product quality will not entirely compensate for these losses.

High-sulfur bitumen may require hydrotreating, in addition to coking, to reduce sufficiently the sulfur content of the product $011 .^{2}$

Another process for upgrading extracted tar-sand bitumen is visbreaking (or hydro-visbreaking when conducted in the presence of hydrogen). This procedure can be either a thermal or a catalytic-conversion process. Visbreaking is designed to lower the viscosity, pour point, and molecular weight of extracted tar-sand bitumen by mildly "cracking" the bitumen to produce lower-molecular-weight hydrocarbons with a minimum of coking.

Results from laboratory visbreaking studies at the University of Utah indicate that in order to upgrade extracted bitumen into a pumpable fluid (normally $<1000 \mathrm{CP}$ is required to facilitate efficient pumping and handling) the following conditions may be necessary ${ }^{37}$ :

- A temperature $\geq 500^{\circ} \mathrm{C}\left(932^{\circ} \mathrm{F}\right)$,

- Elevated pressures (but not so high as to increase the formation of aromatics and coke), and

- A temporal and spatial residence of longer than 3 minutes at a high temperature and pressure.

For bitumen extracted from tar-sand deposits in Utah, visbreaking may be a suitable upgrading technique; however, a large molecular-weight reduction still needs to be obtained in the product derivates before the visbreaking process will be acceptable. Moreover, the long temporal and spatial residence at high temperature and pressure that may be necessary before bitumen viscosity is reduced to $1000 \mathrm{cP}$ represent severe conditions that could adversely affect processing. 
Other upgrading procedures being investigated include vacuum distillation followed by solvent de-asphalting and hydrotreating of the resulting liquids; direct catalytic cracking; and hydropyrolysis. Additional studies need to be performed to prove that these methods will neither render the bitumen more difficult to process nor be adversely affected by properties inherent in bitumen from particular tar-sand deposits. For instance, preliminary studies using catalytic cracking indicate that it may be a suitable procedure for upgrading extracted bitumen, if problems such as catalyst poisoning from nitrogen constituents (particularly in tar-sand bitumen from the Uinta Basin) can be prevented.

Further research is also needed to determine if any of the aforementioned upgrading processes are suitable for use as supplements to one another or even independently as primary surface-extraction techniques for producing high-quality synthetic crude oil and other valuable petroleum by-products.

\section{COMMERCIALIZATION}

Although no commercial tar-sand oil-recovery facilities exist in the United States at this time, both in situ and surface $t$ ar-sand technologies are perceived to be candidates for commercialization. The potential production rate for individual commercial tar-sands projects that may evolve from the present U.S. research is estimated to range from a conservative 10,000 barrels of oil per day ${ }^{4}$ to a more optimistic 57,000 barrels of $0 i l$ per day. ${ }^{38}$ Plans for possible commercialization of tar-sand oil-extraction methods and their anticipated production rates by 1990 have already been announced by

- Getty $0 i l$ Company for a 20,000-bbl/d production facility near Mckittrick, California, 26

- Standard 0il Company of Ohio for a 25,000-bbl/d production facility on the Asphalt Ridge near Vernal, Utah, 27 and - Conoco $0 i 1$ Company for a 25,000-bbl/d production facility in Uvalde, Texas. 10

Many other projects are also being evaluated for their commercial applicability but at this time remain proprietary. Therefore, a reasonable estimate of tar-sand $0 i l$ production in the U.S. by 1990 would be 80,000 to $120,000 \mathrm{bbl} / \mathrm{d}$ if anticipated commercial projects become fully operational. 
Among the several tar-sand oil-recovery demonstration projects now planned or already underway in the United States, two are distinguished by the availability of quantitative information concerning their operation. These two projects are (1) the examination of both a pilot surface-retort and a surface-solvent oil-extraction unit for potential commercial application on privately owned diatomaceous-earth tar sands located near the city of Mckittrick in Kern County, California, and (2) the in situ combustion and steam-drive technology research and development being performed by DOE/LETC near Vernal, Utah, for use on tar-sand resources that cannot be economically recovered using mining and surface extraction methods.

The information from these research endeavors and announced plans for commercial activities indicate that the first tar-sand technologies to achieve commercial status will be designed to produce about 20,000 barrels of oil per day. $10,11,26,27$ Not only is this figure within the range of production-rate values $(10,000$ to $57,000 \mathrm{bb}] / \mathrm{d})$ now generally considered commercially possible, ${ }^{4,38}$ but also a $20,000-b b l / d$ tar-sand oil-production rate for a single facility reflects a convenient plant size for capital acquisition and engineering scale-up, and represents a beneficial contribution to domestic petroleum production for an individual operating unit (approximately $0.1 \%$ of the U.S. daily consumption rate).

\section{ENVIRONMENTAL ANALYSIS AND ASSESSMENT}

ENVIRONMENTAL, HEALTH, SAFETY, AND SOCIOECONOMIC IMPACTS

Available data from nascent tar-sand surface and in situ field tests in California and Utah, respectively, were extrapolated to correspond to a 20,000-bbl/d oil-production rate. This information is used to identify the potentially significant environmental, health, safety, and socioeconomic impacts that could result from commercialization of these types of systems. These impacts can be divided into the following categories:

- Land surface disturbance and alteration,

- Atmospheric emissions,

- Noise and light problems, 
- Worker exposure to hazardous substances and situations,

- Ground or surface water availability, consumption, contamination and interruptions,

- Waste generation and disposal, and

- Impacts on community infrastructure.

Commercial tar-sand projects might also affect historical and archaeological sites and aesthetics, and may lead to deterioration of pristine federal lands, such as National Parks and Recreation Areas, many of which are near sites of potential tar-sand activities in Utah (see Figure 1).

Surface-Mining Activities

In Canada, commercial tar-sand surface-mining activities have been in progress on the Athabasca Deposit in the province of Alberta for more than 10 years. Surface-mineable tar-sand deposits also exist in the United States; however, a viable commercial tar-sand surface-mining project has only recently been proposed for application in the U.S. This project involves petroleum extraction from the diatomaceous-earth tar sands located in Kern County, California. Attention is now focused on information about this proposed tar-sand mining project for two reasons. First, preliminary calculations have been made concerning the mine design and operation. Second, since this project is proposed for tar sands located in the U.S., the procedure is indicative of mining operations that $c$ an be used on other domestic tar-sand deposits.

Land Disturbance. As discussed earlier, a commercial phased multi-bench open-pit surface mine has been proposed for the diatomaceous-earth tar sands in Kern County, California, that are located near the city of Mckittrick. This mining project is expected to result in (1) the disturbance of over 1000 acres during a projected active mining period of 48 years, (2) the creation, at any one time, of a maximum open-pit size of 350 acres, excavated to a maximum depth of 1200 feet $(360 \mathrm{~m}$ ) (see Appendix A), and (3) the daily handling, transport, and storage of an estirnated 100,000 tons of earth. 26 At any tar-sand deposit, the previously described surface-mining operation could (1) destroy critical habitats, (2) threaten the existence of 
endangered flora and fauna, (3) expose solid materials, heavy metals, and organic compounds in the earth and within stored material to erosion and dispersal in air and water, (4) cause the loss or destruction of important surface and subsurface historical, paleontological, and archaeological artifacts and sites, and (5) interfere with the intrinsic beauty of the environment.

The occurrence and severity of the above impacts, however, will be related to the predevelopment environment of the particular tar-sand deposit being excavated. For example, at some sites critical habitats and endangered species may not be present, and aesthetic considerations may not pose a restriction on development. Erosion problems may also be minimal at sites where rainfall is limited and effective drainage diversions çan be constructed.

Suitable precautions can also be taken to prevent the loss or destruction of historical and archaeological artifacts and sites that may exist in mining areas. These precautions could include the completion of an archaeological survey of the mining area before development starts, and continued reconnaissance during operation of the mine and the construction and use of pipelines, drainage diversions, roads, and storage sites.

Atmospheric Emissions. Atmospheric emission rates have been calculated for the criteria air pollutants (i.e., those for which NAAQS exist) expected to be produced by commercial tar-sand mining activities near Mckittrick, California. These emission rates, their sources, and the anticipated air-pollution control methods and their related efficiencies are presented in Table 5 .

The data presented in Table 5 indicate that the mining equipment (e.g., non-point-source gasoline- and diesel-powered scrapers, bulldozers, trucks, etc.) is the source of most of the criteria pollutant emissions. Table 5 also shows that the fugitive emissions of total suspended particulates (TSP) from the mine pit and storage areas are substantially greater than those produced by the mining equipment and the crushing apparatus. Fugitive emissions of total hydrocarbons (THC) from the mine pit and storage areas are projected to be about one-third of the rate predicted for the mining equipment (Table 5). According to research studies performed on test pits near Mckittrick, California, the major constituents of the THC emissions from the exposed mine pit include 26 
Table 5. Estimated controlled criteria-pollutant atmospheric emission rates and control technologies for the typical "phased multi-bench open-pit surface mine" planned for use at the proposed 20,000-bbl/d commercial diatomaceous-earth tar-sand oil-recovery facility near Mckittrick, California. ${ }^{a}$

\begin{tabular}{|c|c|c|c|c|c|}
\hline Source & $\begin{array}{l}\text { Atmospheric } \\
\text { emission }\end{array}$ & $\frac{\text { Emission }}{(1 \mathrm{~b} / \mathrm{h})}$ & $\frac{\text { rate }}{(g / s)}$ & $\begin{array}{l}\text { Emission-control } \\
\text { technique }\end{array}$ & $\begin{array}{l}\text { mission-control } \\
\text { eff iciency } \\
(\%)\end{array}$ \\
\hline \multirow[t]{5}{*}{ Mining equipment } & $\mathrm{SO}_{2}$ & 15.6 & 2.0 & None & \\
\hline & $\mathrm{NO}_{x}\left(\right.$ as $\left.\mathrm{NO}_{2}\right)$ & 210.5 & 26.0 & None & \\
\hline & $\mathrm{CO}$ & 88.8 & 11.0 & None & \\
\hline & THC & 22.6 & 3.0 & None & \\
\hline & TSP & 13.7 & 2.0 & None & \\
\hline Crushing apparatus & TSP & 1.3 & 0.2 & Baghouse & 99.5 \\
\hline $\begin{array}{l}\text { Mine pit and } \\
\text { storage areas }\end{array}$ & $\begin{array}{l}\text { Fugitive THC } \\
\text { Fugitive TSP }\end{array}$ & $\begin{array}{r}7.4 \\
233.0\end{array}$ & $\begin{array}{r}1.0 \\
29.0\end{array}$ & $\begin{array}{l}\text { Dust suppression by } \\
\text { the use of water } \\
\text { and the natural } \\
\text { oil composition of } \\
\text { the tar sands }\end{array}$ & 80.0 \\
\hline
\end{tabular}

a From Ref. 26. 

- Propane (38. $4 \%$ by $w t)$
- Octane (23.8\% by wt)
- Hexane (13.5\% by $w t)$
- Decane (11.0\% by wt)
- Methane

The criteria-pollutant atmospheric-emission rates calculated for the mining equipment and crushing apparatus for the proposed 20,000-bbl/d tar-sand surface-mining facility near Mckittrick, California, (Table 5) are presumed to be typical values for any tar-sand surface-mining operation. This is because such mining equipment and the crushing apparatus are essential components of these operations. The emission rates of THC and TSP from the mine pit and storage area (Table 5) may, however, be lower at other tar-sand surface-mining facilities because

- The bitumen of the diatomaceous-earth tar sands near Mckittrick, California, possesses a higher API gravity (is lighter) than most other tar-sand bitumen and therefore is more volatile. 8 This condition yields a higher THC emission rate than may be produced at other tar-sand surface mines.

- Diatomaceous-earth tar sand is unique because it is much finer, and less tightly bound together than sandstone tar sand. Therefore, the TSP emission rate is likely to be greater from diatomaceous-earth tar sand.

In addition, the major constituents of the THC emissions may differ at different tar-sand mining operations. Further source-term characterization studies need to be performed to determine other constituents, such as trace elements, that may also be released from specific tar-sand mining facilities, and contribute to atmospheric pollution.

The magnitude of any adverse ambient-air-quality impact from tar-sand mining activities depends ultimately on the pre-existing ambient air quality in a particular region and the effectiveness of the emission-control methods that are used. For instance, at the Mckittrick, California, surface mine the TSP emissions from the crushing apparatus will be controlled by a baghouse, and emissions from the mine pit and storage area will be controlled by 
dust-suppression methods (Table 5). The efficiencies of the baghouse (99.5\%) and dust-suppression methods (80\%) are expected to mitigate effectively any potentially serious adverse ambient-air-quality impacts from TSP loading in that region. Additional pollution-control devices and strategies may be necessary for TSP and the other criteria pollutants if a tar-sand mining operation is conducted in a different region with different ambient air quality.

Noise. The tar-sand mining operation near Mckittrick is expected to generate an average equivalent-sound-level of approximately $61 \mathrm{dBA}$ at $500 \mathrm{ft}$ from the source of activity. Since neighboring residential areas near this site and most other sites are located at distances greater than $500 \mathrm{ft}$, this predicted noise level is not expected to cause the EPA's short-term soundlevel goal for such communities ${ }^{\dagger}\left(L_{d n}=65 \mathrm{dBA}\right)$ to be exceeded. 26

Light. Mining activities are likely to be conducted 24 hours a day, 7 days a week. Therefore, illumination will be required for working at night. Such lighting may prove deleterious to the ecology in the immediate area by interrupting circadian rhythms characteristic of both plants and animals. The illumination could also represent a nuisance for nearby communities by interfering with the natural setting. These effects reflect a localized impact and the severity will depend on the proximity of a particular mining site to nearby population areas and the sensitivity of the ecology at the site to disruption by lighting.

\footnotetext{
* $\mathrm{dBA}$ is a sound-pressure level expressed in decibels with frequencies weighted according to the " $A$ " scale. The A-weighted scale is a logarithmic ratio of the measured sound pressure to a reference. level and is a frequency response curve that simulates the response of the human ear.

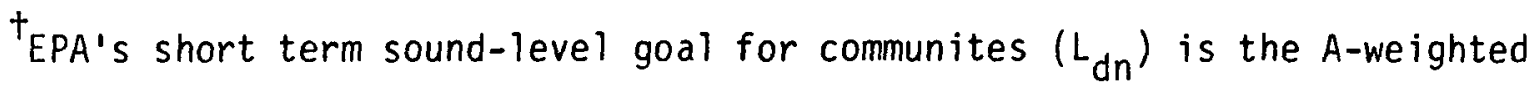
equivalent sound level for a 24-hour period, with an additional 10-decibel weighting imposed on the equivalent sound levels occurring during the night-time hours of $10 \mathrm{p} . \mathrm{m}$. to $7 \mathrm{a} . \mathrm{m}$.
} 
Worker Health and Safety. As mentioned before, mining activities do produce noise. Occupational noise exposures are regulated by the Occupational Safety and Health Administration (OSHA) and the Mining Safety and Health Administration (MSHA). Workers conducting tar-sand mining near Mckittrick are expected to be subjected to 84 to $88 \mathrm{dBA}$ within 15 feet of operating equipment. 26 This range of sound level is likely to be encountered by workers at any commercial tar-sand mining project and is within equipment noise-level ranges recommended in the 1972 Noise Control Act. 18

Workers involved in surface mining will come in contact with large operating equipment and vehicles that will require careful handling to prevent injuries. Another situation that may affect the workers' safety is the generation of suspended particulates by mining activities. Particulates and substances on their surface (such as sulfates) could represent a potential respiratory problem if inhaled in significant quantities. Thus, in addition to dust suppression control, filtering masks or respirators may be required for those working in a mine pit. Further research appears to be needed to characterize particles and the chemicals adsorbed/absorbed on their surfaces so that occupational health risks can be adequately estimated. Employees working in the outdoors may also be subjected to natural environmental extremes in climate, and could be susceptible to insect bites or valley fever (coccidioidomycosis), especially in the San Joaquin Valley of California where the Mckittrick tar sands are located.

Water. An environmental consequence of surface-mining activities could be interruption or disruption of surface and underground aquifer systems. This is unlikely in the Mckittrick project area where surface streams and underlying surface aquifers are absent. However, this situation needs to be addressed for other tar-sand surface-mining areas before commercial mining begins. Aquifer disturbances, such as flow reduction or elimination, can cause adverse ecological impacts, and water-quality degradation can affect potable water sources. At those locations where such conditions could occur, drainage diversions and other control methodologies for preventing interruption or disruption of aquifer systems and water contamination will be needed.

Water requirements for the diatomaceous-earth tar-sand mining operation near Mckittrick, California, will be about $2000 \mathrm{~m}^{3}$ per day $(1.6 \mathrm{af} / \mathrm{d})$, of which only $132 \mathrm{~m}^{3}$ per day $(0.1 \mathrm{af} / \mathrm{d})$ or approximately $7 \%$ must be fresh 
water. 26 The greatest amount of water can therefore be brackish and will be used primarily for haul-road spraying. The brackish water for tar sands mined near Mckittrick, California, will be obtained from wells in the "Mckittrick 0il Field" and the fresh water will be supplied from the West Kern County Water District and privately-owned wells in Tupman, California. 26 Almost $2080 \mathrm{~m}^{3}$ per day $(1.7 \mathrm{af} / \mathrm{d})$ of additional fresh water will be needed for irrigation and dust containment at the McKittrick tar-sand mining

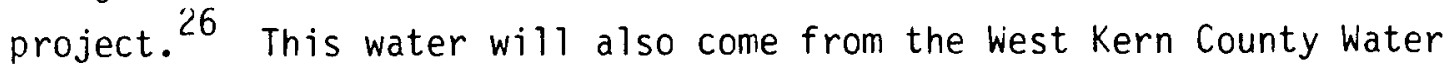
District and the privately-owned wells in Tupman, California. Thus, the total daily water requirement for a representative commercial tar-sand surface-mining operation, like that planned for Mickittrick's tar sands, could exceed $4000 \mathrm{~m}^{3}$ per day $(3.2 \mathrm{af} / \mathrm{d})$.

In order to protect surface and ground waters, a mining operation like that proposed near Mckittrick will probably have to introduce measures for controlling erosion, diverting natural drainage around raw- and spent-ore storage areas, and for trapping run-off and the materials it contains. As mentioned previously, there is no ground water beneath the diatomaceous-earth tar sands near Mckittrick, California, so the potential for impacts from leaching and percolation into ground water is not present at that site. However, this absence of ground water may not be duplicated at other tar-sand sites where similar mining techniques can be employed. Therefore, at sites where ground water problems may occur, it is important that the water quality impacts possible from run-off, percolation, and infiltration from the natural ground cover and from stockpiles of ore and waste be ascertained and mitigated. A study is already being planned to determine the effects that run-off, percolation, and infiltration may have during the pilot-plant research that is to be conducted using the diatomaceous-earth tar sands near Mckittrick, California. These studies are essential before a comprehensive assessment of major water contaminants from tar-sand mining activities can be completed.

Waste Generation and Disposal. One plan for disposal of the spent tar-sand ore is to use it as backfili for the excavated mine. ${ }^{26}$ The stored spent ore may contain residual hydrocarbons and organic material or heavy metals that $c$ an be leached by run-off and percolation. The percolation studies planned during pilot-scale project activities of the surface retort 
and solvent systems near Mckittrick, California, will also address this potential problem. These studies will identify contaminants in the leachates from spent-ore storage piles that could deleteriously affect surface and ground water at this tar-sand site and suggest the potential contaminants that may need to be looked for at other sites.

Community Infrastructure. The mining work force of 220 workers per day for the proposed Mckittrick commercial tar-sand surface-mining project is probably not enough to stress an established community infrastructure like that which exists in Kern County, California. However, commercial tar-sand mining projects may be conducted in other locations that may be in relatively inaccessible and sparsely populated areas. In these areas it will be necessary to import the work force. Such a situation may result in severe short-term stresses on housing supplies and community services.

\section{Surface Retort or Solvent Processes}

In the United States surface retort and solvent systems for extracting oil from surface-mineable tar-sand ore are currently being evaluated on a pilot scale. The most representative and complete technical data concerning the operation of these surface systems are available for the planned utilization of a 20,000-bbl/d commercial retort or solvent process near Mckittrick, California. 26 This section of the report describes the potential environmental, health, safety, and socioeconomic impacts that could result from the commercialization of these technologies, and is based on the representative data for the planned commercial tar-sand project in California.

Land Disturbance. The land-surface area required for a representative retort or solvent system will be about 100 acres, and the storage areas for the tar-sand ore will require an additional 1400 acres. The entire surface area for a typical commercial surface facility (the mine area and its facilities, the pipelines, drainage structures, and roads) involves about 2600 acres. 26 Utilization of this area will require a long-term commitment, and will necessitate careful planning to avoid permanent destruction of critical habitats; endangered species; valuable historical, paleontological and 
archaeological artifacts; and aesthetics related to a rural and natural setting. In addition, care will have to be taken during the clearing of land areas for construction in order to minimize the impacts of increased run-off.

Atmospheric Emissions. The estimated emission rates for criteria pollutants from equipment associated with the representative commercial retort and solvent processes, with emission-control technologies in place, are presented in Tables 6 and 7 , respectively. These data are based on projected controlled criteria-pollutant emission-rates for the proposed 20,000-bbl/d commercial retort and solvent systems being pilot tested and considered for use near Mckittrick, California.

These projected data indicate that retort flue-gas will be the primary source of atmospheric emissions of criteria pollutants from a retort system (Table 6); and the auxiliary-boiler flue-gas will be the primary source of criteria-pollutant atmospheric-emissions from a solvent process (Table 7 ). Tables 6 and 7 also indicate the estimated efficiencies of air-pollution control technologies that may be selected for application on typical retort and solvent processes. Furthermore, the data in Tables 6 and 7 show that the total hydrocarbon emissions from hydrocarbon storage tanks, valves, pumps and compressors can be effectively reduced using techniques now common in the petroleum and chemical industries.

Since the stack gases represent the predominant sources of criteria pollutant emissions for both retort and solvent processes, it is worthwhile to determine the potential ambient-air-quality impacts that could be produced from these stationary point-emission sources. The maximum ambient-air-quality impact estimated at ground level for criteria pollutants produced by stack gases from the proposed 20,000-bbl/d commercial retort and solvent processes are presented in Tables 8 and 9 , respectively.

Tables 8 and 9 also compare the total criteria-pollutant concentrations with National Ambient Air Quality Standards (NAAQS) and restate the air-pollution-control methods that may be employed and their efficiencies.

The maximum ambient-air-quality impacts at ground level are preliminary estimates that were calculated using the U.S. Environmental Protection Agency (EPA) "Simple Screening Procedure"39 (see Appendix B). While the "Simple Screening Procedure" is not a very sophisticated analytical model with great 
Table 6. Estimated controlled criteria-pollutant atmospheric emission rates and control-technologies for a proposed 20,000-bbl/d commercial tar-sand surface-retort process. ${ }^{a}$

\begin{tabular}{|c|c|c|c|c|c|}
\hline Source & $\begin{array}{l}\text { Atmospheric } \\
\text { emission }\end{array}$ & $\frac{\text { Emissio }}{(1 \mathrm{~b} / \mathrm{h})}$ & $\frac{\text { rate }}{(g / s)}$ & $\begin{array}{l}\text { Emission-control } \\
\text { technique }\end{array}$ & $\begin{array}{c}\text { Emission-control } \\
\text { efficiency } \\
(\%)\end{array}$ \\
\hline \multirow[t]{5}{*}{ Retort flue-gas } & $\mathrm{SO}_{2}$ & 228.8 & 28.8 & $\begin{array}{l}\text { Lime injection } \\
\text { and scrubbing }\end{array}$ & 97.0 \\
\hline & $\mathrm{NO}_{x}$ (as $\left.\mathrm{NO}_{2}\right)$ & 89.5 & 11.3 & None & \\
\hline & $\mathrm{CO}$ & None & None & None & \\
\hline & THC & None & None & None & \\
\hline & TSP & 217.8 & 27.4 & $\begin{array}{l}\text { Electrostatic } \\
\text { precipitator }\end{array}$ & 99.5 \\
\hline \multirow{5}{*}{$\begin{array}{l}\text { Fuel burning equipment } \\
\text { (distillation furnace, } \\
\text { hydrogen plant, hydro- } \\
\text { genation unit) }\end{array}$} & $\mathrm{SO}_{2}$ & 5.9 & 0.7 & $\begin{array}{l}\text { Low-sulfur }(0.25 \% \\
\text { by wt) fuel }\end{array}$ & \\
\hline & $\mathrm{NO}_{x}\left(\right.$ as $\left.\mathrm{NO}_{2}\right)$ & 23.7 & 3.0 & $\begin{array}{l}\text { Ammonia injection } \\
\left(\mathrm{NH}_{3}: \mathrm{NO}_{\mathrm{x}}=1.5\right)\end{array}$ & 50.0 \\
\hline & $\mathrm{CO}$ & 3.8 & 0.5 & None & \\
\hline & THC & 0.7 & 0.1 & None & \\
\hline & TSP & 4.5 & 0.6 & None & \\
\hline $\begin{array}{l}\text { Hydrocarbon } \\
\text { storage tanks }\end{array}$ & THC & 1.0 & 0.1 & $\begin{array}{l}\text { Double seal } \\
\text { floating roof }\end{array}$ & 75.0 \\
\hline $\begin{array}{l}\text { Valves, pumps and } \\
\text { compressors }\end{array}$ & THC & 6.6 & 0.8 & $\begin{array}{l}\text { Strict maintenance } \\
\text { program }\end{array}$ & 73.0 \\
\hline
\end{tabular}

a From Ref. 26. 
Table 7. Estimated controlled criteria-pollutant atmospheric emission rates and control-technologies for a proposed 20,000-bbl/d commercial tar-sand surface-solvent process. ${ }^{\text {a }}$

\begin{tabular}{|c|c|c|c|c|c|}
\hline \multirow[b]{2}{*}{ Source } & \multirow{2}{*}{$\begin{array}{l}\text { Atmospheric } \\
\text { emission }\end{array}$} & \multicolumn{2}{|c|}{ Emission rate } & \multirow{2}{*}{$\begin{array}{l}\text { Emission-control } \\
\text { technique }\end{array}$} & \multirow{2}{*}{$\begin{array}{c}\text { Emission-contro } \\
\text { eff iciency } \\
(\%)\end{array}$} \\
\hline & & $(1 b / h)$ & $(g / s)$ & & \\
\hline \multirow[t]{5}{*}{$\begin{array}{l}\text { Auxiliary-boiler } \\
\text { flue-gas }\end{array}$} & $\mathrm{SO}_{2}$ & 171.6 & 21.6 & $\begin{array}{l}\text { Low-sulfur }(0.25 \% \\
\text { by wt) fuel }\end{array}$ & \\
\hline & $\mathrm{NO}_{x}\left(\right.$ as $\left.\mathrm{NO}_{2}\right)$ & 97.5 & 12.3 & $\begin{array}{l}\text { Ammonia injection } \\
\left(\mathrm{NH}_{3}: \mathrm{NO}_{\mathrm{X}}=1.5\right)\end{array}$ & 50.0 \\
\hline & $\mathrm{CO}$ & 21.4 & 2.7 & None & \\
\hline & THC & 4.6 & 0.6 & None & \\
\hline & TSP & 26.0 & 3.3 & None & \\
\hline \multirow[t]{5}{*}{$\begin{array}{l}\text { Heating oil-furnace } \\
\text { flue-gas }\end{array}$} & $\mathrm{SO}_{2}$ & 1.6 & 0.2 & $\begin{array}{l}\text { Low-sulfur }(0.25 \% \\
\text { by wt) fuel }\end{array}$ & \\
\hline & $\mathrm{NO}_{X}\left(\right.$ as $\left.\mathrm{NO}_{2}\right)$ & 0.9 & 0.1 & $\begin{array}{l}\text { Ammonia injection } \\
\left(\mathrm{NH}_{3}: \mathrm{NO}_{\mathrm{x}}=1.5\right)\end{array}$ & 50.0 \\
\hline & $\mathrm{CO}$ & 0.2 & 0.02 & None & \\
\hline & $\mathrm{THC}$ & 0.04 & 0.005 & None & \\
\hline & TSP & 0.2 & 0.02 & None & \\
\hline Solvent storage tank & THC & None & None & $\begin{array}{l}\text { Vapor recovery } \\
\text { incineration }\end{array}$ & 100.0 \\
\hline $\begin{array}{l}\text { Hydrocarbon storage } \\
\text { tank }\end{array}$ & THC & 5.2 & 0.7 & $\begin{array}{l}\text { Double seal floating } \\
\text { roof }\end{array}$ & 75.0 \\
\hline Valves and pumps & THC & 7.8 & 1.0 & $\begin{array}{l}\text { Strict maintenance } \\
\text { program }\end{array}$ & 74.0 \\
\hline
\end{tabular}

aFrom Ref. 26. 
Table 8. Estimated ambient-air-quality impact for controlled stack-gas emissions of criteria pollutants from a proposed 20,000-bbl/d commercial tar-sand surface-retort system. ${ }^{a}$

\begin{tabular}{|c|c|c|c|c|c|c|c|c|c|c|}
\hline \multirow{2}{*}{$\begin{array}{l}\text { Emission } \\
\text { source }^{b}\end{array}$} & \multirow{2}{*}{$\begin{array}{l}\text { Atmospheric } \\
\text { emission }\end{array}$} & \multicolumn{2}{|c|}{$\begin{array}{c}\text { Emission } \\
\text { rate }\end{array}$} & \multicolumn{3}{|c|}{$\begin{array}{l}\text { Estimated maximum ambient- } \\
\text { air-quality impact }\left(\mathrm{\mu g} / \mathrm{m}^{3}\right) \mathrm{c}\end{array}$} & \multicolumn{2}{|c|}{$\begin{array}{c}\text { National ambient- } \\
\text { air-quality standard }\end{array}$} & \multirow{2}{*}{$\begin{array}{l}\text { Emission-control } \\
\text { technique }\end{array}$} & \multirow{2}{*}{$\begin{array}{c}\text { Emission- } \\
\text { control } \\
\text { efficiency } \\
(\%)\end{array}$} \\
\hline & & $(1 b / h)$ & $(g / s)$ & $x_{1,3}$ & $x_{8}$ & $x_{24}$ & $\left(\mu \mathrm{g} / \mathrm{m}^{3}\right)$ & (avg. time) & & \\
\hline Retort flue-gas & $\mathrm{SO}_{2}$ & 229 & 29 & 174 & 157 & 104 & & & $\begin{array}{l}\text { Lime injection and } \\
\text { scrubbing }\end{array}$ & 97 \\
\hline $\begin{array}{l}\text { Fuel-combustion } \\
\text { equipment }\end{array}$ & $\mathrm{SO}_{2}$ & 6 & 0.8 & 11 & 10 & 7 & & & $\begin{array}{l}\text { Low-sulfur }(0.25 \% \\
\text { by wt) fuel }\end{array}$ & \\
\hline Total & $\mathrm{SO}_{2}$ & 235 & 29.8 & 185 & 167 & 111 & 365 & $24 \mathrm{~h}$ & & \\
\hline Retort flue-gas & $\mathrm{NO}_{x}\left(\right.$ as $\left.\mathrm{NO}_{2}\right)$ & 90 & 11 & 66 & 59 & 40 & & & None & \\
\hline $\begin{array}{l}\text { Fuel-combustion } \\
\text { equipment }\end{array}$ & $\mathrm{NO}_{x}\left(\operatorname{as} \mathrm{NO}_{2}\right)$ & 24 & 3 & 45 & 40 & 27 & & & $\begin{array}{l}\text { Ammonia injection } \\
\left(\mathrm{NH}_{3}: \mathrm{NO}_{\mathrm{x}}=1.5\right)\end{array}$ & 50 \\
\hline Total & $\mathrm{NO}_{x}\left(\right.$ as $\left.\mathrm{NO}_{2}\right)$ & 114 & 14 & 111 & 99 & 67 & 100 & $1 y$ & & \\
\hline Retort flue-gas & $\mathrm{CO}$ & None & None & None & None & None & & & & \\
\hline $\begin{array}{l}\text { Fuel-combustion } \\
\text { equipment }\end{array}$ & $\mathrm{CO}$ & 4 & 0.5 & 8 & 7 & 4 & & & None & \\
\hline Total & $\mathrm{CO}$ & 4 & 0.5 & 8 & 7 & 4 & 10,000 & $\mathrm{lh}$ & None & \\
\hline Retort flue-gas & THC & None & None & None & None & None & & & None & \\
\hline $\begin{array}{l}\text { Fuel-combustion } \\
\text { equipment }\end{array}$ & THC & 0.7 & 0.1 & 1.5 & 1.4 & 0.9 & & & None & \\
\hline Totai & THC & 0.7 & 0.1 & 1.5 & 1.4 & 0.9 & 160 & $\begin{array}{c}3 \mathrm{~h} \\
(6 a m-9 a m)\end{array}$ & & \\
\hline
\end{tabular}


Table 8. (continued)

\begin{tabular}{|c|c|c|c|c|c|c|c|c|c|c|}
\hline \multirow{2}{*}{$\begin{array}{l}\text { Emission } \\
\text { source }\end{array}$} & \multirow{2}{*}{$\begin{array}{l}\text { Atmospheric } \\
\text { emission }\end{array}$} & \multicolumn{2}{|c|}{$\begin{array}{c}\text { Emission } \\
\text { rate }\end{array}$} & \multicolumn{3}{|c|}{$\begin{array}{l}\text { Estimated maximum ambient-- } \\
\text { air-quality impact }\left(\mu \mathrm{g} / \mathrm{m}^{3}\right)^{\mathrm{C}} \\
\end{array}$} & \multicolumn{2}{|c|}{$\begin{array}{l}\text { National ambient- } \\
\text { air-quality standard }\end{array}$} & \multirow{2}{*}{$\begin{array}{l}\text { Emission-control } \\
\text { technique }\end{array}$} & \multirow{2}{*}{$\begin{array}{c}\text { Emission- } \\
\text { control } \\
\text { efficiency } \\
(\%)\end{array}$} \\
\hline & & $(1 b / h)$ & $(g / s)$ & $x_{1,3}$ & $x_{8}$ & $x_{24}$ & $\left(\mu \mathrm{g} / \mathrm{m}^{3}\right)$ & (avg. time) & & \\
\hline Retort flue-gas & TSP & 218 & 27 & 162 & 146 & 97 & & & \multirow{2}{*}{$\begin{array}{c}\text { Electrostatic } \\
\text { precipitation } \\
\text { None }\end{array}$} & 99.5 \\
\hline $\begin{array}{l}\text { Fuel-combustion } \\
\text { equipment }\end{array}$ & TSP & 4 & 0.6 & 9 & 8 & 5 & & & & \\
\hline Total & TSP & 222 & 27.6 & 171 & 154 & 102 & 260 & $24 \mathrm{~h}$ & & \\
\hline
\end{tabular}

a Based on projected emission rates, process-design operating parameters, and proposed control technologies for a Lurgi-Ruhrgas $(L-R)$ retort. 26

b Flue-gas characteristics for the L-R retort: Volume flow-rate $=24.6 \times 10^{6} \mathrm{scf} / \mathrm{h}\left(193.4 \mathrm{~m}^{3} / \mathrm{s}\right)$; stack-gas temperature $=190^{\circ} \mathrm{F}\left(88^{\circ} \mathrm{C}\right)$; stack height $=250 \mathrm{ft}(76 \mathrm{~m})$. Stack-gas characteristics for the fossil-fuel-burning equipment associated with L-R retort: Volume flow-rate $=2.8 \times 10^{6} \mathrm{scf} / \mathrm{h}\left(22 \cdot \mathrm{m}^{3} / \mathrm{s}\right) ;$ stack-gas temperature $=500^{\circ} \mathrm{F}\left(260^{\circ} \mathrm{C}\right) ; \mathrm{stack}$ height $=250 \mathrm{ft}(76 \mathrm{~m})$.

$c_{x_{1,3}}=$ maximum 1- or 3-hour averaging-time ground-level concentration; $x_{8}=$ maximum 8 -hour averaging-time ground-level concentration; $x_{24}=$ maximum 24 -hour averaging-time ground-level concentration; all calculated using U.S. Environmental Protection Agency "Simple Screening Procedure" (see Appendix B). 
Table 9. Estimated ambient-air-quality impact for controlled stack-gas emissions of criteria pollutants from a proposed $20,000-b b 1 / d$ cormercial tar-sand surface-solvent system. ${ }^{a}$

\begin{tabular}{|c|c|c|c|c|c|c|c|c|c|c|}
\hline \multirow{2}{*}{$\begin{array}{l}\text { Emission } \\
\text { source }^{b}\end{array}$} & \multirow{2}{*}{$\begin{array}{l}\text { Atmospheric } \\
\text { emission }\end{array}$} & \multicolumn{2}{|c|}{$\begin{array}{c}\text { Emission } \\
\text { rate }\end{array}$} & \multicolumn{3}{|c|}{$\begin{array}{l}\text { Estimated maximum ambient- } \\
\text { air-quality impact }\left(\mu \mathrm{g} / \mathrm{m}^{3}\right) \mathrm{c}\end{array}$} & \multicolumn{2}{|c|}{$\begin{array}{l}\text { National ambient- } \\
\text { air-quality standard }\end{array}$} & \multirow{2}{*}{$\begin{array}{l}\text { Emission-control } \\
\text { technique }\end{array}$} & \multirow{2}{*}{$\begin{array}{l}\text { Emission- } \\
\text { control } \\
\text { efficiency } \\
(\%)\end{array}$} \\
\hline & & $(1 \mathrm{~b} / \mathrm{h})$ & $(g / s)$ & $x_{1,3}$ & $x_{8}$ & $x_{24}$ & $\left(\mu \mathrm{g} / \mathrm{m}^{3}\right)$ & (avg. time) & & \\
\hline $\begin{array}{l}\text { Auxiliary boiler } \\
\text { flue-gas }\end{array}$ & $\mathrm{SO}_{2}$ & 172 & 22 & 150 & 135 & 90 & & & $\begin{array}{l}\text { Low-sulfur }(0.25 \% \\
\text { by wt) fuel }\end{array}$ & \\
\hline $\begin{array}{l}\text { Heating oil- } \\
\text { furnace flue-gas }\end{array}$ & $\mathrm{SO}_{2}$ & 2 & 0.3 & 44 & 40 & 27 & & & $\begin{array}{l}\text { Low-sulfur }(0.25 \% \\
\text { by wt) fuel }\end{array}$ & \\
\hline Total & $\mathrm{SO}_{2}$ & 174 & 22.3 & 194 & 175 & 117 & 365 & $24 h$ & & \\
\hline $\begin{array}{l}\text { Auxiliary boiler } \\
\text { flue-gas }\end{array}$ & $\mathrm{NO}_{\mathrm{X}}\left(\right.$ as $\left.\mathrm{NO}_{2}\right)$ & 98 & 12 & 82 & 73 & 49 & & & $\begin{array}{l}\text { Ammonia injection } \\
\left(\mathrm{NO}_{\mathrm{x}}: \mathrm{NH}_{3}=1.5\right)\end{array}$ & 50 \\
\hline $\begin{array}{l}\text { Heating oil- } \\
\text { furnace flue-gas }\end{array}$ & $\mathrm{NO}_{x}$ (as $\left.\mathrm{NO}_{2}\right)$ & 1 & 0.1 & 15 & 13 & 9 & & & $\begin{array}{c}\text { Ammonia injection } \\
\left(\mathrm{NO}_{\mathrm{x}}: \mathrm{NH}_{3}=1.5\right)\end{array}$ & 50 \\
\hline Total & $\mathrm{NO}_{\mathrm{x}}\left(\right.$ as $\left.\mathrm{NO}_{2}\right)$ & 99 & 12.1 & 97 & 86 & 58 & 100 & $1 \mathrm{y}$ & & \\
\hline $\begin{array}{l}\text { Auxiliary boiler } \\
\text { flue-gas }\end{array}$ & $\mathrm{CO}$ & 21 & 3 & 20 & 18 & 12 & & & None & \\
\hline $\begin{array}{l}\text { Heating oil- } \\
\text { furnace flue-gas }\end{array}$ & $\mathrm{CO}$ & 0.2 & 0.03 & 4 & 4 & 3 & & & None & . \\
\hline Total & $\mathrm{CO}$ & 21.2 & 3.03 & 24 & 22 & 15 & 10,000 & $1 \mathrm{~h}$ & & \\
\hline $\begin{array}{l}\text { Auxiliary boiler } \\
\text { flue-gas }\end{array}$ & THC & 4.6 & 0.6 & 4 & 4 & 3 & & & None & \\
\hline $\begin{array}{l}\text { He ating oil- } \\
\text { furnace flue-gas }\end{array}$ & THC & 0.04 & 0.01 & 2 & 2 & 1 & & & None & \\
\hline Total & THC & 4.64 & 0.61 & 6 & 6 & 4 & 160 & $\begin{array}{c}3 \mathrm{~h} \\
(6 a m-9 a m)\end{array}$ & & \\
\hline
\end{tabular}


Table 9. (continued)

\begin{tabular}{|c|c|c|c|c|c|c|c|c|c|}
\hline \multirow{2}{*}{$\begin{array}{l}\text { Emission } \\
\text { source }\end{array}$} & \multirow{2}{*}{$\begin{array}{l}\text { Atmospher ic } \\
\text { emission }\end{array}$} & \multicolumn{2}{|c|}{$\begin{array}{l}\text { Emission } \\
\text { rate }\end{array}$} & \multicolumn{3}{|c|}{$\begin{array}{l}\text { Estimated maximum ambient- } \\
\text { air-quality impact }\left(\mu \mathrm{g} / \mathrm{m}^{3}\right)^{\mathrm{c}}\end{array}$} & $\begin{array}{l}\text { National ambient- } \\
\text { air-quality standard }\end{array}$ & \multirow{2}{*}{$\begin{array}{l}\text { Emission-control } \\
\text { technique }\end{array}$} & \multirow{2}{*}{$\begin{array}{l}\text { Emission- } \\
\text { control } \\
\text { efficiency } \\
\quad(\%)\end{array}$} \\
\hline & & $(1 b / h)$ & $(g / s)$ & $x_{1,3}$ & $x_{8}$ & $x_{24}$ & $\left(\mathrm{\mu g} / \mathrm{m}^{3}\right)$ (avg. time) & & \\
\hline $\begin{array}{l}\text { Auxiliary boiler } \\
\text { flue-gas }\end{array}$ & TSP & 26 & 3 & 20 & 18 & 12 & & None & \\
\hline $\begin{array}{l}\text { Heating oil- } \\
\text { furnace flue-gas }\end{array}$ & TSP & 0.2 & 0.03 & 4 & 4 & 3 & & None & \\
\hline Total & TSP & 26.2 & 3.03 & 24 & 22 & 15 & $24 \mathrm{~h}$ & & \\
\hline
\end{tabular}

a Based on projected emission rates, process-design operating parameters, and proposed control technologies for a Dravo solvent oil-extraction system. 25

b Auxiliary boiler stack-gas characteristics for the solvent system: Volume flow-rate $=7.8 \times 10^{6} \mathrm{scf} / \mathrm{h}(61 \mathrm{~m} / \mathrm{s}) ; \mathrm{stack}-\mathrm{gas}$ temperature $=500^{\circ} \mathrm{F}\left(260^{\circ} \mathrm{C}\right)$; stack height $=250 \mathrm{ft}(76 \mathrm{~m})$. Stack-gas characteristics of associated heating-oil furnace: Volume flow-rate $=7.2 \times 10^{4} \mathrm{scf} / \mathrm{h}\left(0.6 \mathrm{~m}^{3} / \mathrm{s}\right) ;$ stack-gas temperature $=500^{\circ} \mathrm{F}\left(260^{\circ} \mathrm{C}\right) ;$ stack height $=250 \mathrm{ft}(76 \mathrm{~m})$.

$c_{1,3}=$ maximum 1 - or 3-hour averaging-time ground-level concentration; $x_{8}=$ maximum 8-hour averaging-time ground-level concentration; $x_{24}=$ maximum 24-hour averaging-time ground-level concentration, all calculated using the U.S. Environmental Protection Agency "Simple Screening Procedure" (see Appendix B). 
accuracy for individual sites; it is designed to effectively "eliminate from further consideration" those stationary sources that will not cause nor contribute to pollutant ambient-air concentrations in excess of short-term air-quality standards. It is also recommended by EPA as the "first phase" of analysis for assessing the ambient-air-quality impact of a new stationary source. 39 For these reasons, and because site-specific air-pollution modeling is not the goal of this report, the Simple Screening Procedure was used. In addition, the preliminary estimates of ambient-air-quality impacts predicted using the "Simple Screening Procedure" are meant only to draw industry and government attention to potential ambient-air-quality problems, and indicate the need for these problems to be addressed using more sophisticated models when tar-sand development activities are being planned for specific sites.

According to the preliminary estimates of the maximum ambient-air-quality impact for criteria pollutants from the surface retort system, no NAAQS will be exceeded (Table 8). The estimated maximum ambient-air-quality impact calculations for the criteria pollutants from the solvent process again indicate that no NAAQS are likely to be exceeded (Table 9). These results suggest that the application of these available control techniques described in Tables 8 and 9 may successfully mitigate ambient-air-quality impacts.

It must be recognized, however, that these results are preliminary. There is a need for more comprehensive modeling and for a field monitoring program at specific sites so that the significant impacts from not only the criteria pollutants but all of the pollutants regulated under the Clean Air Act can be determined. A comprehensive modeling and monitoring program will also help to confirm whether the allowable Prevention of Significant Deterioration (PSD) increments will be exceeded either in the region where the operation of a commercial tar-sand project is to take place or in any nearby National Parklands.

PSD increments are established by EPA to prevent significant deterioration of air quality from TSP and $\mathrm{SO}_{2}$ in areas where TSP and $\mathrm{SO}_{2}$ NAAQS are currently not exceeded (attainment areas). Preliminary estimates show that in ClasS II attainment areas PSD increments for TSP would be exceeded by emissions from retort processes and for $\mathrm{SO}_{2}$ by emissions from both retort and solvent processes. Class II areas allow moderate increases in atmospheric $\mathrm{SO}_{2}$ and TSP levels. The allowable PSD incremental increases for 
these Class II areas are $91 \mu \mathrm{g} / \mathrm{m}^{3}$ for $\mathrm{SO}_{2}$ and $37 \mathrm{\mu g} / \mathrm{m}^{3}$ for TSP for a 24-h averaging time. 18 These increments may represent a limiting factor for development, as initial tar-sand commercialization is likely to concentrate in Class II areas. National Parklands are Class I areas and the allowable PSD incremental increases in these areas are more limited than in Class II areas.

Noise. The sound levels from processing equipment associated with the operation of commercial retort and solvent tar-sand technologies are expected to be in the range of 73 to $88 \mathrm{dBA}$ at 50 feet. ${ }^{26}$ This noise level is not expected to cause a serious impact on neighboring communities because it is not considered sufficient to cause the EPA-suggested short-term goal for communities $\left(L_{d n}=65 \mathrm{dBA}\right)$ to be exceeded. 26 Additionally, enclosing noise-producing equipment, limiting employee exposure, and installing noise-suppression equipment (e.g., mufflers, blow-down mutes, and pipe wrap), will reduce impacts on the proximal work force from the noise generated by retort or solvent operations.

Worker Health and Safety. The commercial retort and solvent processes will pose safety hazards to workers from potential contact with hot pipes, fluids, and vapors. Worker contact with the chemical agents used to extract oil from the bitumen and to reduce air-pollutant emissions represents another potential hazard. For example, a commercial retort process employs caustic compounds for sulfur removal that could result in contact dermatitis for exposed workers. The heptane, cyclohexane, and ethanol solvent vapors associated with the solvent method may be irritating to the respiratory tract, or can act as asphyxiants should workers become exposed to very high concentrations under accidental conditions. 40 Further analysis of the petroleum products produced by the retort and solvent processes needs to be performed to determine if they have carcinogenic properties, or if upon contact they can induce chronic effects (e.g., dermatosis) that would pose a health risk to workers. While similar hazards are dealt with routinely by the petroleum and chemical industries, such problems need to be identified for tar-sand projects so that appropriate precautions can be transferred to the tar-sand industry or new ones developed. 
Water. Both retort and solvent operations will require the consumptive use of water. A commercial retort process may require almost $1900 \mathrm{~m}^{3}$ of water per day $(1.5 \mathrm{af} / \mathrm{d})$ and $\mathrm{a} l 1$ of this will probably have to be fresh water. 26 Operation of a commercial solvent process could require approximately $17,000 \mathrm{~m}^{3}$ of water per day (14 af/day) but for this process only $22 \%\left(3750 \mathrm{~m}^{3} / \mathrm{d}\right.$ or 3 af $\left./ \mathrm{d}\right)$ needs to be fresh water. 26 The remaining $78 \%$ can be treated wastewater. The fresh water for either a retort or solvent process for the-tar sand project near Mckittrick, California, will be available from the West Kern County Water District allotment and from privately-owned wells in nearby Tupman. 26 To ensure that fresh water removal from the Tupman wells will not jeopardize the productivity of neighboring wells or contribute to an overdraft of the ground-water supply, monitoring studies of the Tupman wells are planned. ${ }^{26}$ For projects at other sites in the United States, water-supply arrangements similar to those just described for the Mckittrick tar-sand project may be necessary.

The use of treated wastewater for the commercial solvent process represents an attractive alternative to the exclusive use of fresh water because in many areas substantial quantities of fresh water are difficult to obtain. However, the treated wastewater to be used in the solvent system may have to be transported over a significant distance. For example, in the Mckittrick area where treated wastewater may be used to support a commercial 20,000-bbl/d solvent system, the treated wastewater will need to be piped 55 miles from the Kern County $0 i 1$ Field. 26

Associated with the transport of treated wastewater over long distances is the potential for spills due to pipe, valve, and pump failures. One estimate indicates that a worst-case spill from the planned 55-mi waste-water pipeline to Mckittrick, California, could pour almost $4000 \mathrm{~m}^{3}$ (3.2 af) of treated wastewater into the environment. 26 Contaminants contained in this water could degrade surface- and ground-water quality before being significantly diluted by those water supplies. Furthermore, a spill of this magnitude could result in contamination of ecological habitats from retention of contaminants in soils, their uptake by vegetation, and their ingestion by animals. The source and nature of the treated wastewater will determine the specific temporal aspects of the adverse impacts. 
Although the solvent process may prove to be suitable for commercialization, the quantity of treated wastewater necessary to operate it may preclude its use. For example, the lack of available treated wastewater, or excessive costs related to its transport over long distances, may make this process uneconomical for some tar-sand sites.

Waste Generation and Disposal. All waste matter generated by either a commercial retort or solvent process $c$ an be used in mine-reclamation activities. These wastes include the water, solids, environmental controltechnology by-products (e.g., spent lime, and spent caustic soda/soda ash from $\mathrm{SO}_{2}$ removal equipment), and those spent catalysts not reprocessed for metals recovery. These substances must be stored prior to being used in the backfilling of the mine. The potential effect on water quality from the leaching of toxic substances contained in this waste must be determined so that serious water-quality problems can be avoided. Monitoring of the leachate from the reclaimed mine area and waste-storage piles will be necessary to determine if migration of toxic substances occurs, and for developing proper mitigation if a toxic-substances-transport problem is ident ified.

Community Infrastructure. A commercial tar-sand-retort process, such as the one that has been discussed for McKittrick, California, will require an average daily on-site construction work-force of 500 people during its anticipated two-year construction period, and a projected maximum work-force during construction periods of 1000.26 The operating work-force needed to perform the mining, processing, and managing of the completed 20,000-bb1/d retort facility has been estimated at 474 people. 26

According to the projections made for a 20,000-bbl/d commercial solvent process, an estimated average daily on-site construction work force of 200 people and a peak work force of 450 will be needed during the two-year

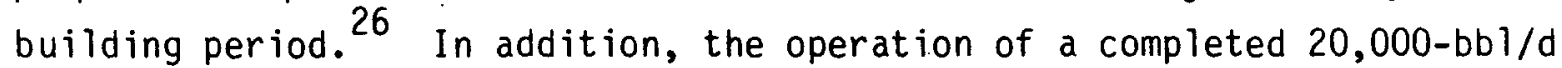
solvent process is estimated to require a total of 457 workers for mining, processing, and the management of the facility. 26

The personnel requirements for either the commercial retort system or the solvent process would probably not produce a significant impact on publicservice systems or housing near Mckittrick, California. The reason for this 
is that the labor pool available throughout the neighboring communities in Kern County is considered sufficient to fill the majority of positions necessary to construct and operate a facility. Therefore substantial commuting to Mckittrick from existing residences in Kern County communities is expected to take place. More specifically, it is considered likely that $75 \%$ of the construction work-force would commute from residences in Kern County. ${ }^{26}$ The remaining $25 \%$ of the construction labor force, presumably temporary in-migrants, could use existing rental housing facilities available near the site or in Bakersfield, about 40 miles away. 26

The Kern County labor pool is also considered adequate to supply most of the necessary skilled personnel to operate either a commercial retort or a solvent tar-sand system near Mckittrick. ${ }^{26}$ The detailed estimates of each labor category needed to operate either system indicate that approximately 315 of the needed employees could come from Kern County and the remainder (about 150) would be in-migrants. 26 If the Kern County average of 2.8 persons per household is assumed for the 150 in-migrating workers, a population increase of 420 persons is anticipated. 26 This population increase is not large enough to impact significantly the Kern County community infrastructure unless a 11420 were to migrate into the immediate project area where family housing is limited. However, the migration of all 420 persons into the immediate vicinity of the project is unlikely because the nearby Bakersfield area can offer both housing and a greater selection of schools, retail centers, and other amenities, and is within commuting distance. ${ }^{26}$ Thus, the public services related to fire and police protection, schools, medical care, utilities, and sanitation all appear to be sufficient for supporting either a commercial retort or solvent tar-sand oil-recovery operation in Kern County, California. These estimates of potential effects on the community infrastructure of Kern County from surface tar-sand activities were presented because they represent the most detailed information currently available on this subject.

The projected situation for Kern County may, however, not exist for tarsand activities taking place in areas that have low population densities, marginal public infrastructural systems, and inadequately skilled local workforces. Under these circumstances, the majority of the construction and operating work-force will have to in-migrate and this may produce significant impacts on some infrastructural public systems and housing. For instance, 
a commercial retort process would produce a peak population increase of about 2100 people during the two-year construction period, and nearly 1000 people for plant operation. These figures are based on the Kern County average of 2.8 persons per dwelling, the work-force totals previously discussed, and a $75 \%$ in-migration figure. Similarly, a commercial solvent project would cause a maximum population increase of nearly 1000 people for construction and the same amount for operation. The combined personnel figures for construction and operation of either a retort or a solvent process could represent a significant increase to communities with small indigenous populations, such as in the Uinta Basin of Utah where only 33,000 reside. 41

\section{In-Situ Combustion or Steam-Injection Processes}

In situ combustion and steam-injection methods for extracting petroleum directly from underground tar-sand reservoirs are also being developed for commercial application in the United States. The most detailed quantitative data now available on these techniques are from field tests performed by the U.S. Department of Energy (DOE), Laramie Energy Technology Center (LETC). Those data are primarily used here to derive the potential environmental, health, safety, and socioeconomic impacts that could result from commercialization of these procedures. This information will therefore need to be addressed for development to proceed in an environmentally acceptable manner.

Land Disturbance. The three major land disturbances which can evolve from construction and operation activities related to in situ processes are (1) soil loss, (2) seismic activity, and (3) subsidence.

Soil loss can occur if increased run-off results from vegetation removal and ground compaction associated with land clearing for buildings, roads, and drilling pads. Soil loss and subsequent sediment delivery to receiving waters can also occur if the ground is made more impervious and if the unobstructed flow of run-off are allowed to occur. Seismicity may be induced by fluid injection and increased pressures acting to lubricate fault planes in a tar-sand formation. Subsidence may occur if fluid withdrawal from the tar-sand reservoir lowers pore pressures in the formation to a level that 
permits sediments to compact. The compaction could then be translated to the surface in the form of subsidence, and the significance of the impact would depend on existing 1 and uses.

At the site of the in situ tar-sand field tests near Vernal, Utah, the likelihood of significant adverse impacts from soil erosion, induced seismic activity, and subsidence is considered to be small. This conclusion is based on the following facts: (1) the small size of the field-testing activities, (2) the geophysical composition of the Northwest Asphalt Ridge tar-sand formation that is being used, and (3) the minimal impact any subsidence could have on the surrounding lands that are being used only for the purpose of grazing cattle. Such site-specific evaluations need to be performed for all tar-sand locations selected for application of in situ petroleum-recovery methods. In this way the significant adverse impacts related to erosion, seismic effects, and subsidence can be identified and mitigated whenever necessary. Moreover, many effective mitigating procedures are already being employed by the oil and gas industry and may be directly transferable to in situ tar-sand activities.

One quantitative estimate of the magnitude of the land disturbance that could result from the application of a commercial in situ tar-sand process indicates that a 10,000-bbl/d operation could require that between 40 to 100 acres per year be cleared. 28 Therefore, depending on the characteristics of a particular tar-sand deposit, it is conceivable that a $20,000 \mathrm{bbl} / \mathrm{d}$ in situ project could require that about twice this amount of 1 and be cleared during each year of operation.

Another quantitative estimate of the amount of 1 and disturbance that may result from the use of a commercial in situ tar-sand process was calculated by ESSO Resources Canada, Limited. The in situ tar-sand project proposed by ESSO to begin in the mid 1980s will take place in Canada, and it is projected to produce about 140,000 barrels of petroleum per day. Over a 25-year lifetime, this project is predicted to involve the drilling of about 16,000 wells with a spacing of $330 \mathrm{ft}(100 \mathrm{~m})$, covering a surface area of about 25,000 acres. 5 Therefore, it is possible that a facility in the U.S. one seventh this size $(20,000 \mathrm{bbl} / \mathrm{d})$ could, over 25 years, involve about 2300 wells that would, if spaced $330 \mathrm{ft}(100 \mathrm{~m})$ apart, cover a surface area of about 4000 acres. This would be equivalent to an average rate of 1 and clearing of about 160 acres per year. 
It is important to note that land disturbance from activities such as well-drilling and building construction can also cause the destruction or loss of valuable historical, paleontological and archaeological sites and artifacts, critical and sensitive ecological habitats, and rare and endangered species. Measures should therefore be taken at any site to prevent such losses. These measures might include employing qualified personnel to determine if artifacts, critical ecological habitats, and rare and endangered species are present; and if they are, to recommend the necessary precautions to prevent adverse impacts.

Atmospheric Emissions. Commercial application of in situ combustion or steam-injection techniques for oil recovery from tar sands will produce atmospheric emissions. These emissions will be released as exhaust-gas emissions from vehicle operation, fugitive dust from land-movement activities, and emissions from stacks venting to the atmosphere.

At the present time the exact number of vehicles and the precise amount of 1 and movement that will be required to support a 20,000-bbl/d in situ project in the U.S. still need to be ascertained, and the emissions from these mobile and area sources quantitatively described. The air pollution from vehicles and earth-moving activities will only last for short periods of time, however, and are therefore assumed to contribute minimally to any long-term degradation of ambient-air quality. Thus, the most significant long-term impacts on ambient-air quality will be from stack-gas emissions.

The potential ambient-air-quality impacts from the uncontrolled stack-gas emissions produced by a conceptual 20,000-bbl/d in situ tar-sand combustion or steam-injection facility were estimated by applying the U.S. EPA "Simple Screening Procedure" 39 (Appendix B). Emission rates for conceptual 20,000-bb1/d in situ processes were scaled from limited quantitative data from the (1) unpublished results of the cursory emission-monitoring program performed for the LETC TS-2C echoing in situ combustion field-test ${ }^{42}$ (i.e., reverse combustion used as a preparatory phase for forward combustion), and (2) the predicted emission rates for criteria pollutants from the stack of a fossil-fuel-fired steam boiler used for the LETC TS-1S steam-injection fieldtest. 35

Table 10 contains the best documented measurements of the produced offgases from the TS-2C in situ combustion field-test. The estimated ambientair-quality impacts from the uncontrolled release of such product-gases from a 
Table 10. Average composition of the product gas from the TS-2C in situ combustion experiment.

Species

Concentration

$\%^{\mathrm{a}}$

I.

$\mathrm{H}_{2}$ (Hydrogen)

2

$\mathrm{N}_{2}$ (Nitrogen)

80

$\mathrm{O}_{2}$ (Oxygen)

Ar (Argon)

CO (Carbon monoxide)

$\mathrm{CH}_{4}$ (Methane)

$\mathrm{CO}_{2}$ (Carbon dioxide)

13

$\mathrm{CH}_{2}=\mathrm{CH}_{2}$ (Ethylene)

0.2

$\mathrm{CH}_{3}-\mathrm{CH}_{3}$ (Ethane)

0.1

$\mathrm{CH}_{3}-\mathrm{CH}=\mathrm{CH}_{2}$ (Propylene)

0.07

$\mathrm{CH}_{3}-\mathrm{CH}_{2}-\mathrm{CH}_{3}$ (Propane)

0.07

I I. C

COS (Carbonyl sulfide)

0.02

$\mathrm{H}_{2} \mathrm{~S}$ (Hydrogen sulfide)

0.2

$\mathrm{NH}_{3}$ (Ammonia)

0.09

I II. d

NO (Nitrogen oxides)

0.01

TSP (Total suspended particulates)

a Except TSP, which is expressed as $\mathrm{g} / \mathrm{m}^{3}$.

b Average dry gas analys is of produced gas based on wet and dry composition and interval flow-rates. 34

$c$ Based on statistical analyses of gaseous species analyzed by a mass spectrometer. 42

$d$ The $\mathrm{NO}_{x}$ concentration was estimated from monitoring data where fluctuations above and below the reported concentration were observed and process changes were occurring. ${ }^{42}$ Vent gases were monitored for particulates (mass loading) using an Alundum (ceramic) thimble. ${ }^{42}$ 
conceptual 20,000-bbl/d in situ combustion process are presented in Table 11, and compared to NAAQS and recommended ambient-air-level goals based on health effects. The latter are proposed by EPA as Multimedia Environmental Goals (MEG's). 43 The estimated uncontrolled emission-rates and corresponding ambient-air-quality concentrations for criteria pollutants $\left(\mathrm{SO}_{2}, \mathrm{NO}_{x}\right.$, TSP, THC, and CO) released from a conceptual 20,000-bbl/d in situ steam-injection process are presented in Table 12, along with the applicable National Ambient Air Quality Standards for purposes of comparison.

It is important to emphasize that the monitoring data concerning the TS-2C in situ combustion field-test presented in Tables 10 and 11 are from unpublished information that is very limited in scope. A comprehensive air-monitoring program had not yet been employed, engineering parameters were changing during monitoring, and problems and inconsistencies in sampling techniques were observed. 42 The ambient-air-quality impacts for a commercial steam-injection process (Table 12) were based on preliminary calculations of maximum uncontrolled emission rates for the steam generator planned for implementation in the steam-injection field experiment conducted by LETC near Vernal, Utah. 35

The resulting estimated ambient-air-quality impacts, computed from the limited and preliminary quantitative information for the in situ field tests, must therefore be considered first-order approximations. Nevertheless, these data can be used to indicate the potential need for application of (1) control technologies, (2) more sophisticated monitoring and air-quality modeling, and (3) detailed worker and public health-effects analyses.

The stack height for either a combustion or a steam-injection 20,000-bbl/d project is assumed to be 250 feet $(76 \mathrm{~m})$ : The stack-gas temperature for the combustion process is assumed to be $100^{\circ} \mathrm{F}\left(38^{\circ} \mathrm{C}\right)$, and the stack-gas temperature for the steam generator is estimated to be $400^{\circ} \mathrm{F}$ $\left(204^{\circ} \mathrm{C}\right)$. These assumptions are necessary for calculating potential ambient-air-quality impacts.

The data in Table 11 suggest that the uncontrolled release from a combustion process of (1) carbon monoxide, (2) non-methane hydrocarbon species individually or collectively (ethylene, ethane, propylene, and propane), (3) nitrogen oxides (as nitrogen dioxide), and (4) total suspended particles could cause NAAQS for these pollutants to be exceeded. The estimated concentration 
Table 11. Estimated emission rates and ambient-air-quality impacts from the uncontrolled release of product gases from a conceptual 20,000-bbl/d commercial in situ tar-sand combustion process. ${ }^{a}$

\begin{tabular}{|c|c|c|c|c|c|c|c|}
\hline \multirow[b]{2}{*}{ Species $^{b}$} & \multirow{2}{*}{$\begin{array}{c}\text { Emission } \\
\text { rate } \\
(\mathrm{g} / \mathrm{s}) \\
\end{array}$} & \multicolumn{3}{|c|}{$\begin{array}{l}\text { Estimated maximum ambient- } \\
\text { air-quality impact }\left(\mu \mathrm{g} / \mathrm{m}^{3}\right)^{\mathrm{c}} \\
\end{array}$} & \multicolumn{2}{|c|}{$\begin{array}{l}\text { National ambient- } \\
\text { air-quality standard }\end{array}$} & \multirow{2}{*}{$\begin{array}{c}M^{M E G^{d}} \\
\left(\mu \mathrm{g} / \mathrm{m}^{3}\right)\end{array}$} \\
\hline & & $x_{1,3}$ & $x_{8}$ & $x_{24}$ & $\left(\mu \mathrm{g} / \mathrm{m}^{3}\right)$ & (avg. time) & \\
\hline I. $\mathrm{CO}$ & 11,000 & 83,000 & 75,000 & 50,000 & 10,000 & $l \mathrm{~h}$ & \\
\hline $\mathrm{CO}_{2}$ & 120,000 & 850,000 & 770,000 & $510,000)$ & & & 539,000 \\
\hline $\mathrm{CH}_{2}{ }^{2}=\mathrm{CH}_{2}$ & 1,000 & 8,000 & 8,000 & 5,000 & & & 13,600 \\
\hline $\mathrm{CH}_{3}-\mathrm{CH}_{3}$ & 600 & 4,000 & 4,000 & 3,000 & 160 & $3 \mathrm{~h}$ & 14,600 \\
\hline $\mathrm{CH}_{3}-\mathrm{CH}=\mathrm{CH}_{2}$ & 600 & 4,000 & 4,000 & 3,000 & & (6am-9am) & 20,000 \\
\hline $\mathrm{CH}_{3}-\mathrm{CH}_{2}-\mathrm{CH}_{3}$ & 600 & 5,000 & 4,000 & 3,000 & & & 21,400 \\
\hline \multicolumn{8}{|l|}{ II. } \\
\hline $\cos$ & 200 & 2,000 & 2,000 & 1,000 & & & 800 \\
\hline $\mathrm{H}_{2} \mathrm{~S}$ & 1,000 & 10,000 & 9,000 & 6,000 & & & 36 \\
\hline $\mathrm{NH}_{3}$ & 300 & 2,000 & 2,000 & 1,000 & & & 43 \\
\hline \multicolumn{8}{|l|}{ III. } \\
\hline $\mathrm{NO}_{x}\left(\right.$ as $\left.\mathrm{NO}_{2}\right)$ & 90 & 700 & 600 & 400 & 100 & $1 y$ & \\
\hline$T S \hat{P}$ & 32,000 & 230,000 & 210,000 & 140,000 & 260 & $24 \mathrm{~h}$ & \\
\hline
\end{tabular}

a The LETC TS-2C experiment produced a gas/0il ratio of $68,800 \mathrm{scf} / \mathrm{bbl} .^{34}$ Assumed stack-gas characteristics: Volume flow-rate $=57 \times 10^{6} \mathrm{scf} / \mathrm{h}(450 \mathrm{~m} / \mathrm{s})$; stack-gas temperature $=100^{\circ} \mathrm{F}$ $\left(38^{\circ} \mathrm{C}\right)^{31}$; stack height $=250 \mathrm{ft}(76 \mathrm{~m})$.

b $\mathrm{CO}$ : carbon monoxide; $\mathrm{CO}_{2}$ : carbon dioxide; $\mathrm{CH}_{2}=\mathrm{CH}_{2}$ : ethylene; $\mathrm{CH}_{3}-\mathrm{CH}_{3}$ : ethane;

$\mathrm{CH}_{3}-\mathrm{CH}=\mathrm{CH}_{2}$ : propylene; $\mathrm{CH}_{3}-\mathrm{CH}_{2}-\mathrm{CH}_{3}$ : propane; COS: carbonyl sulfide; $\mathrm{H}_{2} \mathrm{~S}$ : hydrogen sulfide; $\mathrm{NH}_{3}$ : ammonia; $\mathrm{NO}_{X}$ : nitrogen oxides (as nitrogen dioxide); TSP: total suspended particulates.

c $x_{1,3}=$ maximum 1 - or 3-hour averaging-time ground-level concentration; $x_{8}=$ maximum 8-hour averaging-time ground-level concentration; $x_{24}=$ maximum 24-hour averaging-time ground-level concentration, all calculated using the U.S. Environmental Protection Agency "Simple Screening Procedure" (see Appendix B).

d U.S. Environmental Protection Agency Multimedia Environmental Goals (MEG) for ambient air quality represent estimated permissible concentrations based ori human health. ${ }^{43}$ 
Table 12. Estimated emission rates and ambient-air-quality impacts from the uncontrolled release of product gases from steam generators associated with a conceptual 20,000-bbl/d commercial in situ steam-injection tar-sand project.

\begin{tabular}{|c|c|c|c|c|c|c|c|}
\hline \multirow{2}{*}{$\begin{array}{l}\text { Emission } \\
\text { species }\end{array}$} & \multirow{2}{*}{$\frac{\text { Emission }}{(1 b / h)}$} & \multirow{2}{*}{$\frac{\text { rate }^{a, b}}{(g / s)}$} & \multicolumn{3}{|c|}{$\begin{array}{l}\text { Estimated maximum ambient- } \\
\text { air-quality impact }\left(\mathrm{\mu g} / \mathrm{m}^{3}\right)^{\mathrm{c}}\end{array}$} & \multicolumn{2}{|c|}{$\begin{array}{l}\text { National ambient- } \\
\text { air-quality standard }\end{array}$} \\
\hline & & & $x_{1,3}$ & $x_{8}$ & $x_{24}$ & $\left(\mu \mathrm{g} / \mathrm{m}^{3}\right)$ & (avg. time) \\
\hline $\mathrm{SO}_{2}$ & 2,800 & 350 & 1,400 & 1,200 & 800 & 365 & $24 h$ \\
\hline $\mathrm{NO}_{X}$ & 1,400 & 170 & 700 & 600 & 400 & 100 & $\left(\right.$ as $\left.\mathrm{NO}_{2}^{\mathrm{y}}\right)$ \\
\hline $\mathrm{CO}$ & 60 & 7 & 30 & 20 & 20 & 10,000 & $1 \mathrm{~h}$ \\
\hline THC & 30 & 4 & 20 & 10 & 10 & 160 & $\begin{array}{c}3 \mathrm{~h} \\
(6 \mathrm{am}-9 \mathrm{am})\end{array}$ \\
\hline TSP & 200 & 30 & 100 & 100 & 60 & 260 & $24 \mathrm{~h}$ \\
\hline
\end{tabular}

a Emission rates were calculated from LETC data pertaining to the steam generator and the use of low-sulfur (1.5\% by wt) No. 6 fuel oil for the TS-1S steam-injection experiment. 35,36 These calculations are described in the text.

b Assumed stack-gas characteristics for a single stack associated with commercial in situ steam injection: Volume flow rate $=22 \times 10^{6} \mathrm{scf} / \mathrm{h}$ $\left(170 \mathrm{~m}^{3} / \mathrm{s}\right)$; stack-gas temperature $=400^{\circ} \mathrm{F}\left(204^{\circ} \mathrm{C}\right)^{44}$, stack height $=$ $250 \mathrm{ft}(76 \mathrm{~m})$. Volume flow rate calculated for a single stack emitting combustion products associated with the production of steam from $6,700 \mathrm{bbl} / \mathrm{d}$ of typical low-sulfur (1.5\% by wt) No. 6 fuel $0 i 1$.

c $x_{1,3}=$ maximum 1 - or 3-hour averaging-time ground-level concentration; $x_{8}=$ maximum 8-hour averaging-time ground-level concentration, all calculated using the U.S. Environmental Protection Agency "Simple Screening Procedure" (see Appendix B). 
of TSP is also computed to exceed the "Prevention of Significant Deterioration" (PSD) allowable increment limitations for Class II areas $18\left(37 \mathrm{\mu g} / \mathrm{m}^{3}\right.$ for 24-hour average), i.e., the areas where tar-sand commercial technologies are likely to develop. Therefore it appears control technologies will be needed for these pollutants.

The estimated ambient air concentrations of carbon dioxide, carbonyl sulfide, hydrogen sulfide, and ammonia from the commercial combustion process (Table 11) exceed U.S. Environmental Protection Agency recommended MEG values for ambient air quality based on health effects. ${ }^{43}$ Among these pollutants hydrogen sulfide is likely to be responsible for the most serious impacts. The concentration levels from uncontrolled release of $\mathrm{H}_{2} \mathrm{~S}$ into the ambient air correspond to a range of 4.3 to 7.1 ppmv. This concentration range can result in a nuisance odor, and irritation of moist membranes of the eye and respiratory tract for exposed populations. ${ }^{45}$ For these reasons the atmospheric release of $\mathrm{H}_{2} \mathrm{~S}$ will probably require application of an atmospheric emission control technology.

Individually the non-methane hydrocarbons will not exceed MEG values based on human-health effects. However, additional monitoring should be performed in order to ascertain any local impacts on native vegetation from exposure to product gases that may be released into the ambient air. Ethylene, for example, was recorded in small quantities in produced gas from the echoing in situ combustion field-test conducted near Vernal, Utah, 34 and there is evidence ${ }^{46}$ to suggest that exposure to ethylene concentrations as low as 2.5 to 10 ppmv may increase senescence in vegetation such as juniper which may surround typical tar-sand sites. The potential ambient-airconcentration estimates for uncontrolled ethylene emissions from a 20,000-bbl/d in situ combustion operation (Table 11) correspond to a range of 4.4 to 7.0 ppmv. Thus vegetation proximal to commercial in situ combustion projects could be adversely affected by uncontrolled emissions of ethylene.

An estimate of the criteria-pollutant stack-gas emission rates for a 20,000-bb1/d in situ steam-injection project was calculated with emission-rate data predicted for the steam generator employed for the steam-injection field tests near Vernal, Utah.35,44 The emission rates for the in situ field-demonstration steam-generator were computed for a maximum daily fuelconsumption rate and the use of low-sulfur (1.5\% by wt) No. 6 fuel 0i1.35,36 Based on the current assumption that 1 barrel of fuel 0 il will need to be consumed to produce 3 barrels of tar-sand product $0 i 1^{4}$; a 
20,000-bbl/d commercial in situ facility will require the consumption of about $6700 \mathrm{bbl} / \mathrm{d}$ of fuel oil. An estimate of the criteria-pollutant emission rates for a 20,000-bbl/d steam-injection facility was derived by dividing 6700 barrels of $0 i l$ by the maximum daily fuel-consumption rate $(44.39 \mathrm{bbl} / \mathrm{d})$ and then multiplying the emission rates predicted for a fuel-consumption rate of $44.39 \mathrm{bbl} / \mathrm{d}$ by the result of this division (i.e., 150). For the same reasons as described previously, the EPA "Simple Screening Procedure" 39 was employed to estimate the ambient-air-quality impacts from these emissions. The potential uncontrolled emission rates of criteria pollutants and their potential ambient air concentrations from a conceptual 20,000-bbl/d steam-injection process are summarized, and compared with National Ambient Air Quality Standards in Table 12. The data indicate that $\mathrm{SO}_{2}$ and $\mathrm{NO}_{x}$ may exceed their National Ambient Air Quality Standards unless they are controlled. Therefore, implementation of emission-control procedures for these criteria pollutants may be necessary before in situ steam-injection processes can be used commercially. The application of emission-control techniques such as those used for enhanced-oil-recovery steam generators now operating in Kern County, California, may resolve this problem. However, further analysis will be required to determine the actual emissions, and the necessary control technologies that may be needed if tar-sand product-oil instead of low-sulfur fuel-oil is used for generating steam.

The information in Table 12 can be substantiated by normalizing the available criteria-pollutant emission-rate data for commercial steam generators to a fuel-consumption rate of $6700 \mathrm{bbl} / \mathrm{d}$. These data are available for typical steam generators currently used to extract heavy oil from sites in Kern County, California. The typical steam generator in Kern County produces $50 \times 10^{6} \mathrm{Btu} / \mathrm{h}$ and uses about $3340 \mathrm{lbs} / \mathrm{h}$ or $240 \mathrm{bbl} / \mathrm{d}$ (assuming continuous operation over a 24-hour period) of "lease crude oil" (i.e., oil extracted from the lease site, minimally treated, and then used to fuel the steam generator). The lease crude $0 i 1$ generally has an average specific gravity of approximately 0.95 (i.e., density of about $8.0 \mathrm{lbs} / \mathrm{gallion}$ ), and a sulfur content of about $1.1 \%$ by weight. 47

The uncontrolled atmospheric emission rates of $\mathrm{SO}_{2}, \mathrm{NO}_{x}$, and TSP from a typical $50 \times 10^{6} \mathrm{Btu} / \mathrm{h}$ steam generator that consumes $240 \mathrm{bbl} / \mathrm{d}$ of lease crude fuel have been estimated to be the following ${ }^{47,48}$ : 
- $\mathrm{SO}_{2}: 74 \mathrm{lbs} / \mathrm{h}$ or $1800 \mathrm{lbs} / \mathrm{d}$

- NO ${ }_{x}: 30 \mathrm{lbs} / \mathrm{h}$ or $720 \mathrm{lbs} / \mathrm{d}$

(assuming a typical average $\mathrm{NO}_{x}$ emission rate of 3 lbs $\mathrm{NO}_{x} / \mathrm{bbl}$

lease crude oil burned)

- TSP: $10 \mathrm{lbs} / \mathrm{h}$ or $240 \mathrm{lbs} / \mathrm{d}$

(assuming the ash content of the lease crude $0 i 1$ is $0.3 \%$ by weight, and $96 \%$ of the ash contributes to atmospheric particulate loading)

These emission rates are normalized to correspond to a lease crude $0 i 1$ consumption rate of $6700 \mathrm{bbl/d}$ by multiplying them by a factor of 28 (i.e., the result of normalizing $240 \mathrm{bbl} / \mathrm{d}$ to a $6700-\mathrm{bbl} / \mathrm{d}$ consumption rate). The resulting normalized values for the typical Kern County steam generator are presented and compared in Table 13 with the estimated emission-rates for the $18 \times 10^{6} \mathrm{Btu} / \mathrm{h}$ steam generator used for in situ steam-injection field testing on the Northwest Asphalt Ridge tar sands near Vernal, Utah. Comparison of the normalized values in Table 13 indicates that emission rates of $\mathrm{SO}_{2}, \mathrm{NO}_{x}$ and TSP from both steam generators are similar, and suggests the need for controls.

Noise. Noise levels of commercial in situ combustion or steam-injection tar-sand operations have not yet been estimated. It is unlikely that detrimental sound levels will be produced by these processes, since similar methodologies are already being employed by the $0 i 1$ and gas industry without causing standards to be exceeded. However, accurate noise-level figures should be determined.

Worker Health and Safety. Worker health and safety problems at in situ combustion and steam-injection projects can result from contact with high-temperature fluids, piping, and operating equipment; or exposure to hazardous or toxic agents in recovered process $0 i l$ and water, water/oil treatment chemicals, and stack- or process-line gases. In addition, storage of liquid fuels and chemicals can represent a flammability problem, although auto-ignition of these substances is unlikely. Exposure of workers to hazards could also result from rupture of piping, or from accidents that occur when routine maintenance or operating procedures are performed during active processing. 
Table 13. Emission-rate estimates of uncontrolled $\mathrm{SO}_{2}, \mathrm{NO}_{x}$, and TSP pollutants from steam-injection systems in Kern County, California, and Vernal, Utah, with fuel-consumption rates normalized to $6700 \mathrm{bbl} / \mathrm{d} .^{\mathrm{a}}$

\section{Estimated uncontrolled emission rates $(\mathrm{lb} / \mathrm{h})$}

\begin{tabular}{ll}
\hline Typical commercial 50-MBtu/h & An 18-MBtu/h steam generator \\
steam generator used in & used for the in situ steam- \\
Kern County, Californiab & injection field test near \\
& Vernal, Utah
\end{tabular}

$\begin{array}{lrr}\mathrm{SO}_{2} & 2100 & 2800 \\ \mathrm{NO}_{x} & 850 & 1400 \\ \mathrm{TSP} & 280 & 200\end{array}$

a Based on the current assumption that $1 \mathrm{bbl}$ of fuel $0 \mathrm{il}$ is needed to produce 3 bbls of product $0 i 1 .{ }^{4}$ Therefore a $20,000 \mathrm{bbl} / \mathrm{d}$ steam-injection facility will consume approximately $6700 \mathrm{bbl} / \mathrm{d}$ of fuel oil.

b Fuel $0 i 1$ is "lease crude" with a density of about $8.0 \mathrm{lbs} / \mathrm{gallon}$, and a sulfur content of $1.1 \%$ by weight. ${ }^{47}$

C Fuel oil is No. 6 fuel oil with an average density estimated to be about $8.2 \mathrm{lbs} / \mathrm{gallon}$, and a maximum sulfur content of $1.5 \%$ by weight. 48,49

For the in situ steam-injection field test near Vernal, Utah, researchers have implemented safety precautions. ${ }^{50}$ These include the following procedures:

- Workers handling product oil and recovered process water as if they were toxic substances (although the toxicity of these fluids is not yet known),

- Workers using proper handling procedures to prevent exposure to oil/water and water/oil de-emulsifiers, water-treatment chemicals, oxygen scavengers (Calgon LS-32, liquid sodium sulfite), organic sequestering agents (Calgon SL-500, liquid NTA and EDTA) and corrosion-control substances ( $f i l m i n g$ amine), and 
- Management requiring that workers wear protective apparel and receive safety education at the site.

Comparable worker-safety precautions would presumably be incorporated into commercial in situ combustion and steam-injection processes.

Water. The total water-consumption rate for a 20,000-bbl/d in situ tar-sand combustion process cannot be extrapolated at this time from field-test information. However, field-test information does indicate that the principal water uses for a commercial in situ combustion facility will be the following 31,34 :

- On-site power generation,

- Pollution-control devices,

- Steam tracing, and

- Domestic uses.

In situ combustion of tar sands to recover oil may also produce large volumes of water. The production rate of water could range from 1 to 2 barrels for every barrel of oil produced, as suggested by results from the in situ combustion field tests near Vernal, Utah. 31,34 Process-water

production rates will depend on the characteristics of the in situ combustion process, and the properties of the tar sands in the formation.

The commercial application of in situ steam injection to produce $20,000 \mathrm{bbl} / \mathrm{d}$ of 0 il from tar sands may require anywhere from 0.67 to $20 \mathrm{bbls}$ of water for each barrel of oil produced according to "...best guesses on production requirements." 38 However, 5 bbls of water per barrel of 0 il is presently considered to be the most reasonable estimate. 38 This figure is supported by a calculation of the potential water consumption at the steaminjection experiment near Vernal, Utah. Under maximum operating conditions approximately 600 barrels of water $\left(95 \mathrm{~m}^{3}\right.$ or 0.08 af) and about 45 barrels of low-sulfur No. 6 fuel oil may be used each day by the steam generator. 35 If 1 barrel of fuel oil is used to produce 3 barrels of tar-sand product $0 i 1,4$ then more than 130 barrels of oil can theoretically be produced, and this corresponds to a water-consumption rate of about 4.5 barrels of water per 
barrel of 0 il produced. These figures suggest that a 20,000-bbl/d steaminjection process could require almost $1600 \mathrm{~m}^{3}$ of water per day $(1.3 \mathrm{af} / \mathrm{d})$. The precise amount of water that is needed will depend on the geophysical properties of a tar-sand reservoir, because these properties determine the amount of injected steam channelled away from the target area and the amount of water that can be recovered for recycling.

Many of the substantial tar-sand deposits in Utah where commercial in situ combustion or steam injection could be used are located in areas where only a small amount of water is available. 31,38 Therefore obtaining water for a combustion process may be difficult, and acquiring it for steaminjection may represent an even greater challenge. Complicating factors are water-quality requirements for process operation, legal water entitlements of competing interests such as agriculture or other energy-producing projects, and the difficulties in obtaining guarantees that the necessary volume of water will be available for the life of the project. 38

Some of the more creative water-development plans for supplying water for commercial in situ tar-sand projects include 38

- The transport of water from areas where it is available (e.g., surface streams or deep underground aquifers) to those areas where it is needed,

- The capture and storage of run-off water,

- The purchase of guaranteed water-rights from present owners,

- Detailed water exploration where limited data are avajlable,

- The conservation and recycling of available water to extend apparently inadequate water supplies to levels that could support development, and

- The request for water that may be planned for other projects such as oil-shale development.

Application of any or all of these plans will require careful consideration of the potential impacts that could result. These impacts may involve ecological habitat destruction, overdraft of ground water, and the removal of supplies of potable ground water from arid areas. Furthermore, tar-sand projects may restrict (or be restricted by) development of other industries in areas where available quantities of water are limited. 
Water contamination from in situ commercial development could also result from the following mechanisms $3 \overline{1}$ :

- Contamination of ground water from contact with drilling muds near the site of the drill hole. In addition, drilling muds that are left to form ponds on the surface represent a potential source of contamination to surface and shallow ground-water systems.

- Communication between adjacent aquifers as a result of drilling could lead to interruption of flow and contamination of one aquifer by another.

- An in situ combustion process can cause ground-water-quality degradation from migration of produced gases or process waters away from the burn area and into nearby aquifers. This contamination can be promoted by compressed-air-generated fractures that can create channels for transport of pollutants, or by water seepage or groundwater intrusion into retort areas.

- In situ steam injection may also be responsible for ground-water contamination from mechanisms such as migration of injection waters from the target zone into adjacent aquifers, and water seepage or ground-water intrusion into retort areas.

The federal and state underground injection control (UIC) programs that have been enacted will ensure that appropriate ground-water protection strategies and monitoring plans are employed to minimize many of the potential adverse impacts just described.

Process waters were sampled twice for the first in situ combustion field test (TS-IC): initially during the first four weeks of the field-test, and then 1 year later from the non-steam-cleaned monitoring wel1s. ${ }^{32}$ The average concentrations of constituents in these samples are presented in Table 14. Also presented in Table 14 are the concentrations of contaminants estimated to be in waters produced by the in situ steam-injection field test just completed near Vernal, Utah. 35 The applicable Drinking Water Standards, 51 and EPA recommended Multimedia Environmental Goals (MEG) for water quality based on human-health effects, ${ }^{40}$ are also presented in Table 14 for purposes of comparison. 
Those contaminants measured in the process waters sampled either during the first in situ combustion field test or one year later, that are equal to or exceed adopted or recommended safe drinking water standards or EPA recommended MEG values for ambient water quality are aluminum, ammonium (as $\mathrm{NH}_{3}$ ), arsenic, barium, boron, cadmium, chromium, cobalt, total dissolved solids, fluoride, iron, lead, lithium, magnesium, manganese, mercury, nickel, phosphorus, potassium (as $\mathrm{KOH}$ ), silver, and sulfate. Those contaminants found in high concentrations that do not have a corresponding standard are bicarbonate, calcium, chemical oxygen demand, total nitrogen, and total organic carbon. Unless controlled, such concentrations of these substances could lead to the deterioration of ground-water quality during commercial in situ activities.

The organic compounds that were identified ${ }^{31,32}$ in the produced waters from in situ combustion field tests include phenol, cresol, carboxylic acids in the $\mathrm{C}_{2}$ to $\mathrm{C}_{6}$ range, alcohols, lactones, and ketones. The $\mathrm{pH}$ was acidic during the experiment and neutral one year later.

The recently completed in situ steam-injection field test could produce worst-case concentrations of aluminum, ammonium (as $\mathrm{NH}_{3}$ ), boron, total dissolved solids, fluoride, iron, lead, magnesium, manganese, mercury, nickel, potassium (as $\mathrm{KOH}$ ), silver, and sulfate at levels equal to or exceeding either recommended or adopted drinking water standards or recommended MEG values. Elevated worst-case concentrations of bicarbonate, calcium, and total organic carbon were also predicted, ${ }^{35}$ and these levels could lead to further deterioration of ground-water quality. The estimated most-probable-case concentrations of many contaminants also exceed allowable recommended or adopted limits (Table 14).

The potential impacts on surface and ground waters from the accumulation of the nutrients, heavy metals, toxic organic compounds and other substances found in significant concentrations in process waters from in situ field tests can represent a serious environmental problem. However, further research is needed to identify the long-term effects, and the ecosystem-transport behavior of these contaminants before definitive conclusions can be drawn for specific tar-sand sites. 
Table 14. Concentrations of selected effluents in water from in situ tar-sand experiments: Comparison of experimental data with standards.

\begin{tabular}{|c|c|c|c|c|c|c|c|}
\hline \multirow[b]{3}{*}{ Constituents } & \multicolumn{2}{|c|}{$\begin{array}{l}\text { Composition of process } \\
\text { water from TS-1C in situ } \\
\text { Combustion field test }(\mathrm{ppm}) \mathrm{a}\end{array}$} & \multirow{2}{*}{\multicolumn{2}{|c|}{$\begin{array}{l}\text { Estimated composition of } \\
\text { produced water for the TS-1S } \\
\text { in situ steam-injection field } \\
\text { test }(\mathrm{mg} / \mathrm{x})^{b}\end{array}$}} & \multirow{2}{*}{\multicolumn{2}{|c|}{$\begin{array}{c}\text { Applicable drinking } \\
\text { water standardsc } \\
(\mathrm{mg} / \mathrm{x})\end{array}$}} & \multirow{3}{*}{$\begin{array}{l}M{ }^{d} \\
(m g / x)\end{array}$} \\
\hline & \multirow{2}{*}{$\begin{array}{l}\text { During } \\
\text { combustion }\end{array}$} & \multirow{2}{*}{$\begin{array}{l}1 \text { year after } \\
\text { combustion }^{f}\end{array}$} & & & & & \\
\hline & & & Worst case & Most probable case & Adopted & Recommended & \\
\hline Aluminum & 3 & & 0.6 & 0.4 & & & 0.07 \\
\hline Arsenic & 0.05 & 0.05 & 0.1 & $<0.02$ & 0.05 & & \\
\hline Barium & 0.5 & 1.1 & $<0.5$ & $<0.5$ & 1.0 & & \\
\hline Beryllium & 0.001 & & & & & & 0.004 \\
\hline Bicarbonate & 0 & 1400 & 350 & $200 \pm 100$ & & & \\
\hline Boron & 5 & 0.8 & 0.8 & 0.1 & & & 0.043 \\
\hline Cadmium & 0.01 & 0.01 & $<0.01$ & $<0.01$ & 0.01 & & \\
\hline Carbonate & 0 & 0 & 0 & 0 & & & \\
\hline Chemical oxygen demand & 37,000 & 1900 & 2000 & \pm 1000 & & & \\
\hline Chlorive & 75 & 50 & 190 & \pm 100 & & & \\
\hline Chromium & 0.1 & 0.1 & $<0.1$ & $<0.1$ & 0.05 & & \\
\hline Cobalt & 0.005 & & & & & & 0.0007 \\
\hline Copper & 0.01 & 0.08 & 0.03 & $<0.01$ & 1.0 & & \\
\hline Total dissolved solids & 1050 & 3300 & 6000 & \pm 200 & & 500 & \\
\hline Fluoride & 6 & 3 & 7 & $4 \pm 4$ & $1.4-2$ & & \\
\hline Gallium & 0.001 & & & & & & 0.04 \\
\hline Iron & 110 & 30 & 1.0 & 0 & 0.3 & & \\
\hline Lead & 0.1 & 0.2 & $<0.1$ & $<0.1$ & 0.05 & & \\
\hline Lithium & 0.001 & & & & & & 0.0003 \\
\hline Magnesium & 0.6 & 320 & 500 & $10 \pm 10$ & & 125 & \\
\hline Mercury & 0.002 & 0.001 & 0.007 & 0.002 & 0.002 & & \\
\hline Nickel & 0.1 & 0.1 & 0.4 & $<0.1$ & & & 0.001 \\
\hline Nitrate & & & & & $10^{i}$ & & \\
\hline Total nitrogen & 270 & 6 & 120 & 20 & & & \\
\hline Total organic carbon & 11,000 & & $600^{\mathrm{j}}$ & $250 \pm 250^{j}$ & & & \\
\hline
\end{tabular}


Table 14. (continued)

\begin{tabular}{|c|c|c|c|c|c|c|c|}
\hline \multirow[b]{3}{*}{ Constituents } & \multicolumn{2}{|c|}{$\begin{array}{l}\text { Composition of process } \\
\text { water from TS- } 1 C \text { in situ } \\
\text { Combustion field test (ppm)a }\end{array}$} & \multirow{2}{*}{\multicolumn{2}{|c|}{$\begin{array}{l}\text { Estimated composition of } \\
\text { produced water for the TS-1S } \\
\text { in situ steam-injection field } \\
\text { test }(\mathrm{mg} / \mathrm{x})^{\mathrm{b}}\end{array}$}} & \multirow{2}{*}{\multicolumn{2}{|c|}{$\begin{array}{l}\text { Applicable drinking } \\
\text { water standardsc } \\
(\mathrm{mg} / \mathrm{x})\end{array}$}} & \multirow{3}{*}{$\begin{array}{l}M E G^{d} \\
(m g / x)\end{array}$} \\
\hline & During & 1 year after & & & & & \\
\hline & combustion ${ }^{e}$ & combustion $^{f}$ & Worst case & Most probable case & Adopted & Recommended & \\
\hline $\mathrm{pH}$ & 3 & 7 & 7 & 7.3 & & & \\
\hline Phosphorus & 0.08 & & & & & & 0.001 \\
\hline Potassium & 0.5 & 170 & 130 & $50 \pm 50$ & & & $0.075^{k}$ \\
\hline Selenium & & $<0.001$ & 0.02 & $<0.005$ & 0.01 & & \\
\hline Silica & 14 & & & & & & \\
\hline Silicon & 0.3 & & & & & & \\
\hline Silver & 0.5 & 0.5 & $<0.1$ & $<0.1$ & 0.05 & & \\
\hline Sodium & 0.3 & 160 & 2000 & 1000 & & 270 & \\
\hline Stront ium & 0.003 & & & & & & 0.027 \\
\hline Sulfate & 90 & 1300 & 2500 & $750 \pm 500$ & 250 & & \\
\hline Titanium & 0.004 & & & & & & 0.083 \\
\hline Tungsten & 0.002 & & & & & & 0.014 \\
\hline Vanadium & 0.001 & & & & & & 0.007 \\
\hline$Z$ inc & 0.2 & & 0.6 & 0.05 & 5 & & \\
\hline Zirconium & 0.001 & & & & & & \\
\hline
\end{tabular}

\footnotetext{
a From Ref. 32.

b Constructed on the basis of laboratory steam tests, steam injection tests, and other information. From Ref. 35.

c From Ref. 51.

d U.S. Environmental Protection Agency Multimedia Environmental Goals (MEG) for ambient water quality are for estimated permissible concentrations based on human-health effects. 40

e Average of results from sample measurements made during 4-week lifespan of experiment.

$f$ Average of results from sample measurements made from wells not steam cleaned prior to sampling.

9 As $\mathrm{NH}_{3}$.

$h$ Range is given due to temperature dependence of concentration.

i As Nitrogen.

$\mathrm{j}$ Dissolved organic carbon.

${ }^{k}$ As $\mathrm{KOH}$.
} 
Waste Generation and Disposal. The most serious waste generation and disposal problem associated with in situ combustion and steam-injection processes involves the recovered process water and the sludges that precipitate from it. In addition, by-products resulting from the use of control technologies, such as sulfur-dioxide emission controls, will require disposal. Recovered process waters from the in situ research experiments near Vernal, Utah, are examined and then disposed of in approved landfills along with any waste sludges. 31,35 However, approved surface-disposal areas may not be conveniently located nor be able to handle the wastewater and sludge quantities produced by a particular commercial in situ tar-sand development. Furthermore, the environmental ramifications from surface disposal of waters and sludges may include significant emissions from the evaporation of light hydrocarbons, leaching of toxic agents concentrated in sludges, and potential fire hazards. All of these potential problems will need further investigation and analysis for specific in situ tar-sand projects. Such problems also need to be addressed in conjunction with regulations under Resource Conservation and Recovery Act (RCRA) legislation.

The potentially suitable alternatives to surface disposal of in situ tar-sand process-wastewaters, are underground injection 31 in areas where there is no potential underground source of drinking water, and clean-up and reuse of recovered process water. The latter technique would represent effective water management in areas of 1 imited water supply. Uses for cleaned-up water could include dust control, irrigation, 31 cooling water, and reinjection as steam. Feasibility studies are recommended to determine the levels of treatment required, treatment strategies needed, and related costs for proposed reuse strategies for recovered process waters from in situ tar-sand projects. Such systems and their costs may be similar to those already used by heavy-oil producers in Kern County, California.

Sludge deposits could be handled by cementing them within disposal areas to prevent transport of concentrated heavy metals and organic compounds.

Community Infrastructure. The potential size of the work-force needed to construct and operate either a 20,000-bbl/d commercial in situ combustion or steam-injection tar-sand oil-extraction system cannot be easily estimated at this time due to the early stage of development of these technologies. 
However, the effects on community infrastructure in a tar-sand resource area are expected to be significant if a substantial proportion of the work-force must come from outside the resource area. For instance, if the existing housing and public facilities and services are inadequate to accommodate the influx of population into the vicinity of an in situ tar-sand project, then a boom-town effect could result. The problems that would be created include adverse impacts on police and fire protection, schools, medical care, utilities and sanitation.

There is already available evidence to suggest that the commercial application of in situ technologies near Vernal, Utah, could adversely strain the existing community infrastructure and fiscal resources in that area. For example, the population of the Uinta Basin in Utah from which the work-force could be drawn is only about 33,000 according to recent estimates. 41 This population does not appear to be sufficient to sustain development of a commercial tar-sand industry. Supporting this conclusion is the fact that there is already a rapid increase in mobile homes in Uintah County from a population influx that is attributed to accelerated growth in the oil industry in that region. 31 Moreover the city of Vernal (the county seat for Uintah County), which is within seven miles of the site of present in situ tar-sand field testing (see Figure 1), currently has an inadequate sewage-disposal system. This system was designed for a population of 6000 and has recently had to accommodate more than 7000 residents. 31 Preliminary indications are that Vernal is also experiencing a shortage of rental-housing units. 31 Furthermore, officials of the Uintah County School District indicate that existing schools cannot satisfactorily accommodate a substantial increase in the number of school children. 31 Finally, according to a recent survey of community attitudes, residents also perceive an immediate need for improved streets and roads, better water, and more water. 31

Although tar-sand development could result in adverse socioeconomic impacts, efforts are under way to mitigate some of the problems. For instance, expansion of the sewage-treatment facility in Vernal is already being planned, and planning studies are being performed to evaluate other areas of concern and to determine appropriate measures of mitigation. 
Conclusions from a study considering the socioeconomic impacts from oil-shale development activities on rural communities in northwestern Colorado include the following ${ }^{52}$ :

- Existing community populations in northwest Colorado could increase by as much as five-fold by 1990 .

- Industry and/or state and federal government assistance may be necessary to establish adequate housing supplies for an emerging oil-shale industry.

- The expansion of existing human services and programs designed to prevent negative social impacts will require early implementation to meet new needs and increased demands.

- Uncertainties surrounding the schedule and magnitude of oil-shale development conflict with the timely implementation of growthmanagement plans.

The information concerning socioeconomic issues related to development of tar-sand technologies near Vernal, Utah, and oil-shale technologies in the northwest region of Colorado strongly suggests the following. Rural areas that have undergone slow historical rates of change, like those of Utah and Colorado, are highly susceptible to serious socioeconomic impacts from development of emerging energy technologies. Therefore, to mitigate these problems advance planning has to be initiated and uncertainties concerning development plans must be reduced.

\section{ELABORATION OF SOCIOECONOMIC CONSIDERATIONS}

The complete spectrum of potential socioeconomic impacts that can be produced by commercial application of tar-sand technologies is illustrated by directly comparing the most pertinent characteristics of Kern county, California, with those of Uintah County in the Uinta Basin of Utah. This comparison is significant because both Kern County and Uintah County are possible sites for the commercial application of tar-sand technologies, but they possess different socioeconomic characteristics. 
The population of Kern County for 1980 has been projected to be about 366,000 people. 26 According to a recent estimate, the entire Uinta Basin, a three-county area that includes Uintah, Duchesne, and Daggett Counties, has a population of only about 33,000 people, 41 or less than one-tenth the population of Kern County.

The Kern County population is believed to be able to provide most of the skilled workers necessary to construct and operate the commercial tar-sand technologies planned for that area. 26 This is not likely to be the case in Uintah County or the Uinta Basin in general, because projections for that area suggest that energy-development activities already well along in planning and preparation could produce a population increase of nearly 27,000 people by 1988. 41 Tar-sand development, which was not considered in the Uinta Basin projections, would therefore add to the projected population increase.

The small population increase expected from tar-sand technology commercialization in Kern County will probably not be sufficient to adversely impact housing and public infrastructure. Tar-sand commercialization near Vernal, Utah, could, however, adversely impact an already inadequate sewagesystem, housing situation, school-system, and water-supply; as well as other services in the community. 31 These facts emphasize the dramatic differences between the two tar-sand development areas.

The previous information also indicates that proper forecasting and planning are needed not only to mitigate the problems that may be created for rural areas, such as Uintah County, but also to evaluate the extent of the benefits that might result from increased revenues. To accomplish these tasks, key issues need to be addressed by the decision makers responsible for selecting the strategies that will be used to manage changes in community infrastructure. These issues have been defined for rural communities in northwestern Colorado and are applicable for other rural areas as well. They include 52

- The scope and pace of new development activity,

- The location of growth (i.e., in the core of an existing community, or in a new community),

- The methodology for responding to socioeconomic impacts (i.e., a proactive response or program of anticipatory prevention vs a reactive or after-the-fact response), 
- The amount of lead-time available for instituting programs designed to manage changes before impacts begin,

- The selection and organization of a human-impact planning body, and specifications concerning its affiliation with government and the extent of its authority, and

- The allocation of resources for programs designed to manage changes, and related to this, decisions concerning (1) Who bears the cost? (2) Who determines appropriate expenditures? and (3) How is responsibility assigned?

Careful consideration of each topic will help to resolve potential major socioeconomic impacts.

\section{ENVIRONMENTAL CONTROL TECHNOLOGIES}

In previous sections of this report the available data concerning the release of potential air, land, and water pollutants were presented. The specific air-pollution-control measures being considered for reducing criteria-pollutant atmospheric emissions from tar-sand facilities were also identified. Furthermore, the regulatory framework affecting the development of a tar-sand industry was briefly described. In this section, some major environmental control technologies that may be suitable for tar-sand technologies are summarized. Wherever possible their effectiveness and readiness for implementation are indicated, and an estimate of cost is provided.

The readiness of a control technology for implementation is defined here as the confidence of developers that an effective methodology can be transferred directly from other industries without extensive research, development, and modification. Wherever feasible, costs are expressed in terms of dollars per barrel of oil produced, and are presented for complete air, land, or water pollution control systems that could be used with commercial tar-sand processes. These costs are estimated on the basis of projections for other industries (notably oil shale). The costs of pollution control for tar-sand projects can be influenced by many factors, especially: (1) project lifetime, (2) facility design, (3) scale of operation, and (4) the amount of emission-removal efficiency desired or required by environmental standards. However, the cost estimates presented are considered to be 
accurate to within a factor of two, and appear to be of minor economic importance now that domestic oil prices have increased to more than $\$ 23 / b b 1$ at the well-head, and the most expensive imported oil (i.e., Algerian, Libyan, Nigerian) has a landed cost exceeding $\$ 40 / \mathrm{bb} 1.53$ Furthermore, it appears that oil prices will continue to increase at a rate no less than that of inflation, depending of course on world economic activity, supply interruptions, major discoveries and synfüels development. This economic situation makes environmental control costs for commercial tar-sand projects less of an issue.

Several factors will need to be considered to determine the suitability of a particular environmental-control strategy for tar-sand oil-recovery technologies. These factors and considerations include

- Characteristics of the untreated emission streams,

- Emission levels allowed by environmental regulatory standards,

- Products desired from the tar-sand facility and the emission-control process,

- Availability and costs of water and electrical power to operate a pollution-control system,

- Land availability for solid-waste disposal of the by-products from pollution-control systems,

- Reliability of a pollution-control system, and

- Labor, material, and maintenance requirements for operating the system.

Therefore it is important to recognize that the compatability of a particular pollution-control system with a specific tar-sand technology is ultimately process dependent and for the most part site specific.

Atmospheric Emission Controls

The air-pollution-control technologies that are possible choices for reducing criteria-pollutant and hydrogen-sulfide emissions from proposed commercial oil-shale processes are also candidate control technologies for tar-sand operations. These control systems are presented in Table 15, along with their efficiency and readiness, and other pertinent information. 
Table 15. Air-pollution-control systems potentially suitable for reducing emissions of criteria pollutants (i.e., TSP, $\mathrm{SO}_{2}, \mathrm{NO} \mathrm{x}_{x}, \mathrm{HC}$, and $\mathrm{CO}$ ) and $\mathrm{H}_{2} \mathrm{~S}$ from commercial tar-sand projects. ${ }^{\mathrm{a}}$

\begin{tabular}{llll}
\hline $\begin{array}{l}\text { Air-pollution- } \\
\text { control system }\end{array}$ & $\begin{array}{c}\text { Efficiency } \\
\text { (\% emissions reduction) }\end{array}$ & $\begin{array}{c}\text { of thess } \\
\text { of thechology }\end{array}$ & $\begin{array}{c}\text { Other } \\
\text { considerations }\end{array}$ \\
\hline
\end{tabular}

\section{POLLUTANT: Total suspended particulates (TSP)}

\begin{tabular}{|c|c|c|c|}
\hline Water sprays & 80 to 98 for particles $>5 \mu$ & High & $\begin{array}{l}\text { Additives such as } \\
\text { wetting agents and } \\
\text { chemical binders } \\
\text { improve efficiency }\end{array}$ \\
\hline $\begin{array}{l}\text { Cyclone } \\
\text { separators }\end{array}$ & $\begin{array}{l}\text { Up to } 90 \text { for large particles, and } \\
\text { Up to } 50 \text { for particles }<10 \mu\end{array}$ & High & \\
\hline Scrubbers & 93.6 to 99.8 for particles $<5 \mu$ & High & Little maintenance \\
\hline Baghouse filters & Up to 99 for particles $\geq 1 \mu$ & Medium & Moderate maintenance \\
\hline $\begin{array}{l}\text { Electrostatic } \\
\text { precipitators }\end{array}$ & Up to 99.9 & $\begin{array}{l}\text { Low to } \\
\text { medium }\end{array}$ & Little maintenance \\
\hline
\end{tabular}

POLLUTANT: Sulfur dioxide $\left(\mathrm{SO}_{2}\right)$

\begin{tabular}{lccl}
\hline $\begin{array}{c}\text { Wellman-Lord } \\
\text { process }\end{array}$ & About $90^{\mathrm{b}}$ & Medium & Sludge disposal \\
$\begin{array}{c}\text { Double alkali } \\
\begin{array}{c}\text { Nahcolite-ore } \\
\text { process }\end{array}\end{array}$ & Greater than 99 for $\left[\mathrm{SO}_{2}\right]<10 \mathrm{ppm}$ & Medium & Sludge disposal \\
& Low 80 & $\begin{array}{l}\text { Experimental } \\
\text { technology. Efficiency } \\
\text { is a function of flow } \\
\text { rate and ratio of } \\
\text { Nahcolite to SO2. }\end{array}$ \\
\hline
\end{tabular}

POLLUTANT: Hydrocarbon (HC) and carbon monoxide (CO)

Combustion control
Evaporation control
Control of fugitive emissions

$\begin{array}{ll}\text { High } & \begin{array}{l}\text { Use of excess air for } \\ \text { complete combustion } \\ \text { easily accomplished, } \\ \text { but careful maintenance } \\ \text { necessary. }\end{array} \\ \text { High } & \begin{array}{l}\text { Floating roof tanks } \\ \text { accommodate high vapor } \\ \text { pressure without need } \\ \text { for venting. }\end{array} \\ \text { Low } & \begin{array}{l}\text { Difficult due to large } \\ \text { number of dispersed } \\ \text { sources. }\end{array}\end{array}$


Table 15. (continued) Air-pollution-control systems potentially suitable for reducing emissions of criteria pollutants (i.e., $\mathrm{TSP}, \mathrm{SO}_{2}, \mathrm{NO}_{x}, \mathrm{HC}$, and $\mathrm{CO}$ ) and $\mathrm{H}_{2} \mathrm{~S}$ from commercial tar-sand projects. ${ }^{\mathrm{a}}$

\begin{tabular}{lccl}
\hline $\begin{array}{c}\text { Air-pollution- } \\
\text { control system }\end{array}$ & $\begin{array}{c}\text { Efficiency } \\
\text { (\% emissions reduction) }\end{array}$ & $\begin{array}{c}\text { Readiness } \\
\text { of the } \\
\text { technology }\end{array}$ & $\begin{array}{c}\text { other } \\
\text { considerations }\end{array}$ \\
\hline $\begin{array}{l}\text { Combustion } \\
\text { control }\end{array}$ & $\begin{array}{c}\text { Can achieve compliance with } \\
\text { regulations }\end{array}$ & High & $\begin{array}{c}\text { Supplemental gas } \\
\text { cleaning systems can be } \\
\text { added if necessary. }\end{array}$ \\
$\begin{array}{c}\text { Diesel-exhaust } \\
\text { control }\end{array}$ & $\begin{array}{c}\text { Can achieve compliance with } \\
\text { regulations }\end{array}$ & Medium & $\begin{array}{l}\text { Recirculation of exhaust } \\
\text { gases can produce } \\
\text { maintenance problems. }\end{array}$ \\
\hline
\end{tabular}

POLLUTANT: Hydrogen sulfide $\left(\mathrm{H}_{2} \mathrm{~S}\right)$

Stretford process

Selexol and other physical absorption

processes

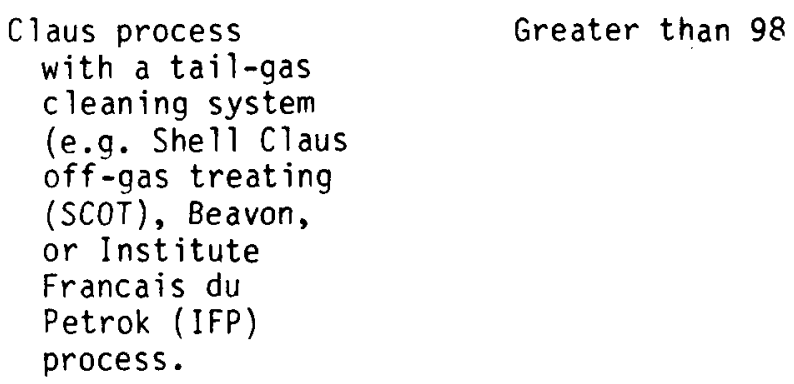

Greater than 98

Greater than 98
Medium

Up to 99.9
High
High chemical make-up

costs. If $\mathrm{COS}$, and $\mathrm{CS}_{2}$ are present, then pretreatment will be necessary to remove them to prevent their interference with $\mathrm{H}_{2} \mathrm{~S}$ removal.

Medium

Long experience by industry but downt ime and maintenance problems exist and back-up units are required.

a Data taken from Ref. 54, pp. 269-276.

b From Ref. 55, p. 210. 
Many of these systems are already being operated successfully in the utility and petroleum industries. The costs of an atmospheric-emission control system that could reduce fugitive dust by $92.2 \%$; particulates by 99.5\%; $\mathrm{SO}_{2}$ by $99.0 \%$; $\mathrm{NO}_{x}$ by the maximum amount (using combustion control); and $\mathrm{HC}$ and $\mathrm{CO}$ by 50.5 to $89.0 \%$ have been estimated for commercial oil-shale processes. 54 According to this estimate the overall cost to control only these criteria pollutants would range from $\$ 0.92$ to $\$ 1.16$ per barrel of shale-oil produced. 54 This range also appears to be reasonable for the tar-sand technologies considered for commercialization at this time.

Another atmospheric-emission-control process is on the horizon for the in situ steam-injection tar-sand oil-recovery technology, specifically. This process uses a downhole steam-generator. The downhole steam-generator is currently being developed by both the U.S. Department of Energy and private companies to recover heavy oil from formations at or below $2500 \mathrm{ft}$. Present steam-delivery systems use steam produced by low-pressure steam-boilers and are limited to shallow reservoirs (< $2500 \mathrm{ft}$ ) because of heat transmission losses at greater depths. ${ }^{56}$ Application of a downhole steam-generator to heavy-oil or tar-sand reservoirs will also limit the use of these low-pressure steam boilers that now require expensive $\mathrm{SO}_{2}$ scrubbers and other airpollution-control devices in order to meet state and federal ambientair-quality standards.

The downhole-steam-generator being developed and tested by Sandia National Laboratories is designed to fit down a 7-inch-diameter well casing. Hoses conduct fuel (currently propane or diesel), compressed air (commonly 200 to 300 psig above reservoir pressure), water (at ambient temperature and about 150 psig above the compressed air injection pressure), and electricity (for ignition and monitoring devices) from the surface to the underground generator. 57 The Sandia model of the downhole steam-generator is a non-vented high-pressure system that is designed to limit the amount of criteria pollutants that escape to the atmosphere. Other versions of the downhole steam-generator are being developed by Rocketdyne 57 and Petrosteam. 58 These systems are purposely designed to vent their gases so that reduced pressures can be employed because the cost of compressing air can be very high. However, the vented downhole steam-generator requires that gas collection systems for well-heads be both effective and relatively inexpensive. 
Ideally, the non-vented high-pressure downhole steam-generator being developed by Sandia National Laboratories will inject all of the produced exhaust products into the reservoir with the steam it produces. Further studies will be needed to ensure that significant quantities of exhaust products do not escape to the atmosphere through fissures, or observation- or production-wells. Testing and evaluation are now underway to prove that emission-rates for a non-vented high-pressure downhole-steam-generation system will be well within allowable regulatory standards and far below rates now produced by surface steam boilers. The estimated uncontrolled emission-rates of criteria pollutants from a prototype $5 \times 10^{6} \mathrm{Btu} / \mathrm{h}$ downhole steamgenerator using $1 \%$ sulfur (by wt) lease crude oil are presented in Table 16. It is presumed that these emissions can be injected with the produced steam into a reservoir and will not be emitted into the atmosphere unless venting occurs through fissures or observation- and production-wells. ${ }^{59}$ Venting, however, is presumed to be of minimal concern because it can probably be prevented or its effects mitigated.

Table 16. Estimated uncontrolled emissions from a prototype 5-MBtu/h downhole steam-generator. ${ }^{a}$

\begin{tabular}{ll}
\hline Pollutant & Emission rate $(\mathrm{lbs} / \mathrm{h})$ \\
\hline $\mathrm{SO}_{2}$ & 6.0 \\
$\mathrm{NO}_{2}$ & 2.3 \\
$\mathrm{TSP}$ & 0.5 \\
$\mathrm{HC}$ & 0.05 \\
$\mathrm{CO}$ & 0.02
\end{tabular}

Data taken from Ref. 59, p. 9.

The costs associated with the downhole steam-generator and its associated equipment are difficult to predict at this time of early development. Furthermore, "Final reliable cost estimates for a site-specific project can 
only be made by the lease operator's professional cost-estimator after quotations have been received from vendors. "56 However, preliminary estimates tabulated by researchers at Sandia National Laboratories (see Appendix C) indicate that the capital required for a $10-\mathrm{MBt} / \mathrm{h}$ non-vented downhole steam-delivery system could be $\$ 1,150,500$, and the annual operating cost could be $\$ 1,240,000$ (see Tables $C-1$, and $C-2$ ). 56 The precision of the estimates probably ranges from " $-35 \%$ to $+25 \%$." 56

Water Pollution Control Methodologies

Some of the general categories of potential contaminants expected in wastewater streams from commercial tar-sand processes, and suitable control methods are presented in Table 17. This table was adapted from one included in a report prepared by the Congressional office of Technology Assessment that deals with oil-shale development in the U.S. 54 Included in Table 17 are the removal efficiencies, reliabilities, and adaptabilities of the prospective water-pollution-control methods for oil-shale projects. These are considered to be relatively the same for commercial tar-sand technologies.

The water-pollution-control techniques for removing contaminants have not been tested specifically on oil-shale processes or tar-sand technologies being developed in the United States. Therefore, the effectiveness of these systems needs further evaluation. In addition, some of the methods described in Table 17 may also be suitable for removing (1) trace elements and metals, (2) trace organic compounds, (3) toxic substances, and, of course, (4) sanitary wastes; but the efficiency, reliability, and adaptability of these methods will require further analyses. The total cost of a complete water-treatment system for an oil-shale process may range from approximately $\$ 0.25 / \mathrm{bb} 1$ to about $\$ 1.25 / \mathrm{bb} 1$ of syncrude produced. These costs will depend on the system used, and appear to be lower for above-ground technologies. This estimated cost range should be about the same for commercial tar-sand technologies.

The ultimate disposition of tar-sand wastewater after treatment is likely to be recycling, evaporation, irrigation use, or injection depending on the control system chosen, and what is allowable according to regulations. Additional analyses need to be performed to determine if water-pollutioncontrol strategies should be employed to remove leachates contained in water 
Table 17. Water-pollution control technologies potentially suitable for removing contaminants from wastewater streams produced by commercial tar-sand oil-recovery processes. ${ }^{a}$

\begin{tabular}{|c|c|c|c|c|}
\hline Contaminant & Technology & $\begin{array}{c}\text { Removal efficiency } \\
(\%)\end{array}$ & $\begin{array}{l}\text { Relative } \\
\text { reliability }\end{array}$ & $\begin{array}{c}\text { Relative } \\
\text { adaptability }\end{array}$ \\
\hline $\begin{array}{l}0 i 1 \text { and } \\
\text { grease }\end{array}$ & $\begin{array}{l}\text { Dissolved air flotatio } \\
\text { Coalescing filter } \\
\text { Clarification }\end{array}$ & $\begin{array}{l}90 \\
99 \\
80\end{array}$ & $\begin{array}{l}\text { Very high } \\
\text { High } \\
\text { Very high }\end{array}$ & $\begin{array}{l}\text { Very high } \\
\text { High } \\
\text { Very high }\end{array}$ \\
\hline $\begin{array}{l}\text { Dissolved } \\
\text { gases }\end{array}$ & $\begin{array}{l}\text { Air stripping } \\
\text { Steam stripping } \\
\text { Flue-gas stripping } \\
\text { Biological oxidation }\end{array}$ & $\begin{array}{r}80 \\
95 \\
95 \\
\text { High }\end{array}$ & $\begin{array}{l}\text { High } \\
\text { Very high } \\
\text { High } \\
\text { Medium }\end{array}$ & $\begin{array}{l}\text { High } \\
\text { High } \\
\text { Medium } \\
\text { Medium }\end{array}$ \\
\hline $\begin{array}{l}\text { Dissolved } \\
\text { organic } \\
\text { compounds }\end{array}$ & $\begin{array}{l}\text { Activated sludge } \\
\text { Trickling filter } \\
\text { Aerated lagoon } \\
\text { Rotating contactor } \\
\text { Anaerobic digestion } \\
\text { Wet air oxidation } \\
\text { Photolytic oxidation } \\
\text { Carbon adsorption } \\
\text { Chemical oxidation } \\
\text { Electrolytic oxidation }\end{array}$ & $\begin{array}{ll}95 & \mathrm{BOD}^{\mathrm{b}} / 40 \text { CODC } \\
85 & \mathrm{BOD} \\
80 & \mathrm{BOD} \\
90 & \mathrm{BOD} / 20 \text { to } 50 \mathrm{COD} \\
60 \text { to } 95 \mathrm{BOD} \\
64 \mathrm{BOD} / 74 \mathrm{COD} \\
99 \mathrm{BOD} \\
99 \mathrm{BOD} \\
90 \mathrm{BOD} / 90 \mathrm{COD} \\
95 \mathrm{BOD} / 61 \mathrm{COD}\end{array}$ & $\begin{array}{l}\text { High } \\
\text { High } \\
\text { Medium } \\
\text { D High } \\
\text { High } \\
\text { Medium } \\
\text { Medium } \\
\text { Medium } \\
\text { Very high } \\
\text { Medium }\end{array}$ & $\begin{array}{l}\text { Medium } \\
\text { Medium } \\
\text { Medium } \\
\text { Medium } \\
\text { Medium } \\
\text { High } \\
\text { Very high } \\
\text { High } \\
\text { Very high } \\
\text { Very high }\end{array}$ \\
\hline $\begin{array}{l}\text { Suspended } \\
\text { solids }\end{array}$ & $\begin{array}{l}\text { Clarification } \\
\text { Pressure filtration } \\
\text { Multimedia filtration }\end{array}$ & $\begin{array}{l}50 \\
95 \\
95\end{array}$ & $\begin{array}{l}\text { High } \\
\text { High } \\
\text { Very high }\end{array}$ & $\begin{array}{l}\text { High } \\
\text { High } \\
\text { High }\end{array}$ \\
\hline $\begin{array}{l}\text { Dissolved } \\
\text { solids }\end{array}$ & $\begin{array}{l}\text { Clarification } \\
\text { Distillation } \\
\text { Reverse osmosis } \\
\text { Ion exchange } \\
\text { Electrodialysis }\end{array}$ & $\begin{array}{c}\text { Low except for metals } \\
99 \\
60 \text { to } 95 \\
\text { High } \\
10 \text { to } 40\end{array}$ & $\begin{array}{l}\text { S High } \\
\text { Medium } \\
\text { Medium } \\
\text { High } \\
\text { Medium }\end{array}$ & $\begin{array}{l}\text { Medium } \\
\text { Low } \\
\text { Medium } \\
\text { Low } \\
\text { Medium }\end{array}$ \\
\hline Sludges & $\begin{array}{l}\text { Thickening } \\
\text { Anaerobic digestion } \\
\text { Vacuum filtration } \\
\text { Sludge drying beds } \\
\text { Evaporation basins } \\
\text { Filter press } \\
\text { Aerobic digestion }\end{array}$ & $\begin{array}{c}\text { Product } 6 \text { to } 8 \text { solids } \\
\text { Low } \\
\text { Product } 20 \text { to } 35 \text { solids } \\
\text { Product } 90 \text { solids } \\
\text { Product } 95 \text { solids } \\
\text { Product } 35 \text { solids } \\
\text { Low }\end{array}$ & $\begin{array}{l}\text { Very high } \\
\text { High } \\
\text { s High } \\
\text { Medium } \\
\text { Very high } \\
\text { Very high } \\
\text { Low }\end{array}$ & $\begin{array}{l}\text { High } \\
\text { Medium } \\
\text { High } \\
\text { Low } \\
\text { Low } \\
\text { High } \\
\text { Low }\end{array}$ \\
\hline
\end{tabular}

\footnotetext{
a Data taken from Table 63 , in Ref. 54 , p. 306.

b BOD: Biochemical 0xygen Demand

C COD: Chemical Oxygen Demand
} 
drainage from surface-stored raw and spent ore; and, if abandoned tar-sand reservoirs where in situ technologies took place need to be dewatered and wastewater treatment then applied. The need for long-term monitoring and custodial care should also be evaluated on a site-specific basis in order to guarantee that water quality can be protected.

\section{Land Preservation and Reclamation}

The location, scale, and type of tar-sand technology used will determine its impact on the land. These impacts may include alteration of landscape (topographic changes), interference with wildlife, and air and water pollution. To minimize impacts at any site, methods must be employed to restore disturbed land effectively so that erosion can be controlled and the leaching of solid waste can be mitigated. Depending on the technology, the severest impacts from ineffective land reclamation and preservation can be

- Wildlife extinction,

- Loss of biological productivity on a land surface,

- Air and water quality deterioration from erosion and leaching,

- Subsidence, or

- Seismicity.

Reclamation activities to avoid, minimize, or repair significant environmental impacts from land disturbance include

- Reducing surface waste-disposal by burying waste as backfill or placing it into in situ reservoirs;

- Reducing erosion from waste and spent-ore-storage piles by using biodegradable chemical stabilizers, which will not interfere with seed germination, to temporarily bind particles together until revegetation occurs;

- Using revegetation to reduce overland flow of water and sediments, increase water infiltration, provide food and shelter for returning wildlife, and ameliorate microclimatic conditions, wind erosion, and extremes in soil temperatures; and 
- Landscaping the terrain to its original or an improved state to minimize impacts on wildlife and restore or perhaps even achieve better grazing or agricultural production.

Cost will depend on the extent and complexity of reclamation required and will include the quantity and type of chemical binders and soil amendments that are needed and the equipment and man-power demanded. These costs will also depend on the site that is chosen and the tar-sand technology that is employed. Average costs of reclamation for oil-shale development are estimated to range from $\$ 4,000$ to $\$ 10,000$ per acre, and the costs of reclamation for a 50,000-bbl/d oil-shale project where only surface disposal of waste is used are estimated to range from about 1 to 4 cents per bbl of shale oil. 54 These costs will probably be similar for tar-sand projects.

\section{RISK ASSESSMENT}

Essential to the development of any new energy technology is early consideration of the potential environmental, occupational, health, and safety problems that could be encountered as a result of commercialization. Early identification and understanding of these problems permit developers adequate lead time for sufficiently evaluating the hazards and formulating, testing, and instituting appropriate mitigating measures.

The purpose of this section is to focus attention on potentially serious risks associated with commercial development of tar-sand technologies. Focusing attention on these potential risks will facilitate early planning and execution of efforts to reduce these risks and the subsequent costs to society. The approach taken to accomplish this purpose is to express the potential risks as the likelihood-of-occurrence of possible effects that could result from the operation of representative 20,000-bbl/d commercial surface and in situ technologies. The possible effects and the numerical values indicating their likelihood-of-occurrence are presented in Table 18. The numerical values were subjectively derived from

- Historical information regarding observed health and safety effects reported during development of other emerging energy technologies, 
Table 18. Likelihood-of-occurrence of effects from the operation of commercial tar-sand oil-recovery procedures.

\begin{tabular}{lll}
\hline Possible effects & $\frac{\text { Effect according to process }}{\text { Surface }}$ \\
extraction & $\frac{\text { In situ }}{\text { recovery }}$
\end{tabular}

$\begin{array}{lll}\begin{array}{l}\text { Airborne effluents: } \\ \text { Public health }\end{array} & 2 & 2 \\ \quad \text { Ecosystems } & 2 & 2 \\ \begin{array}{l}\text { Surface water contamination: } \\ \text { Public health } \\ \text { Ecosystems }\end{array} & 1 & 1 \\ \begin{array}{l}\text { Ground water contamination: } \\ \quad \text { Public health }\end{array} & 1 & 2 \\ \begin{array}{l}\text { Land subsidence } \\ \text { Induced seismicity }\end{array} & 2 & 2 \\ \begin{array}{l}\text { Land surface contamination: } \\ \text { Public health } \\ \text { Ecosystems }\end{array} & \text { NA } & 1 \\ \text { Worker health } & 2 & 1 \\ \end{array}$

Key: 3 - Effect likely to occur based upon experience in other industries. 2 - Effect may occur but will be localized and/or controllable.

1 - Effect possible but uniikely to occur. NA - Not applicable.

- Experience in other industries where the existence of occupational, environmental, health, and safety impacts were detected and mitigating measures were instituted,

- Data from Canadian surface hot-water-extraction processes concerning occupational health and safety, 
- Projected data for the potential effects from 20,000-bbl/d commercial surface retort and solvent tar-sand petroleum-extraction facilities proposed for use near Mckittrick, California, and

- Speculative assumptions pertaining to the potential hazards associated with 20,000-bbl/d commercial in situ combustion and steam-injection projects based on data from field tests conducted near Vernal, Utah.

The numerical values are quantified in Table 18 according to the likelihood that

- An effect will occur based upon experience in other industries, Key $=3$;

- An effect may occur, but will be localized and/or controllable thereby reducing its severity, Key = 2;

- An effect is possible but probably will not result, key $=1$.

Naturally there are uncertainties associated with the subjectively determined numerical values introduced in Table 18 for the occurrence of possible effects from commercial tar-sand technologies. These uncertainties are related to

- The early stage of development of tar-sand technologies,

- The overall efficacy of changes in process design vs retrofit additions for achieving environmental protection and ensuring occupational health and safety,

- The preparedness of commercial tar-sand facilities for effectively protecting the environment and workers from hazards unique to tar-sand technologies, and

- The combined influence of regulatory standards and economic factors on the development of an environmentally acceptable tar-sand industry.

Due to the early stage of development of tar-sand technologies in the United States, only limited data are available regarding the release of potential contaminants from surface and in situ processes. As more field testing is performed, analysis of the accumulated data will lead to process 
changes to improve recovery efficiencies and the environmental acceptability of the technologies. Such changes can affect the likelihood-of-occurrence of a particular impact described in Table 18.

The nature of the U.S. tar-sand industry at this time suggests that technology commercialization will probably occur in phases. Thus, once first-generation commercial tar-sand facilities are completed and operating, it will be more economical for developers to meet new regulatory standards and ameliorate newly detected occupational and environmental health and safety impacts by the addition of "retrofit" strategies. Developers of second-generation facilities will, however, be able to incorporate such strategies into their engineering process designs. Evidence from the geothermal power industry indicates that the application of retrofitted control mechanisms can create additional problems, whereas design changes are more effective and desirable. For instance, at The Geysers known Geothermal Resource Area (KGRA) in northern California the first method employed for abatement of $\mathrm{H}_{2} \mathrm{~S}$ atmospheric emissions consisted of converting the cooling tower to a reaction chamber for oxidixing $\mathrm{H}_{2} \mathrm{~S}$ to elemental suifur. 60 This first attempt at reducing $\mathrm{H}_{2} \mathrm{~S}$ emissions caused increased maintenance problems and generated a sludge that collected in the bottom of the cooling tower and required periodic removal. 60,61 Worker health and safety problems then resulted from employee contact with the sludge during cooling tower maintenance and cleaning activities. This abatement method is believed to be solely responsible for a 10-fold increase in reported occupational illnesses for the geothermal industry. 61 The reduction of air emissions of $\mathrm{H}_{2} \mathrm{~S}$ was therefore achieved at the expense of worker health and safety. Later geothermal units were built with a design change for abatement of $\mathrm{H}_{2} \mathrm{~S}$. This change achieved more effective emission control, and improved industrial hygiene by limiting worker contact with the hazardous agents.

The occupational, environmental, health, and safety effects that could result from commercialization of tar-sand technologies may be analogous to those that are already being routinely mitigated in more established industries (e.g., chemical manufacturing). However, due to the emerging status of tar-sand technologies, the circumstances that could produce such effects may not be anticipated and therefore the effective mitigating measures may not be adopted. An example from oil-shale development activities in the 
Estonian Soviet Socialist Republic illustrates this point. Epidemiologic data and hygienic studies strongly suggest that an excess incidence of skin cancer among workers, particularly women, in the emerging oil-shale industry of the Estonian Soviet Socialist Republic is occupationally related. 62

The studies of Estonian oil-shale-workers are based on observed incidence rates in the 35- to 74-age range for the period from 1959 through 1975. These studies specifically indicate that workers exposed to $0 i 1$ shale processing products have a skin-cancer incidence rate three (male) to five (female) times higher than in a control population of urban dwellers. This rise in the incidence of skin cancer among the workers appears to be correlated with length of service in the oil-shale industry. 62

If the developers had anticipated the occurrence of this problem, measures used routinely in the chemical manufacturing industry to protect workers from toxic substances might have been instituted. This action presumably could have significantly reduced the incidence of skin cancer at an earlier point in the development of the industry. U.S. developers of both oil-shale and tar-sand technologies can learn from the Estonian experience, and act early to reduce the likelihood of skin cancer.

Finally, the combination of regulatory standards and petroleum costs will influence tar-sand-technology commercialization. That is, unless developers can realize what they perceive to be a reasonable return on the ir investment after controls are installed, they will not construct new commercial facilities and may close down the ones that have been built. A situation like this occurred in Kern County, California, when oil companies were confronted with a regulation for air-pollutant emissions from steam boilers used in thermal oil-recovery. Regulatory compliance necessitated the institution of improved air-pollution-control equipment. The equipment was initially considered by the industry to be too expensive relative to the price of $0 i 1$, which at that time was about $\$ 4 / b b 1$. Many companies were considering closing their fields. However, as oil prices began to rise the industry was better able to afford to upgrade its air-pollution-control equipment to meet standards. For tar-sand technologies this type of scenario is unlikely because oil prices continue to increase and improve the affordability of controls. Nevertheless, peculiarities of tar-sand technologies could require 
development of more expensive controls that may not be considered economically feasible until oil prices exceed even current levels. These circumstances can be a constraining influence on development.

For the above reasons, the values for likelihood-of-occurrence of possible effects from commercial application of surface and in situ tar-sand technologies are meant to be interpreted only as indicators of potential risks and to denote areas for further investigation. In addition, some of the subjectively determined values in Table 18 reflect the assumption that regulatory and recommended standards represent a threshold level above which adverse effects may result, and below which no adverse effects will occur. This, however, may not be the case for long-term exposure to low (i.e., sub-threshold) concentrations of some substances. Furthermore, if existing control devices are perceived to be effective, but turn out not to be because of the peculiar nature of the technology, additional uncertainties are transferred to the values presented in Table 18.

The nature of the uncertainties related to the subjectively determined values for likelihood-of-occurrence of possible effects from commercial surface and in situ tar-sand technologies has been discussed, and the supporting evidence from which the subjective values were determined will now be described for each of the general categories of possible effects presented in Table 18. Preliminary conclusions can then be drawn as to the environmental acceptability of tar-sand technologies.

\section{Atmospheric Effects}

The controlled emissions of criteria pollutants from a proposed commercial surface retort or solvent process are not expected to cause NAAQS to be exceeded (Tables 8 and 9). However, $\mathrm{SO}_{2}$ and TSP emissions may result in PSD increments being exceeded for Class II attainment areas. In that case $\mathrm{SO}_{2}$ and TSP emissions may need to be controlled further, perhaps by instituting process-design changes. It is anticipated that the public health and ecosystem effects of these controlled emissions will be localized or absent. Additional monitoring, modeling, and analysis are required, however, in order to ascertain the exact composition of the product gases from these processes. This will determine if other pollutants or hazardous substances 
will be emitted and if they should be controlled. This information will be essential for evaluating any potential adverse impacts on public health or ecosystems.

A comparison between standards and estimated ambient air concentrations produced by the uncontrolled emissions from a conceptual in situ combustion project (Table 11), and an in situ steam-injection process (Table 12) reveals that both procedures will require the application of control technologies. If the estimates of ambient-air-quality impacts from commercial operation of these emerging in situ technologies are correct, then there is a possibility that conventional emission-control technologies may not be effective in reducing some emissions to acceptable levels. For instance, a control technology that could be used to abate $\mathrm{H}_{2} \mathrm{~S}$ emissions from in situ combustion processes is the Stretford process. This process was originally designed for the removal of $\mathrm{H}_{2} \mathrm{~S}$ from synthetic fuel gases and is now being used in the geothermal industry where it has been demonstrated to remove at least $99 \%$ of the $\mathrm{H}_{2} \mathrm{~S}$ that enters the abatement system. ${ }^{63}$ Application of this high efficiency emission-control technology to in situ tar-sand projects may however still yield maximum ground-level concentrations of $\mathrm{H}_{2} \mathrm{~S}$ that could range from 60 to $100 \mu \mathrm{g} / \mathrm{m}^{3}$ (0.04 to $\left.0.07 \mathrm{ppmv}\right)$ for 24-hour and 1 - or 3-hour averaging times. These estimates are above the recommended MEG value for $\mathrm{H}_{2} \mathrm{~S}$ and could represent public health problems.

Control technologies for criteria pollutants may be more effective. For example, $\mathrm{SO}_{2}$ from a commercial in situ steam-injection process may be among the product gases that need to be reduced. If $97 \%$ control of $\mathrm{SO}_{2}$ can be achieved as is predicted for surface processes (Table 8), the $\mathrm{SO}_{2}$ concentration from steam injection may be only $25 \mu \mathrm{g} / \mathrm{m}^{3}$ for a 24 -hour averaging time. This concentration is lower than the NAAQS for $\mathrm{SO}_{2}$. This would also be the case if $90 \%$ control of $\mathrm{SO}_{2}$ is achieved. While this is a less optimistic value for the control efficiency of sulfur, it better reflects the average sulfur-control efficiency currently reported by the heavy-oil industry in Kern County. 47

For the above reasons additional research is needed to determine the exact nature of all of the atmospheric emissions from in situ processes, and the control technologies and alternative operating characteristics that can be used to reduce ambient-air-quality impacts to a minimum. Until such control 
methods and operating procedures are more accurately defined and implemented, the effect on public health should be regarded as potentially significant.

A preliminary estimate of the magnitude of the public-health impacts attributable to air pollution from commercial tar-sand facilities may be derived using a health-damage function available for $\mathrm{SO}_{2}$ emissions. Such public-health-damage functions for $\mathrm{SO}_{2}$ have been developed and utilized to determine an index of the public-health impacts that could result from all pollutants released by coal-conversion technologies used for electricity production. The health-damage functions that have been employed in the literature ${ }^{64,65}$ range from 0 to 0.68 and 0 to 0.80 premature deaths per 1000 tons of $\mathrm{SO}_{2}$ emitted. For the latter of these estimates the model assumes Gaussian plume dispersion, first order chemical reactions, a linear dose-response function and a population of $3 \times 10^{6}$ people within $80 \mathrm{~km}$ of an eastern coal-fired power plant. ${ }^{66}$

The estimated number of premature deaths per plant-year for tar-sand technologies was calculated using the relationship of 0 to 0.8 premature deaths per 1000 ton (short) of $\mathrm{SO}_{2}$ released; and an estimated population of 300,000 people within $80 \mathrm{~km}$ (nearly $50 \mathrm{mi}$ ) of Mckittrick, California, and 30,000 people near the tar-sand deposits of Utah. The results from this calculation revealed the following estimates:

- A commercial surface-retort system located at Mckittrick, California, and operating with $97 \%$ control of $\mathrm{SO}_{2}$ emissions (see Table 6 ), may cause 0 to 0.08 premature deaths per plant-year.

- A commercial surface-solvent system located at McKittrick, California, and operating with no control of $\mathrm{SO}_{2}$ emissions other than the use of low-sulfur fuel (see Table 7), may be responsible for 0 to 0.06 premature deaths per plant-year.

- A commercial in situ steam-injection process employed on a tar-sand deposit in Utah, and operating with $97 \%$ control of $\mathrm{SO}_{2}$ emissions, may result in 0 to 0.003 premature deaths per plant-year.

- The potential number of premature deaths due to $\mathrm{SO}_{2}$ released from a commercial in situ combustion process could not be determined due to insufficient data from field tests. 
The foregoing estimates are actually "zero-order" approximations of possible public health impacts and include large uncertainties. Nevertheless, such estimates do draw attention to the potential problem and reflect the need for more detailed analysis.

Atmospheric pollutants from tar-sand facilities can also cause adverse ecological impacts. For example, it is known that $\mathrm{SO}_{2}$ concentrations above tolerance thresholds for plant species can injure leaf tissue and adversely affect growth. 67 One simple linear relationship that has been developed to describe the growth response of vegetation after exposure to concentrations of $\mathrm{SO}_{2}$ above the tolerance threshold is 68

$$
G R=1-P L(S A-C R) \text {, }
$$

where $G R=$ growth response, $P L=$ fraction growth potential lost per ppmv of $\mathrm{SO}_{2}, \mathrm{SA}=$ seasonal average concentration of $\mathrm{SO}_{2}$ (ppmv), and $\mathrm{CR}=$ threshold concentration of $\mathrm{SO}_{2}$ for growth reduction (ppmv).

It is implicit in the use of this equation that no adverse effects will occur at concentrations below the threshold value, and that damage (i.e., reduction of yield) will occur at concentrations at or above it. It is also important to note that threshold values (CR) and the decreased fraction of growth rate per ppmv of $\mathrm{SO}_{2}(\mathrm{PL})$ are species-specific values, and should be evaluated for specific species at potential sites.

A preliminary estimate of the magnitude of the effect on vegetation by controlled $\mathrm{SO}_{2}$ emissions from tar-sand technologies can be calculated using this equation. The $C R$ and $P L$ variables selected were those determined for Ponderosa pine. 68 The $C R$ and $P L$ values for less-sensitive desert species that are likely to be encountered near tar-sand development activities cannot be readily derived. This is due to the fact that threshold levels and yield impacts from $\mathrm{SO}_{2}$ for such species could not be found, even in the comprehensive literature summaries available in EPA documents. The CR and PL values for Ponderosa pine are defensible and have been used in a sophisticated model of the impact of $\mathrm{SO}_{2}$ pollution on the community structure and succession in a coniferous forest of the western U.S.A. ${ }^{69}$ These values are:

Plant species

Ponderosa pine

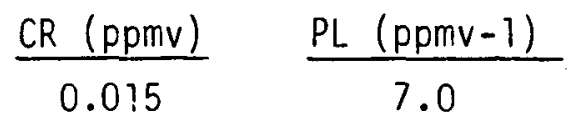


The seasonal average (SA) concentration of $\mathrm{SO}_{2}$ is represented by the maximum ground-level concentration for a 24-hour averaging time estimated for a conceptual commercial retort, solvent, and in situ steam-injection process. These concentrations are

\begin{tabular}{|c|c|c|}
\hline Process & & $\mathrm{SO}_{2}$ concentration (ppmv) \\
\hline Retort & 0.04 & (Assumes $97 \%$ control of $\mathrm{SO}_{2}$ ) \\
\hline Solvent & 0.04 & $\begin{array}{l}\text { (Assumes no control of } \mathrm{SO}_{2} \text { except } \\
\text { the use of low-sulfur fuel) }\end{array}$ \\
\hline Steam injection & 0.01 & (Assumes $97 \%$ control of $\mathrm{SO}_{2}$ ) \\
\hline
\end{tabular}

The preliminary estimate of the growth response (yield) after exposure to $\mathrm{SO}_{2}$ from surface retort and solvent processes is approximately $80 \%$. For an in situ steam process the growth response should not be affected adversely since the $\mathrm{SO}_{2}$ concentration $(0.01 \mathrm{ppmv})$ is below the threshold value for damage (0.015 ppmv) to Ponderosa pine.

The impacts on yield determined using this simple linear relationship are speculative and are used only to provide a preliminary estimate of the potential growth-response effect that tar-sand processes may exert on vegetation in the vicinity of the operation. It is expected that any adverse impacts that do occur will be localized and the application of control technologies will reduce these impacts to their minimum levels. Further examination of the effect on ecosystems from product emissions will be necessary to predict such impacts accurately.

\section{Surface-Water Contamination}

Adverse impacts on public health and ecosystems from direct contamination of surface water are probably unlikely to occur from the operation of commercial surface and in situ systems. This is because the potentially contaminating substances and fluids will generally be physically contained in either vessels and pipelines or the formation itself. Furthermore, drainage diversions installed around the site will channel run-off away from areas sensitive to erosion, and away from areas where leaks or spills may develop. While accidental releases of contained substances into surface waters can occur, it is 
expected that spill-prevention, monitoring, and maintenance programs will effectively reduce the possibility of major spills and leaks, and prevent any that do occur from reaching surface waters. These practices are already commonplace in the chemical industry and need only be applied to commercial tar-sand projects. The value selected for the occurrence of effects associated with surface-water contamination in Table 18 is consistent with the successful application of these mitigating measures. However, the risk of surface-water contamination will increase substantially if planned re-use, recycling, injection, or permanent disposal of large volumes of process waters, sludges, and emission control by-products is not possible.

Ground-Water Contamination

The contamination of ground water from commercial tar-sand projects is of major concern because of the potential adverse health effects that can result when potable ground water is contaminated. Surface processes can cause ground-water contamination from the leaching of substances contained in tar-sand storage piles, spent-ore storage piles, and the operating and backfilled mine areas. These substances may include organic material, metals, and carcinogenic compounds. Research is needed to characterize the composition of leachates and determine the concentration of the constituents. Product waters that were analyzed from in situ combustion and steam-injection field tests contained significant concentrations of trace elements, nutrients, and organic compounds (Table 14). This indicates that potential adverse ground-water-quality impacts could develop, and emphasizes the need for tar-sand developers to monitor and model the transport of such pollutants at specific sites. Such monitoring studies have demonstrated that following undergound coal-gasification, vapor-transported organic materials can be conducted to ground water $250 \mathrm{ft}(76 \mathrm{~m})$ away from the combustion zone. 70

The information above suggests that ground-water contamination may occur and therefore require mitigation. However, due to the slow movement of ground water combined with attenuation of pollutants by soil particles, the effects should be localized. Ground-water-contamination studies analogous to those performed for coal gasification are needed and monitoring is recommended to ascertain the magnitude of any contamination during and after tar-sand-process operation, and to identify impending problems and the need for mitigation. 
Land subsidence and induced seismicity are two potential effects associated exclusively with in situ operations.

The effect of any subsidence produced by commercial in situ tar-sand operations will depend on the land use surrounding the site. For instance, many proposed sites are on grazing land, therefore decreases in land elevation should not be a serious problem. In addition, subsidence represents a localized effect that may be controlled effectively by proper site-selection and operating practices. Subsidence can develop if the extraction of fluids from tar-sand deposits lowers pore pressures in the formation to levels that permit sediments to compact. The compaction can then be translated to the surface in the form of subsidence. Changes in slope that are associated with subsidence in agricultural areas could interfere with irrigation channels and adversely affect the efficient delivery of water to the agricultural 1 ands.

Induced seismicity can result from the high-presssure injection of fluids and resulting lubrication of fault planes in the formation. It is also conceivable that thermal stresses in the formation may cause seismic events. However, seismic events of large magnitude are expected only if fluids are injected above the fracture pressure of the reservoir. Unless unusual conditions exist in the formation, the potential environmental effects from induced seismicity should be insignificant. However, it is recommended that in situ tar-sand procedures be evaluated to ensure that significant seismic events are not induced at specific sites.

\section{Land-Surface Contamination}

Land-surface contamination is more likely to be a major problem from surface tar-sand systems due to the amount of area needed for mining and operating a retort or solvent process above ground. The release of substances onto the ground from surface extraction processes should, however, be minimized by mitigating measures such as spill-prevention programs, monitoring procedures, and maintenance. Careful reclamation and restoration of the mine area will reduce the impacts associated with mining activities. The public-health and ecosystem concerns are related to escape from the site of fluids containing hazardous substances. 
The possibility of land contamination from in situ processes is generally related to leaks or accidental spills from storage vessels and pipes. However, drilling and pumping activities may also contribute to the problem. By using current oil-field procedures for drilling and pumping activities, and containing accidental leaks and spills from pipes and storage vessels, developers can reduce the magnitude of the impacts from these sources. For this reason, the contamination of land by substances directly associated with in situ processes is not likely to be significant.

Worker Health

The risk of morbidity and injury to workers operating commercial surface or in situ tar-sand processes could be significant. Information from other industries such as oil refineries, foreign shale-oil production, coking, and coal conversion indicates that problems can result from exposure to chemical compounds. These compounds are likely to produce toxic, mutagenic, teratogenic, or carcinogenic effects after a single exposure to a high concentration or from chronic exposure to lower concentrations.

For example, a preliminary estimate of the cancer risk for workers at a tar-sand facility can be computed using the approach employed in a comparative assessment of the health and safety impacts from coal use. ${ }^{64}$ In this approach the carcinogenic risks to coke workers $\left(1.6 \times 10^{-4}\right.$ excess cancer deaths per man-year) and oil-refinery workers $\left(4.2 \times 10^{-5}\right.$ excess cancer deaths per man-year) are summed and multiplied by the number of employees needed to operate the facility. The work-force for 20,000-bbl/d commercial tar-sand facilities is assumed to be 128 to 146 employees based on projections for surface retort and solvent processes. 26 Therefore the maximum risk of excess cancer-deaths per plant-year for tar-sand technologies is approximately 0.03. This is probably a very conservative figure as the exposure in a modern tar-sand facility could hopefully be much lower than past exposure in the reference industries because of the availability and increasing use by industries of protective devices such as respirators and protective clothing. While there are uncertainties associated with this risk estimate, it does indicate the need to determine accurately the exact nature of the cancer risk and to implement appropriate monitoring and safety programs to ensure the safety of workers. 
Additional occupational health risks may result from repeated long-term exposures to subacute concentrations of toxic chemicals. For instance, hydrogen sulfide, which was identified as an emission from in situ combustion field tests, was implicated as the chemical responsible for chronic poisoning of workers in the Swedish shale-oil industry when that industry was emerging during the 1940's. 71 This chronic poisoning produced symptoms such as mental depression, weakness, sweating, and frequent chills. Such an etiology for tar-sand technologies will, of course, depend on the duration of exposure, the concentration of the chemical, and the sensitivity of the exposed individuals. However, some residents of communities near units of The Geysers Geothermal Power Plant in California have appeared at hearings of the California Public Utilities Commission and complained of headache, nausea, and sinus congestion that were attributed to the presence of $\mathrm{H}_{2} \mathrm{~S}$ (in concentrations probably as low as 0.1 ppmv). 45

These examples of possible adverse health effects reflect the need to identify such problems and implement suitable medical and health surveillance and safety programs for workers at commercial tar-sand facilities, as is being done in Canada. For instance, studies are now underway by the developers of the Syncrude commercial tar-sand petroleum-extraction facility in Canada to evaluate the carcinogenicity of products; and the Syncrude developers have initiated precautionary protective measures to prevent worker exposure to possible carcinogenic substances. 72 Their studies revealed that after one strain of mice was skin-painted for 60 weeks with heavy-gas $0 i 1$ from the top of the coker, $100 \%$ mortality resulted. Other studies showed that the bitumen froth collected before coking did not induce harmful effects. This animal-testing alerted the Syncrude organization to the fact that maintenance people working on the coker were in jeopardy; especially since (1) the abrasive nature of the input due to its silica content produces holes in the piping that require constant attention by maintenance personnel and (2) the coker is a low-pressure system that permits maintenance to be performed on it during its operation. To mitigate this problem, workers are equipped with respirators and protected head-to-toe with fabric (e.g., neoprene) that is an effective barrier to the toxic agents. These extraordinary precautions appear to be effective. Other problems detected at the tar-sand facility in Canada involved exposure of workers to $\mathrm{H}_{2} \mathrm{~S}$ 
concentrations of $1 \mathrm{ppm}$ and to the odor of mercaptan compounds. Efforts are in progress to prevent serious occupational health and safety risks from these problems.

The data contained in Tables 1 through 4 strongly suggest a nominal correspondence between the characteristics of Athabasca bitumen and that obtained from Utah. For this reason there is a strong possibility that problems similar to those detected by Syncrude could develop at a commercial U.S. surface tar-sand facility, albeit to a greater or lesser degree depending on process characteristics. Therefore, developers of commercial surface tar-sand facilities in the U.S. should be aware of such problems and take precautionary steps to reduce the likelihood of their causing serious environmental or occupational health and safety impacts. Such anticipation at this early stage of tar-sand development in the U.S. will lead to the most effective control mechanisms. In the meantime, worker health problems are more likely to occur at U.S. surface-extraction facilities than at in situ projects. This is because surface extraction procedures will probably require the use of additional reagents that may jeopardize workers' health and safety, as well as produce products that can represent an occupational hazard. In situ technologies, however, are more established since they are used for extraction of heavy oil, and proven environmental control measures routinely used for in situ heavy-oil extraction are probably compatible with in situ extraction of tar-sand bitumen.

Conclusions

Conclusions that result from the assessment of risks for tar-sand technologies are (see Table 18)

- Surface Extraction Technologies

- Occupational health problems, including those related to worker exposure to carcinogenic and other hazardous substances, are likely to occur.

- Public health and/or ecosystem effects from airborne effluents, ground-water contamination, and land-surface contamination may occur but will be localized and/or controllable. 
- Public health and/or ecosystem effects from surface-water contamination are possible, but unlikely to occur.

- Land subsidence and induced seismic effects are not applicable to surface extraction techniques.

- In Situ Processes

- Occupational health problems, including those related to worker exposure to carcinogenic and other hazardous substances, may occur but will be localized and/or controllable.

- Public health effects from airborne effluents, (particularly $\mathrm{SO}_{2}$ and $\mathrm{H}_{2} \mathrm{~S}$ ) and ground-water contamination may occur but will be localized and/or controllable.

- Ecosystem effects from airborne effluents and land subsidence may occur but will be localized and/or controllable.

- Public health and/or ecosystem effects from surface-water contamination and land-surface contamination are possible, but unlikely to occur.

- Induced seismic effects are possible, but unlikely to occur.

\section{RECOMMENDATIONS}

Tar-sand petroleum-extraction technologies are in an early stage of development in the United States. Historically, potential occupational, environmental, health, and safety hazards associated with emerging energy technologies have been most effectively abated by process-design changes rather than retrofitted additions. Therefore, to facilitate the institution of the most effective mitigation measures for reducing the likelihood-of-occurrence and the magnitude of potential impacts from first generation commercial tar-sand facilities, additional studies are recommended before commercialization takes place. These recommended studies should include the following.

First, the technologies, especially in situ methodologies, need to be proven as efficient methods for recovering petroleum from tar sand. Second, a complete chemical characterization of the products must be performed. Third, bioassays and animal testing of the products should be conducted so that 
potential adverse impacts can be identified (e.g., carcinogenicity, mutagenicity, and teratogenicity) and dose responses can be predicted for each toxic agent detected. Fourth, a complete characterization of the atmospheric emissions from tar-sand technologies is necessary. This will establish the need for atmospheric control of criteria and non-criteria pollutants regulated under the Clean Air Act, and indicate the type of air-pollution controls that will be most effective. Fifth, site-specific analyses to determine the size of the public and worker populations that may be affected by effluents from operation of tar-sand technologies need to be performed so that potential health effects can be determined. Sixth, surface- and ground-watercontamination problems need to be defined better and the control technologies for meeting water-pollution-control standards need to be tested on tar-sand wastewaters to prove their effectiveness. Seventh, the hazardous nature of waste material from tar-sand processes needs to be determined. Finally, the potential environmental, health, and safety risks associated with product manufacture, distribution and utilization need to be assessed.

Until such data are collected and carefully analyzed, development of tar-sand technologies should proceed with caution toward commercialization. Furthermore, an institutional commitment for strong safety programs is needed and active participation by government, industry, and workers is essential. The technologies should also be operated under the premise that they will produce potentially hazardous products and operating conditions under some circumstances; workers should be protected accordingly and environmental controls should be employed. Developers should also implement stringent control measures and occupational safety and hygiene procedures until better information is known. While no facility or project can be made completely free from hazard, it is believed that a tar-sand industry can be made a reasonably safe place to work, and environmentally acceptable. 


\section{REFERENCES}

1. "Tar, 0 il Sands Win Bechtel Cost Survey," Synfuels Week, p. 6 (September 29, 1980).

2. N. deNevers, B. Glenne, and C. Bryner, Analys is of the Environmental Control Technology for Tar Sand Development, U.S. Department of Energy, Washington, DC, C00-4043-2 (1979).

3. R. Colman, and E.W. Standley, California Thermal 0il Utilization: Final Report, U.S. Department of Energy, Oakland, CA, SAN-1864-1 (1979), pp. $6-17$.

4. N.A. Frazier, D.W. Hissong, W.E. Ballantyne, and E.J. Mazey, Production and Processing of U.S. Tar Sands: An Environmental Assessment, U.S. Environmental Protection Agency, Cincinnati, OH, EPA-600/7-76-035 (1976).

5. G.D. Mossop, "Geology of the Athabasca $0 i 1$ Sands," Science 207, 145-152 (1980).

6. G.L. Baughman, "0il Sands," in Synthetic Fuels Data Handbook (Cameron Engineers, Inc., Denver, C0, 1978), 2nd ed., pp. 259-321.

7. L. Crook, 0il Terms: A Dictionary of Terms Used in 0il Exploration and Development (Wilton House Publications, London, U.K., 1975).

8. "Toward a Definition of Tar Sands," U.S. Department of Energy Tar-Sand Workshop, Reston, VA, August 7, 1980.

9. S. Matheny, Jr., "EOR Methods Help Ultimate Recovery," 0i1 Gas J. 78(13), $79-124$ (1980).

10. H.R. Anderson, U.S. Department of Energy, Office of Fossil Energy, Washington, DC, private communication (February 1981). 
11. T.H. Maugh, "Work on U.S. 0i1 Sands Heating Up," Science 207, 1191-1192 (1980).

12. G.J. Demaison, "Tar Sands and Supergiant 0il Fields, " 0il Gas J. 76 (17), 198-205 (1978).

13. M.W. Ranney, 0il Shale and Tar Sands Technology - Recent Developments (Noyes Data Corporation, Park Ridge, NJ, 1979), pp. 259-340.

14. J.A. Campbell and H.R. Ritzma, Geology and Petroleum Resources of the Major 0il-Impregnated Sandstone Deposits of Utah, Utah Geological and Mineral Survey, Salt Lake City, UT, Special Studies 50 (1979).

15. J.E. Sepulveda and J.D. Miller, "Separation of Bitumen from Utah Tar Sands by a Hot Water Digestion-Flotation Technique," Min. Eng. 30, 1311-1320 (1978).

16. Code of Federal Regulations, 30 CFR 221, U.S. Govt. Print. Off., Washington, DC (1980).

17. Code of Federal Regulations, 30 CFR 231, U.S. Govt. Print. Off., Washington, DC (1980).

18. D.R. Greenwood, G.L. Kingsley, and J.G. Cleland, A Handbook of Key Federal Regulations and Criteria for Multimedia Environmental Control, U.S. Environmental Protection Agency, Washington, DC, EPA-600/7-79-175 (1979).

19. J.G. Arbuckle, M.A. James, M.L. Miller, T.F.P. Sullivan, and T.C. Watson, Environmental Law Handbook (Government Institutes, Inc., Washington, DC, 1978), 5th ed., p. 125.

20. J.C. Lacy, L.N. French, and T.W. Grimshaw, Regulation of the Hydrologic Impacts of In Situ Fossil Fuel Recoverj', Radian Corporation, Austin, TX, Draft Report (1980). 
21. National Historic Preservation Act of 1966, as amended, 16 U.S.C. Secs. 470-470T (1976).

22. "Protection and Enhancement of the Cultural Environment," Executive Order 11593, Fed. Regist. 36, 8921 (1971).

23. Environmental Protection Agency, "Significant EPA Regulations Under Consideration," Fed. Regist. 46, 3411-3447 (1981).

24. Environmental Protection Agency, "Air Quality Criteria for Particulate Matter and Sulfur 0xides," Fed. Regist. 46, 15569-15570 (1981).

25. K. Maize, "109 Ways to Change Clean Air Act," The Energy Daily $\underline{9}$ (42), $1-3(1981)$.

26. Final EIR for the Proposed Getty 0 il Company Diatomite Mining and 0 il Extraction Project Mckittrick $0 i l$ Field Kern County, California, County of Kern, Planning Department, Bakersfield, CA (1979).

27. "SOHIO Slates Tar Sands Pilot Plant in Utah," 0il Gas J. 79(3), 42 (1981).

28. Committee on Surface Mining and Reclamation, Commission on Natural Resources, "Mining and Processing of $0 i 1$ Shale and Tar Sands," in Surface Mining of Non-Coal Minerals (National Academy of Sciences, National Research Council, Washington, DC, 1980), Appendix II, pp. 148-165.

29. P.L. Terwilliger, "Fireflooding Shallow Tar Sands - A Case History," J. Can. Pet. Technol. 15 (4), 41-48 (1976).

30. C.Q. Cupps, C.S. Land, L.C. Marchant, "Field Experiment of In Situ $0 i 1$ Recovery from a Utah Tar Sand by Reverse Combustion," AIChE Symposium Series 72(155), 61-68 (1976).

31. Q. Skinner, Environmental Survey - Tar Sands In-Situ Processing Research Program (Vernal, Uintah County, Utah), Rocky Mountain Institute for Energy and Environment, University of Wyoming, Laramie, WY, DOE/LETC/IC-80/7 (1980). 
32. F.A. Barbour, F.D. Guffey, and S.M. Dorrence, "Preliminary Examination of Waste Waters Produced During an In Situ Retorting of Tar Sands," in The 0il Sands of Canada-Venezuela 1977, D.A. Redford and A.G. Winestock, Eds. (Canadian Institute of Mining and Metallurgy, Montreal, Canada, 1978), Special Volume 17, pp. 743-748.

33. J.W. Bunger, K.P. Thomas, and S. Dorrence, "Compound Types and Properties of Utah, and Athabasca Tar Sand Bitumens, "Fuel 58, 183-195 (1979).

34. L.A. Johnson, Jr., L. John Fahy, L.J. Romanowski, R.V. Barbour, and K.P. Thomas, "An Echoing In-Situ Combustion 0il Recovery Project in a Utah Tar Sand," J. Pet. Technol. 32, 295-305 (1980).

35. Laramie Energy Technology Center, Environmental Assessment: Tar Sand In Situ Steam Injection Experiment, U.S. Department of Energy, Laramie Energy Technology Center, Laramie, WY, DOE/LETC/EA-0104 (1979).

36. C. Roosmagi, Laramie Energy Technology Center, Laramie, WY, private communication (July 1980).

37. J.W. Bunger, Processing Utah Tar Sand Bitumen, Ph.D. Dissertation in Fuels Engineering, University of Utah, Salt Lake City, UT (University Microfilms, Ann Arbor, MI, March 1979).

38. T.N. Keefer and R.S. McQuivey, Water Availability for Development of Major Tar Sands Areas in Utah, Sutron Corporation, Arlington, VA, LETC-0013-1 (1979).

39. L.J. Budney, Guidelines for Air Quality Maintenance Planning and Analysis, Volume 10 (Revised): Procedures for Evaluating Air Quality Impact of New Stationary Sources, U.S. Environmental Protection Agency, Washington DC, EPA-450/4-77-001 (1977).

40. J.G. Clel and and G.L. Kingsbury, Multimedia Environmental Goals for Environmental Assessment, Volumes I and II, U.S. Environmental Protection Agency, Washington, DC, EPA-600/7-77-136a and b (1977). 
41. Uinta Basin Association of Governments and The Uinta Basin Energy Development Council, Uinta Bas in $0 i 1$ Shale Impact Study Interim Report No. 2, U.S. Department of Energy and Utah Department of Community and Economic Development, Vernal, UT, Draft Report (1980).

42. F.R. McDonald, Laramie Energy Technology Center, Laramie, WY, unpublished process-line and stack-gas emission data for the LETC TS-2C Reverse Combustion Experiment (October to December 1977).

43. G.L. Kingsbury, R.C. Sims, and J.B. White, Multimedia Environmental Goals for Environmental Assessment, Volumes III and IV, U.S. Environmental Protection Agency, Washington, DC, EPA-600/7-79-176a and b (1979).

44. L. Romanowski, Laramie Energy Technology Center, Laramie, WY, private communication (JuTy 1980).

45. L.R. Anspaugh and P. Leitner, "Health and Safety Concerns," Section 10 in An Assessment of Geothermal Development in the Imperial Valley of California, Volume I. Environment, Health, and Socioeconomics, D. Layton Ed., U.S. Department of Energy, Washington, DC, D0E/EV-0092 (1980).

46. M. Treshow, Environment and Plant Response (McGraw-Hill Book Company, San Francisco, CA, 1970), pp. 354-358.

47. A.N. Patkar, S.P. Kothari, and J.D. Tuttle, An Evaluation of Flue Gas Desulfurization Processes for Application to California 0il Fields, U.S. Department of Energy, Oakland, CA, DOE/ET/12088-1 (1980).

48. J. Norton, J. Rouge, S. Husband, S. Peoples, G. Tannahi11, G. Behrens, M. Cappalonga, R. Reich, B. Arnold, and B. Menzies, Impact of Air Pollution Control Regulations on Permitting Processes for Thermal Enhanced 0 il Recovery, Radian Corporation, Austin, TX, Draft U.S. Department of Energy Report (1981). 
49. Babcock and Wilcox Company, Steam, Its Generation and Use (Babcock and Wilcox, New York City, NY, 1978), pp. 5-17.

50. LETC Tar Sands Project Office, "Environmental Safety and Health Accident Prevention, Vernal TS-1S Experiment," in LETC TS-IS Operations Manual, Laramie Energy Technology Center, Laramie, WY, Appendix G (1980).

51. E.J. Calabrese, Methodological Approaches to Deriving Environmental and Occupational Health Standards (John Wiley \& Sons, New York, NY, 1978), pp. 152-159.

52. C. Mangeng, D.A. Rapp, R.L. Mckeown, and J. Kassover, A Review of Socioeconomic Impacts of 0 il Shale Development, Los Alamos National Laboratory, Los Alamos, NM, LA-8791-MS (to be published 1981).

53. Monthly Energy Review, U.S. Department of Energy, Energy Information Administration, Washington, DC, DOE/EIA-0035(81/01) (January 1981), pp. 74,79 .

54. J.H. Gibbons, "Environmental Considerations," Chapter 8 in An Assessment of $0 i 1$ Shale Technologies, Office of Technology Assessment, U.S. Congress, Washington, DC (1980), pp. 255-356.

55. A.V. Slack and G.A. Hollinden, "Alkali Absorbents," in Sulfur Dioxide Removal from Waste Gases (Noyes Data Corporation, Park Ridge, NJ, 1975), 2nd ed., pp. 207-210.

56. C.M. Hart, Comparative Analysis of Steam Delivery Cost for Surface and Downhole Steam Drive Technologies, Sandia National Laboratories, Albuquerque, NM, SAND81-0758, in preparation (1981).

57. B. Donaldson, Sandia National Laboratories, Albuquerque, NM, private communication (April 1981).

58. Enhanced Recovery Week (Observer Publishing Co., Washington, DC, October 13, 1980), p. 2. 
59. H.W. Church and B.D. Zak, Environmental Assessment, Downhole Steam Generator Field Test Project, Deep Steam Enhanced 0il Recovery Project (DOE \#16) Kern County, California, Sandia National Laboratories, Albuquerque, NM, SAND79-0908 (1980).

60. J.L. Hahn, "Occupational Hazards Associated with Geothermal Energy," Geotherm. Resour. Counc. Trans. 3, 283-286 (1979).

61. L.R. Anspaugh and J.L. Hahn, "Human Health Implications of Geothermal Energy," Chapter 41 in Health Implications of New Energy Technologies, W.N. Rom and V.E. Archer, Eds. (Ann Arbor Science Publishers, Inc., Ann Arbor, MI, 1980).

62. M. Purde and S. Etlin, "Cancer Cases Among Workers in the Estonian 0il Shale Processing Industry," Chapter 38 in Health Implications of New Energy Technologies, W.N. Rom and V.E. Archer, Eds. (Ann Arbor Science Publishers, Inc., Ann Arbor, MI, 1980).

63. F. Stephens, "Hydrogen Sulfide Control Technologies," in An Assessment of Geothermal Development in the Imperial Valley of California. Volume II. Environmental Control Technology, W. Morris and J. Hill, Eds., U.S. Department of Energy, Washington, DC, DOE/EV-0092 (1980), pp. 4-34.

64. E. Salmon, Comparative Assessment of Health and Safety Impacts of Coal Use, U.S. Department of Energy, Washington, DC, DOE/EV-0069 (1980).

65. S.C. Morris, P.D. Moskowitz, W.A. Sevian, S. Silberstein, and L.D. Hamilton, "Coal Conversion Technologies: Some Health and Environmental Effects," Science 206, 654-662 (1979).

66. M.G. Morgan, S.C. Morris, A.K. Meier, and D.L. Shenk, "A Probabilistic Methodology for Estimating Air Pollution Health Effects from Coal-Fired Power Plants," in Energy Systems and Policy, Brookhaven National Laboratory, Upton, NY, BNL-23581 (1978), vo1. 2, pp. 287-310. 
67. R. Guderian, Air Pollution. Phytotoxicity of Acid Gases and Its Significance in Air Pollution Control (Springer-Verlag, New York, NY, 1977), pp. 76-80.

68. J.R. Kercher and M.C. Axelrod, SILVA: A Model for Forecasting the Effects of $\mathrm{SO}_{2}$ Pollution on Growth and Succession in a Western Coniferous Forest, Lawrence Livermore National Laboratory, Livermore, CA, UCRL-53109 (1981).

69. J.R. Kercher and M.C. Axelrod, "Modeling the Impact of $\mathrm{SO}_{2}$ Pollution on the Community Structure and Succession in a Coniferous Forest of the Western U.S.A.," in Proc. Int. Conf. Ecol. Impact Acid Precip., D. Drablos and A. Tollan, Eds. (SNSF project, As-NLH, Norway, 1980), pp. 174-175.

70. D.H. Stuermer, D.J. Ng, C.J. Morris, and A. Cotton, Distribution of Neutral Organic Reaction By-Products in the Groundwater at the Underground Coal Gasification Site, Lawrence Livermore National Laboratory, Livermore, CA, UCRL-52847 (1979).

71. G. Ahlborg, "Hydrogen Sulfide Poisoning in Shale 0il Industry," Ind. Hyg. Occup. Med. 3 , 247-266 (1951).

72. G. Neeson, Syncrude, Inc., Ft. McMurray, Alberta, Canada, private communication (February 1981). 
TECHNICAL DESCRIPTION OF A CONCEPTUAL COMMERCIAL "PHASED MULTI-BENCH OPEN-PIT SURFACE MINE" FOR EXCAVATING TAR-SAND ORE

The important information concerning the geometric configuration of a conceptual commercial "phased multi-bench open-pit surface mine" is summarized in this appendix. This technical description is based primarily on available data for the excavation of diatomaceous-earth tar sands near Mckittrick, California. 26

The geometric configuration, dimensions, and mining plan for a conceptual tar-sand surface mine could include the following:

- The maximum total operating mine area will be no larger than 350 acres at any one time.

- The minimum allowable dimensions for the mine-pit floor of a 350-acre mine area would be approximately $500 \mathrm{ft}(150 \mathrm{~m})$ wide by $500 \mathrm{ft}(150 \mathrm{~m})$ long. This size is required to accommodate turn-around by trucks and mining equipment as well as provide a buffer zone against damage by slope failure.

- The maximum depth of the mine will be $1200 \mathrm{ft}(360 \mathrm{~m})$.

- A maximum allowable angle for the slope of the spoil bank of about $37^{\circ}$ is considered feasible. This slope is based on the angle of internal friction commonly used to estimate the maximum-allowable slope that will support sand and gravel spoil and not necessarily diatomaceous earth.

- An angle of $37^{\circ}$ is considered possible for the advancing slopes of the mine pit. This slope is based on projections for the diatomaceous-earth tar-sand mine planned near Mckittrick, California.

A mine-plan (see Figure A-1) for a conceptual surface mine might involve a mine-pit that will initially be nearly square in configuration. Mining would progress on three advancing faces until the maximum desired pit width was established. Then, only one advancing face would be employed. Spent-ore and waste-rock spoil material would be emplaced on the fourth face of the mine. As mentioned above, the minimum acceptable dimensions for the mine-pit floor would be $500 \mathrm{ft}(150 \mathrm{~m})$ by $500 \mathrm{ft}(150 \mathrm{~m})$ so that vehicle turn-around is possible and equipment and personnel safety are ensured. 
(a)
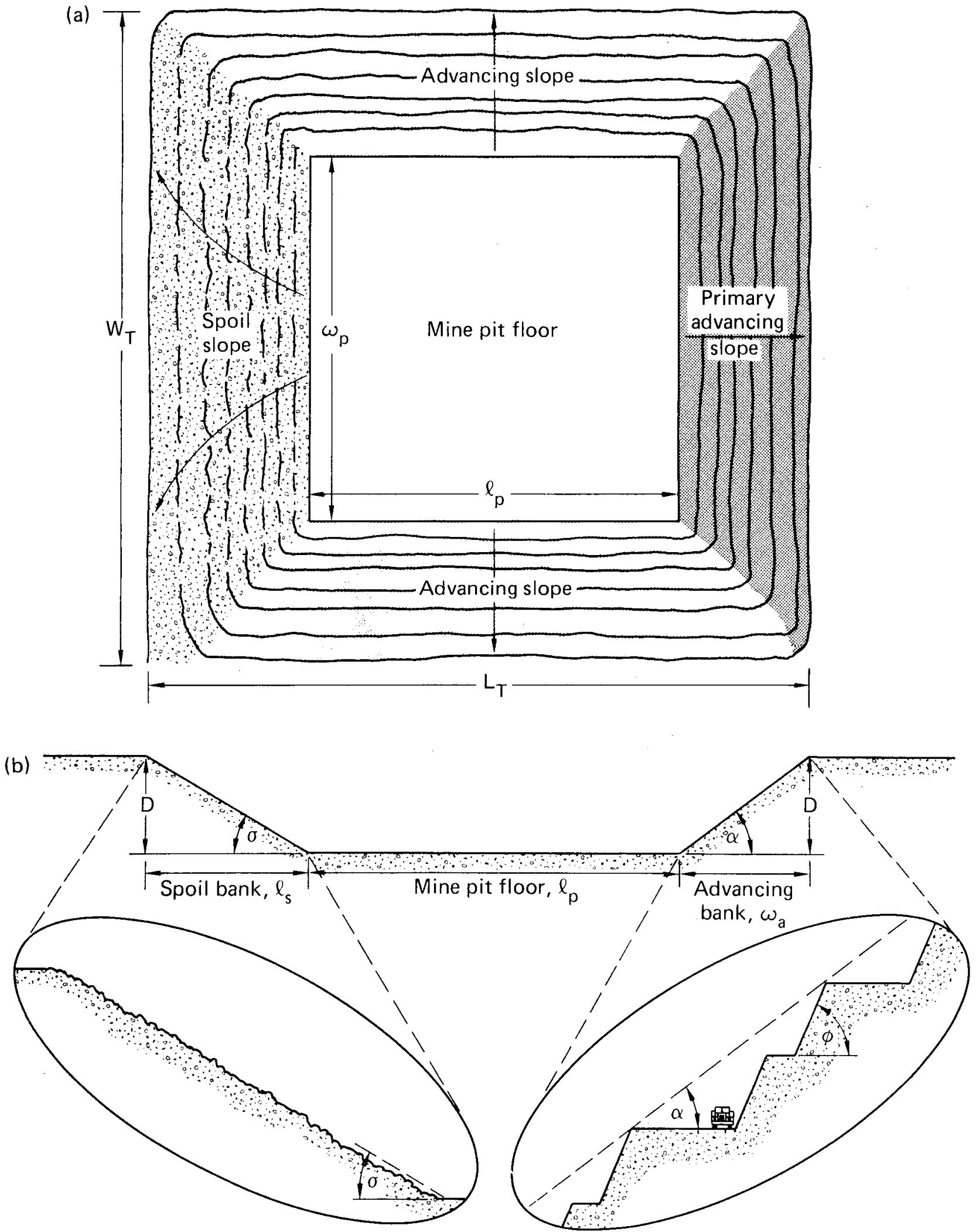

Figure A-1. Diagram of a conceptual phased multi-bench open-pit surface mine for excavating tar-sand ore: (a) Top view, (b) Cross-section. See text for definitions and dimensions. 
Mining would progress by means of benches that are constructed across the advancing banks. These benches need to be wide enough to support vehicles or equipment with a margin of safety. The slope of individual benches will be greater than the slope of the entire advancing bank. For instance, the dimensions of the benches for a conceptual tar-sand surface mine could be the following:

- Bench widths of $40 \mathrm{ft}(12 \mathrm{~m})$ and $120 \mathrm{ft}(36 \mathrm{~m})$ will alternate at $50-\mathrm{ft}$ $(15-\mathrm{m})$ high intervals. The 120-ft benches are the working benches that are reduced to $40 \mathrm{ft}$ by $\mathrm{drilling}$ and blasting (or otherwise excavating) two-thirds $(80 \mathrm{ft})$ of the bench.

- Individual benches are maintained at $62^{\circ}$, to facilitate drilling operations; whereas the final angle of the slope for the entire advancing bank is about $37^{\circ}$.

Waste rock and tar-sand ore will presumably be fractured using the aforementioned inclined drilling and blasting procedures. Broken material will be loaded by shovels onto trucks for transport either out of the pit to a nearby crusher, or over to the spoil bank.

Dimensions for the conceptual surface mine presented in Figure $A-1$ and discussed above can be expressed in the following manner:

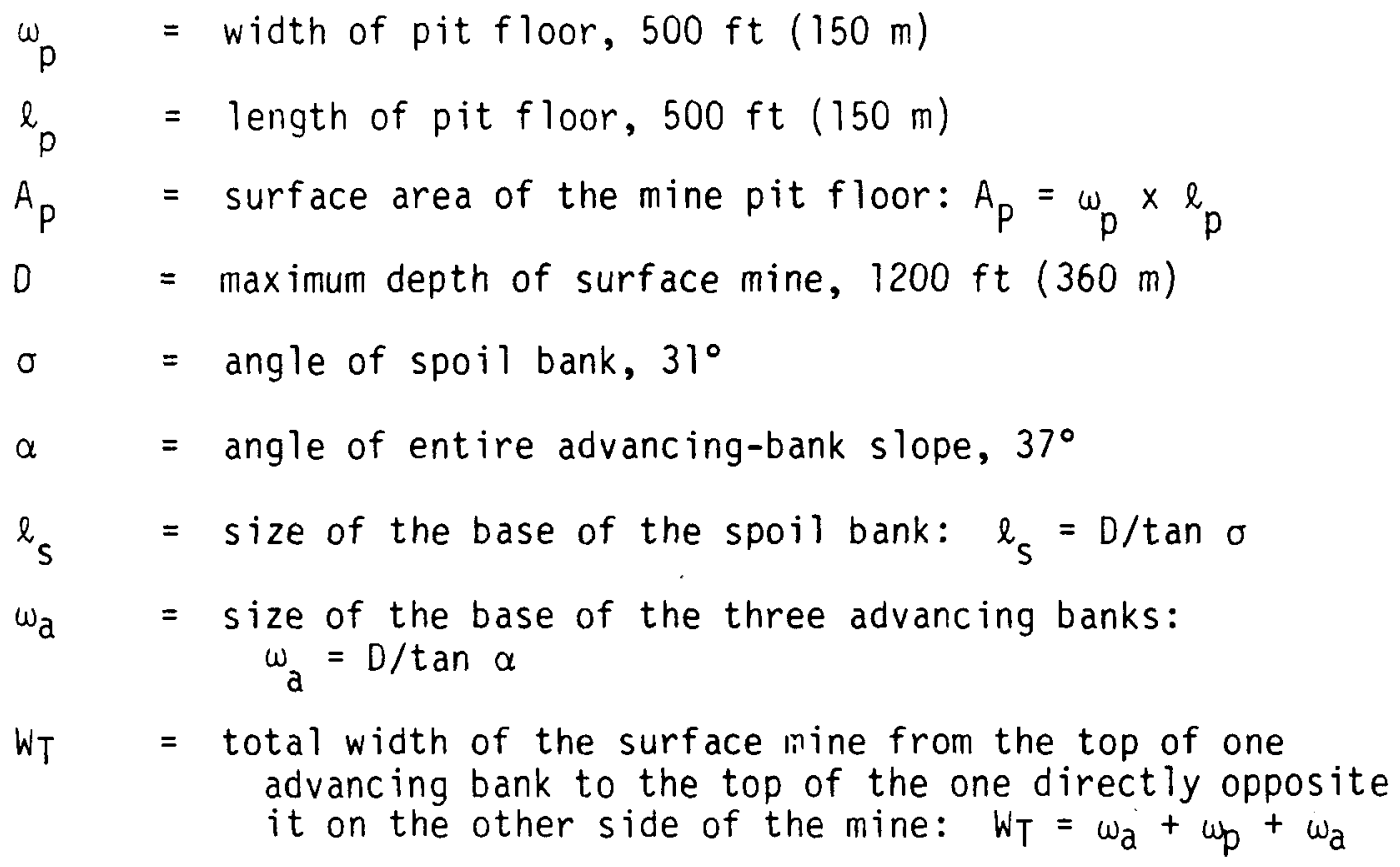


$L_{T}=$ total length of the surface mine from the top of the spoil bank to the top of the advancing bank directly opposite it on the other side of the mine: $L_{T}=l_{s}+l_{p}+\omega_{a}$

$A_{T}=$ total area of surface mine at any one time, 350 acres $\left(1.5 \times 10^{7} \mathrm{ft}^{2}\right): A_{T}=L_{T} \times W_{T}$

$\phi \quad=$ angle of individual bench slopes, $62^{\circ}$. This slope is greater than the slope of the advancing banks, and is governed by the capability of intact tar-sand ore to resist localized failures on a slope. Individual benches $c$ an be maintained at slopes greater than those for the advancing banks because a few small slopes can fail and not adversely impact operation of the mine. 


\section{METHODOLOGY FOR ESTIMATING ATMOSPHERIC EMISSION IMPACTS ON AMBIENT AIR QUALITY}

The Environmental Protection Agency (EPA) recommended "Simple Screening Procedure" 39 is used to estimate the impact on ambient air quality of projected atmospheric emissions from operation of $20,000-b b 1 / d$ representative commercial tar-sand facilities.

PROCEDURE FOR DETERMINING ESTIMATES OF MAXIMUM GROUND-LEVEL CONCENTRATION

1. The normalized plume rise $(u \Delta h)$ is computed by first determining the buoyancy term $F$ :

$$
F=\frac{g}{\pi} v\left[\frac{T_{s}-T_{a}}{T_{s}}\right]
$$

where $\mathrm{g}=$ acceleration due to gravity $\left(9.8 \mathrm{~m} / \mathrm{s}^{2}\right)$

$V=$ actual stack-gas flow rate $\left(\mathrm{m}^{3} / \mathrm{s}\right)$

$T_{S}=$ stack-gas temperature $\left({ }^{\circ} \mathrm{K}\right)$

$T_{a}=$ ambient air temperature (assumed to be $293^{\circ} \mathrm{K}$ )

The normalized plume rise $(u \Delta h)$ is then

$$
\begin{aligned}
& 21.4 \mathrm{~F}^{3 / 4} \text { when } F<55 \mathrm{~m}^{4} / \mathrm{s}^{3} \\
& 38.7 \mathrm{~F}^{3 / 5} \text { when } F \geq 55 \mathrm{~m}^{4} / \mathrm{s}^{3}
\end{aligned}
$$

2. The $u \Delta h$ value obtained is then divided by each of five wind speeds ( $u=$ $0.5,1.0,2.0,3.0$ and $5.0 \mathrm{~m} / \mathrm{s})$ to estimate the actual plume rise $(\Delta \mathrm{h})$ for each wind speed.

$$
\Delta h=\frac{(u \Delta h)}{u} \quad(\text { meters })
$$


3. The plume height $(H)$ that will occur during each wind speed is estimated by adding the respective plume rises to the actual stack height $\left(h_{s}\right)$.

$$
H=h_{s}+\Delta h \text { (meters) }
$$

4. The nomograph of Figure $B-1$ is then employed to estimate $\chi U / Q$ values for those plume heights to which the nomograph could be applied.

5. Each $X U / Q$ value determined from application of Figure $B-1$ is then divided by its respective wind speed to determine the corresponding $x / Q$ values:

$$
x / Q=\frac{x u / Q}{u} \quad\left(s / m^{3}\right)
$$

6. The maximum $X / Q$ value obtained in (5) was multiplied by the projected uncontrolled atmospheric emission rate " $Q$ " $(\mathrm{g} / \mathrm{s})$, and multiplied again by a factor of 2 margin of safety, to obtain the maximum $1-h$ ground-leve 1 concentration " $x_{l}$ ", $\left(\mathrm{g} / \mathrm{m}^{3}\right)$ due to emissions from the stack in question:

$$
x_{1}=2 Q\left[\frac{x}{Q}\right]
$$

7. For averaging times greater than $1 \mathrm{~h}$, the ground-level concentration is estimated by multiplying the $1-h$ value by an appropriate factor $R$ which also takes into account the influence of aerodynamic downwash, or terrain problems known to affect meteorology. Maximum $R$ values for 3-, 8-, and 24-hour averaging times are:

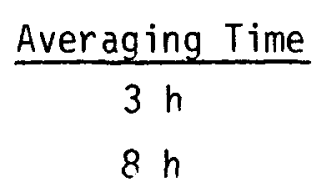

$24 \mathrm{~h}$

\section{Factor R \\ 1.0 \\ 0.9}

0.6 


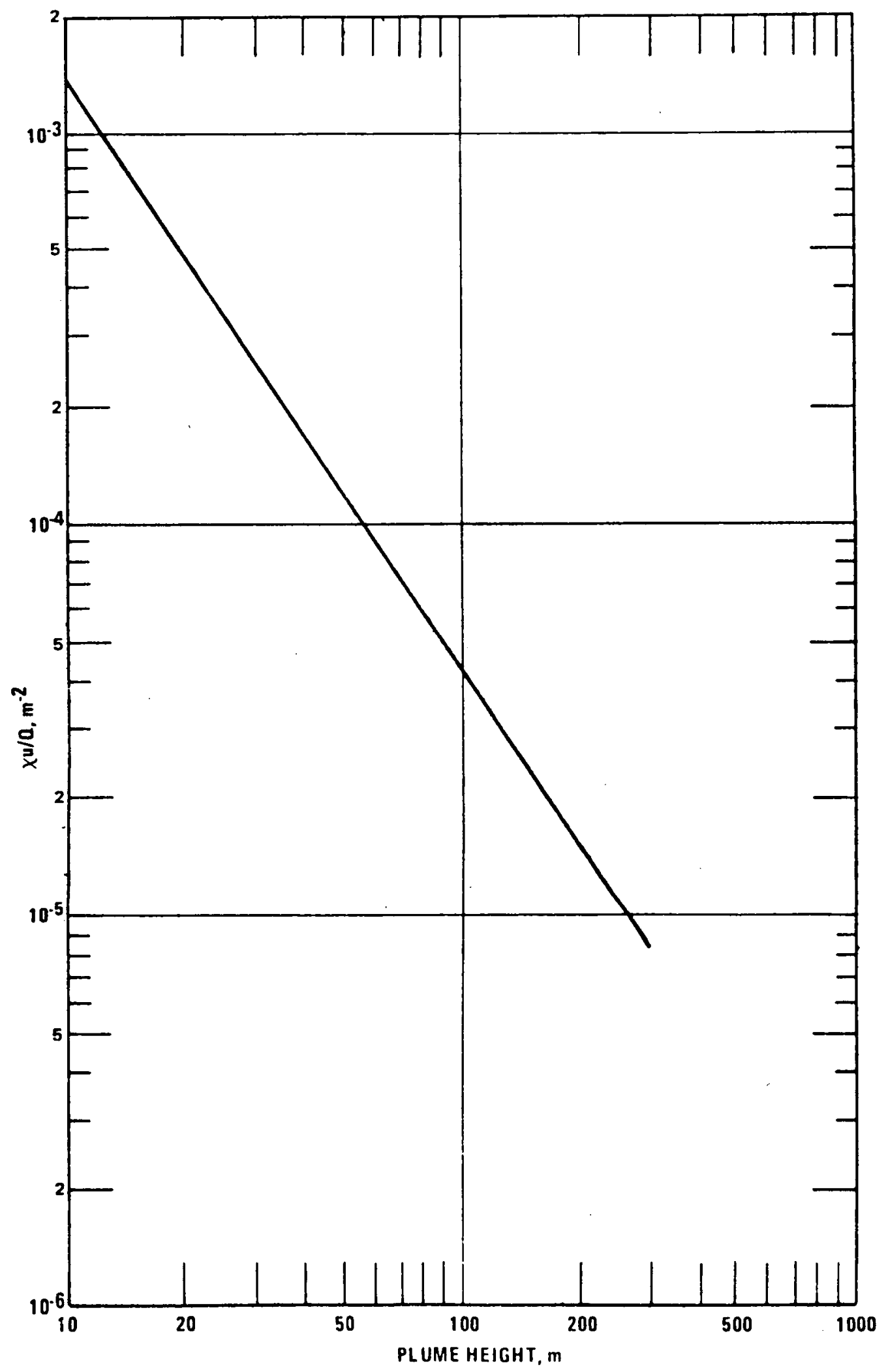

Figure $B-1$. Maximum $X u / Q$ as a function of plume height, $H$. (From Ref. 39, p. 4-4.) 
The concentration estimates obtained through algorithmic calculations of the type just described are subject to inaccuracy. Therefore, a margin-ofsafety factor has been included.

The screening method is particularly suited to estimating ambient-air concentrations with 1- to 24-hour (short-term) averaging times. However, some pollutants (e.g., $\mathrm{NO}_{2}$ ) do not have a regulatory standard corresponding to a short-term averaging time. Nevertheless, because of its regulatory acceptance and feasible application, the "Simple Screening Procedure" was used to calculate the approximate ground-level concentrations for the pollutants with regulatory standards expressed only as long-term averaging times (e.g., 1 year). It must be emphasized that a comparison of the estimated ground-level concentration with the long-term standard provides only a preliminary indication of the potential impact on ambient-air quality. In this and all the other cases, refinement of the results from the application of the "Simple Screening Procedure" can always be accomplished by applying more complex models. However these models will require additional information regarding site-specific meteorological parameters. 


\section{PRELIMINARY COST ESTIMATES FOR SANDIA'S DOWNHOLE STEAM GENERATOR 56}

Preliminary cost estimates for the Sandia non-vented downhole-steamdelivery system have been assembled by researchers at Sandia National Laboratories. The preliminary estimates were prepared for a "...comparative study of surface and downhole steam-drive techniques," and are "...not intended for use in the economic evaluation of a specific enhanced-oil [or tar-sand] recovery project." According to the Sandia investigators, the precision of the estimates is in the range of $-35 \%$ to $+25 \%$. The Sandia cost case-study uses the assumptions presented in Table $\mathrm{C}-1$ as the "representative input parameters," and emphasizes the fact that these parameters can be impacted by the following factors:

- General state of the economy,

- Economic status of the lease operator,

- Scale of the operating facility,

- Characteristics of the reservoir, and

- Properties of the injected steam.

The tabulation of capital and operating costs required for a $10-\mathrm{MBtu} / \mathrm{h}$ downhole steam-generator is presented in Table $\mathrm{C}-2$. These costs were based on the assumptions in Table $\mathrm{C}-1$, are of a preliminary nature, and include the caveats just discussed. A11 cost estimates are given in 1980 dollars. 
Table C-1. Representative input parameters for the downhole-steam-deliverysystem cost case-study performed by Sandia National Laboratories. ${ }^{a}$

Parameter

Assumption

Reservoir

Depth

$3500 \mathrm{ft}$

Original formation pressure

1500 psi

Steam Generation

Generator capacity

$10 \mathrm{MBtu} / \mathrm{h}$

Injection pressure

1800 psi

Injection rate

$500 \mathrm{BCWE}^{\mathrm{b}} / \mathrm{d}$

Sandface quality ${ }^{c}$

$85 \%$

Fuel type

Diese 1

Economic (dollars)

Wholesale fuel cost

$0.90 /$ galion

Water cost

$0.10 /$ barre 1

Maintenance cost

0.05 (uphole capital) +

0.10 (downhole capital)

Labor cost

$15.00 / \mathrm{h}$

a Data taken from Table 1, Ref. 56.

b BCWE - Barrels Cold Water Equivalent.

C Sandface quality - Quality of steam delivered in the borehole at the formation and expressed as the percentage of vapor to liquid. 
Table C-2. Tabulation of capital and operating costs required for a 10-MBtu/h non-vented downhole-steam-delivery system. ${ }^{a, b}$

Estimated Capital Cost $^{\mathrm{C}}$ :

Drilling and completions (D\&C)

of a 3500-ft injection well

High temperature packer.

Generator

Compressor

Site preparation, foundations ${ }^{e}$

Installation (electrical, mechanical contracting)

Piping, valves, structural

$$
\begin{array}{r}
\$ 85 / f t+\$ 10,000^{d} \\
\$ \quad 25,000 \\
25,000 \\
400,000 \\
50,000 \\
100,000 \\
60,000 \\
30,000 \\
65,000 \\
88,000 \\
\hline
\end{array}
$$

Pumps and ancillaries

Water treatment system

Crude treatment system

$$
\text { Total } \$ 1,150,500
$$

Estimated Annual Operating Expenses ${ }^{c}$ :

Generator fue 1

Compressor fuel

Water

Maintenance

Labor

Miscellaneous
$\$ 500,000$

550,000

20,000

75,400

75,000

20,000

$\$ 1,240,000$

Total

Data taken from Table 2, Ref. 56.

b All data are preliminary in nature and "a probable range of precision would be $-35 \%$ to $+25 \%$."

c Cost estimates are in 1980 dollars.

d Rig time for running multiple strings.

e

In addition to D\&C. 